\title{
Secondary Atomization of Single Coal-Water Fuel Droplets
}

Final Report

G.R. Hassel

A.W. Scaroni

March 1989

Work Performed Under Contract No.: DE-FG21-87MC24213

For

U.S. Department of Energy

Office of Fossil Energy

Morgantown Energy Technology Center

Morgantown, West Virginia

By

The Pennsylvania State University

The Combustion Laboratory

University Park, Pennsylvania 


\section{DISCLAIMER}

This report was prepared as an account of work sponsored by an agency of the United States Government. Neither the United States Government nor any agency Thereof, nor any of their employees, makes any warranty, express or implied, or assumes any legal liability or responsibility for the accuracy, completeness, or usefulness of any information, apparatus, product, or process disclosed, or represents that its use would not infringe privately owned rights. Reference herein to any specific commercial product, process, or service by trade name, trademark, manufacturer, or otherwise does not necessarily constitute or imply its endorsement, recommendation, or favoring by the United States Government or any agency thereof. The views and opinions of authors expressed herein do not necessarily state or reflect those of the United States Government or any agency thereof. 


\section{DISCLAIMER}

Portions of this document may be illegible in electronic image products. Images are produced from the best available original document. 


\section{DISCLAIMER}

This report was prepared as an account of work sponsored by an agency of the United States Government. Neither the United States Government nor any agency thereof, nor any of their employees makes any warranty, express of implied, or assumes any legal liability or responsibility for the accuracy, completeness or usefulness of any information, apparatus, product, or process disclosed, or represents that its use would not infringe privately owned rights. Reference herein to any specific commercial product, process, or service by trade name, trademark, manufacturer, or otherwise, does not necessarily constitute or imply its endorsement, recommendation, or favoring by the United States Government or any agency thereof. The views and opinions of authors expressed herein do not necessarily state or reflect those of the United States Government or any agency thereof.

This report has been reproduced directly from the best available copy.

Available to DOE and DOE contractors from the Office of Scientific and Technical Information, P.O. Box 62, Oak Ridge, TN 37831; prices available from (615)576-8401, FTS 626-8401.

Available to the public from the National Technical Information Service, U.S. Department of Commerce, 5285 Port Royal Rd., Springfield, VA 22161.

Price: Printed copy AO6 Microfiche AO1

Codes are used for pricing all publications. The code is determined by the number of pages in the publication. Information pertaining to the pricing codes can be found in the current issues of the following publications, which are generally available in most libraries: Energy Research Abstracts (ERA), Government Reports Announcements and Index (GRA and I); Scientific and Technical Abstracts Reports (STAR); and publication NTIS-PR-360 available from NTIS at the above address. 


\title{
Secondary Atomization of Single Coal-Water Fuel Droplets
}

\author{
Final Report
}

G.R. Hassel

A.W. Scaroni

Work Performed Under Contract No.: DE-FG21-87MC24213

\author{
For \\ U.S. Department of Energy \\ Office of Fossil Energy \\ Morgantown Energy Technology Center \\ P.O. Box 880 \\ Morgantown, West Virginia 26507-0880
}

\author{
By \\ The Pennsylvania State University \\ The Combustion Laboratory \\ University Park, Pennsylvania 16802
}

March 1989 


\begin{abstract}
The evaporative behavior of single, well characterized droplets of a lignite coalwater slurry fuel (CWSF) and a carbon black in water slurry was studied as a function of heating rate and droplet composition. Induced droplet heating rates were varied from 0 to $10^{5} \mathrm{~K} / \mathrm{s}$. Droplets studied were between 97 and $170 \mu \mathrm{m}$ in diameter, with compositions ranging from 25 to $60 \%$ solids by weight. The effect of a commercially available surfactant additive package on droplet evaporation rate, explosive boiling energy requirements, and agglomerate formation was assessed. Surfactant concentrations were varied from none to 2 and $4 \%$ by weight solution ( 1.7 and $3.6 \%$ by weight of active species on a dry coal basis).

The experimental system incorporated an electrodynamic balance to hold single, free droplets, a counterpropagating pulsed laser heating arrangement, and both video and high speed cinematographic recording systems. Data were obtained for ambient droplet evaporation by monitoring the temporal size, weight, and solids concentration changes. Data for heated droplet evaporation and explosive boiling were obtained by gradually increasing the incident energy flux on droplets over the range from 300 to $10,000 \mathrm{~W} / \mathrm{cm}^{2}$ and recording the dynamic response with $\mathbf{5 0 0 0}$ frame per second cinematography.

The high speed films were metered with timing marks and an energy pulse indicator streak so that the energy delivery to the droplets could be resolved over 0.2 millisecond time intervals. The films were further analyzed using an image analysis system to measure the size of droplet shadow images on individual frames. These data were used to estimate the rate of evaporation of water from the droplet. The maximum temperatures achieved by droplets that boiled explosively were estimated based on these data.

It was determined that CWSF droplets of the size studied or smaller boil explosively when pulse heated at a rate of $2 \times 10^{4} \mathrm{~K} / \mathrm{s}$ or greater. Droplet evaporation rates
\end{abstract}


were measured for pulsed heating events and were found to be proportional to the rate of energy absorption. Although the surfactant additive package apparently increased the fraction of water that evaporated from a CWSF droplet before explosive boiling, there was no significant change in the droplet evaporation rates during heating. The energy requirements for explosive boiling were also not significantly altered by the surfactant.

Droplet agglomerates were examined by scanning electron microscopy (SEM). There was no clear evidence of particle fusion, regardless of droplet heating rate or droplet composition, including surfactant concentration.

Carbon black slurry droplets were studied in order to identify the contribution of substrate volatile content to explosive boiling. However, the carbon black slurry droplets usually jumped out of the focal volume of the electrodynamic balance when heated. The contribution of low volatile content to this behavior could not be ascertained. 


\section{TABLE OF CONTENTS}

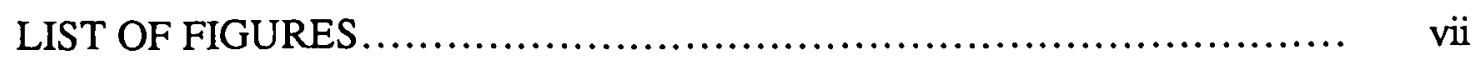

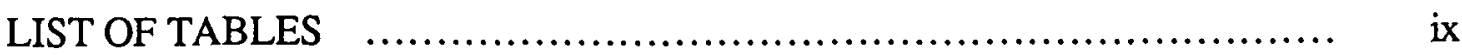

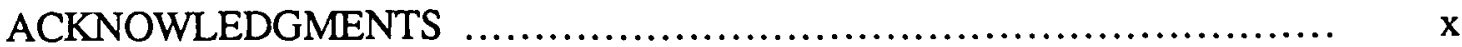

\section{CHAPTER}

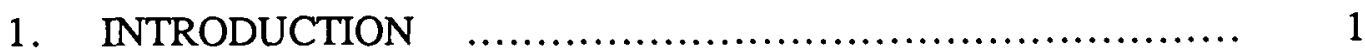

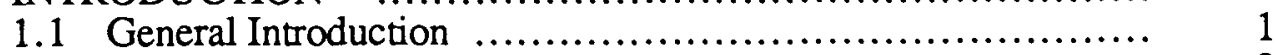

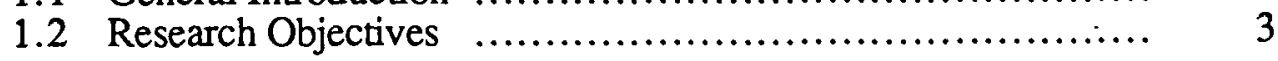

2. SURVEY OF THE LITERATURE $\ldots \ldots \ldots \ldots \ldots \ldots \ldots \ldots \ldots \ldots \ldots, 4$

2.1 Scope of the Survey $\ldots \ldots \ldots \ldots \ldots \ldots \ldots \ldots \ldots \ldots \ldots \ldots \ldots \ldots \ldots, 4$

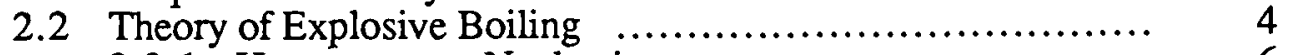

2.2.1 Homogeneous Nucleation ........................... 6

2.2 .2 Heterogeneous Nucleation .............................
8

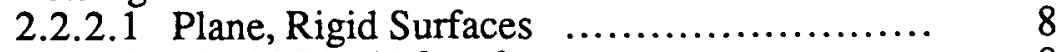

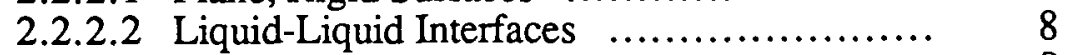

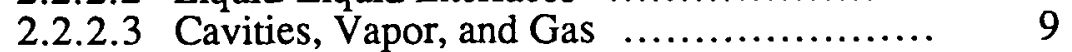

2.2.2.4 Nonuniform Heating ........................ 11

2.3 Explosive Boiling of Liquid Fuel Droplets $\ldots \ldots \ldots \ldots \ldots \ldots \ldots . . \ldots 11$

2.4 Explosive Boiling of Slurry Droplets ...................... 13

2.4.1 Intrusive Single Droplet Studies ................... 15

2.4.1.1 Coal-Oil/Methanol/Water Mixtures .......... 15

2.4.1.2 Coal-Water Slurry Fuels $\ldots \ldots \ldots \ldots \ldots \ldots \ldots . . . . . .15$

2.4.1.3 Other Slurry Fuels $\ldots \ldots \ldots \ldots \ldots \ldots \ldots \ldots \ldots . .16$

2.4.2 Nonintrusive Single Droplet Studies ................. 16

2.4.3 Spray and Combustor Studies ......................... 19

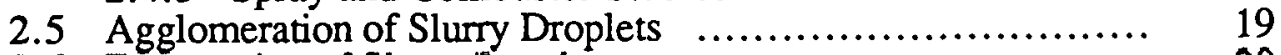

2.6 Evaporation of Slurry Droplets $\ldots \ldots \ldots \ldots \ldots \ldots \ldots \ldots \ldots \ldots . . . \ldots$

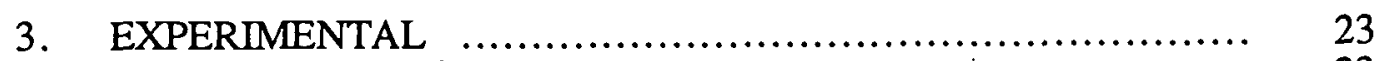

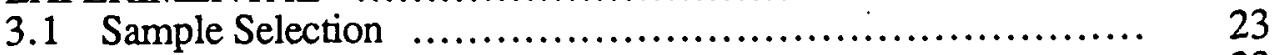

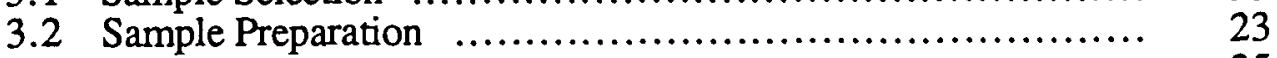

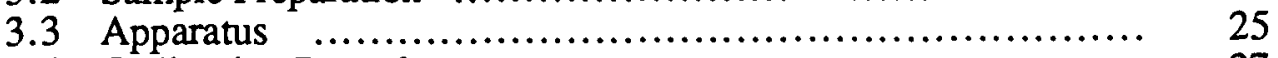

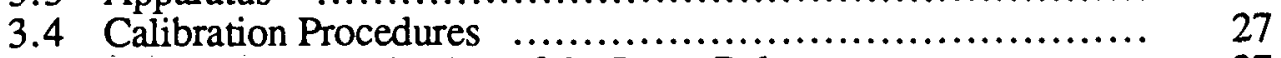

3.4.1 Characterization of the Laser Pulse .................. 27

3.4.2 Calibration of the Droplet Imaging System …........ 32

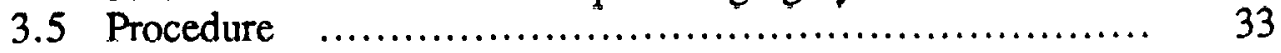

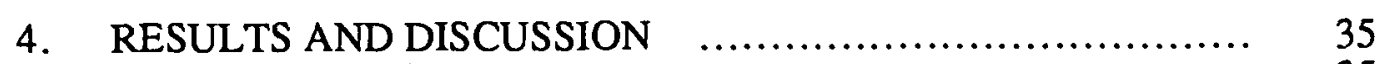

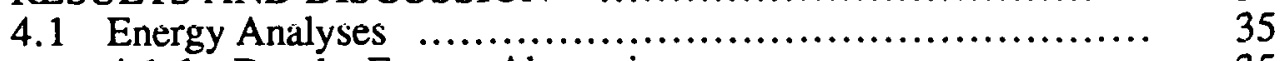

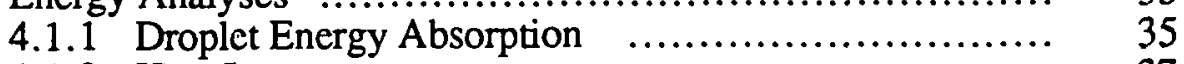

4.1.2 Heat Losses $\ldots \ldots \ldots \ldots \ldots \ldots \ldots \ldots \ldots \ldots \ldots \ldots \ldots . . . . \ldots \ldots$ 
4.1.3 Estimate of Droplet Temperature at Explosive Boiling . $\quad 38$

4.2 Evaporation ................................................ 43

4.2.1 Ambient Evaporation .............................. 43

4.2.2 Evaporation Under Heating Conditions .............. 45

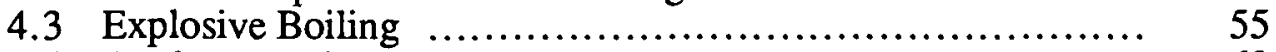

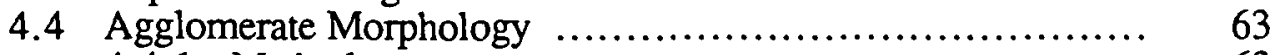

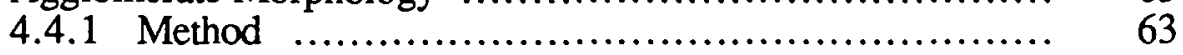

4.4.2 Discussion of the Micrographs ........................ 65

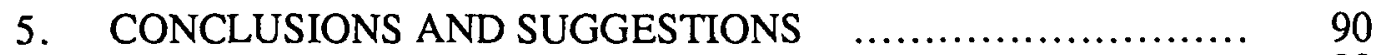

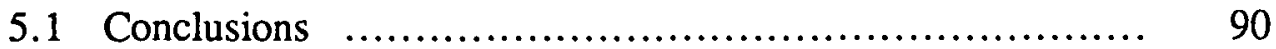

5.2 Suggestions for Future Work $\ldots \ldots \ldots \ldots \ldots \ldots \ldots \ldots \ldots . \ldots . \ldots . \ldots . \ldots$

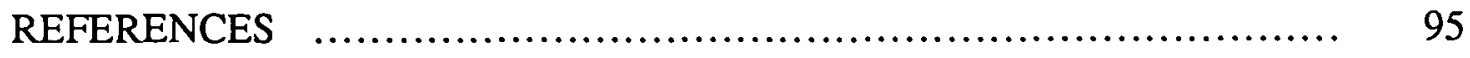

APPENDIX: EQUATIONS AND SLURRY CHARACTERIZATIONS......... 99

A.1 Slurry Preparation . .......................................... 99

A.1.1 Slurry Dilution and Surfactant Addition .................... 99

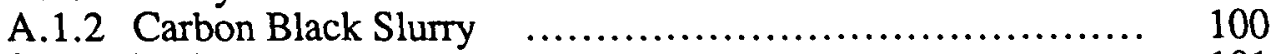

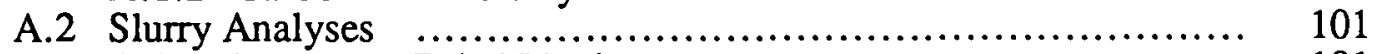

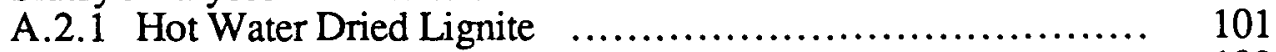

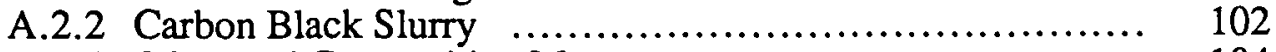

A.3 Droplet Mass and Composition Measurement $\ldots \ldots \ldots \ldots \ldots \ldots \ldots \ldots . . \ldots 104$

A.4 Calculations ...................................................... 106

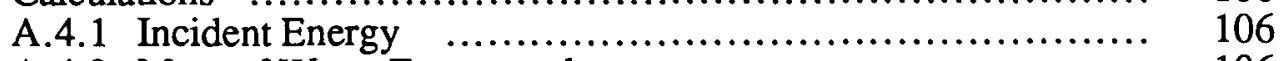

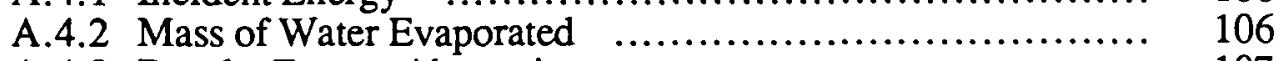

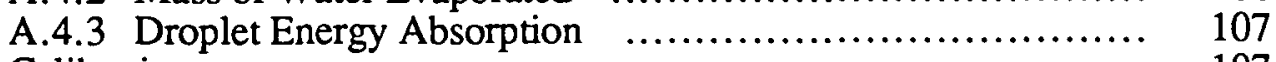

A.5 Calibrations ...................................................... 107

A.5.1 Droplet Size Measurements ................................. 108

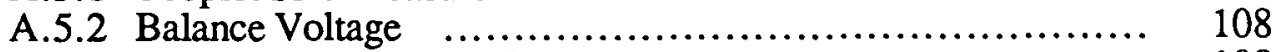

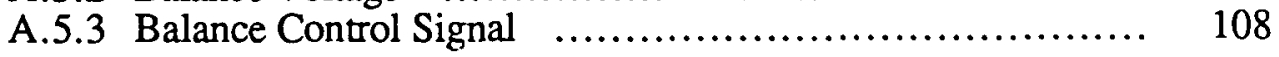




\section{LIST OF FIGURES}

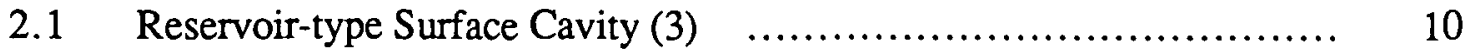

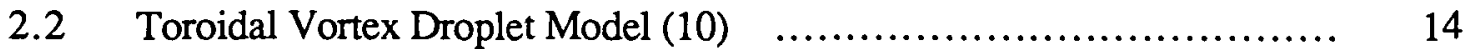

2.3 Schematic Diagram of the Mechanism of Popped Swelling (15) ....... 17

2.4 Rank Effect for the Evaporation and Ignition Sequence of CWSF Droplets (29)

3.1 Experimental Configuration for Droplet Studies $\quad \ldots \ldots \ldots \ldots \ldots \ldots \ldots \ldots . . . . . . .28$

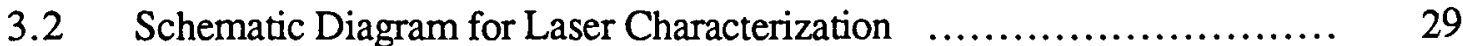

3.3 Schematic Diagram for Focusing Lens Focal Length Determination ..... 31

4.1 Ambient versus Heated Evaporation:

$50 \%$ lignite, $170 \mu \mathrm{m}$ diameter, $0 \%$ surfactant, $1090 \mathrm{~W} / \mathrm{cm}^{2}$

4.2 Heat Capacity Normalized Energy Requirements

for Explosive Boiling

4.3 Ambient versus Heated Evaporation:

$50 \%$ lignite, $140 \mu \mathrm{m}$ diameter, $0 \%$ surfactant, $1030 \mathrm{~W} / \mathrm{cm}^{2}$

4.4 Change in Cross-Sectional Area for Heated CWSF Droplets:

$50 \%$ lignite, $160 \mu \mathrm{m}$ diameter, $4 \%$ surfactant

4.5 Change in Cross-Sectional Area for Heated CWSF Droplets:

$25 \%$ lignite, $170 \mu \mathrm{m}$ diameter, $2 \%$ surfactant

4.6 Change in Cross-Secrional Area for Heated CWSF Droplets:

$50 \%$ lignite, $170 \mu \mathrm{m}$ diameter, $0 \%$ surfactant

4.7 Percent Mass Loss by Evaporation Before Explosive Boiling $\quad . . . \ldots \ldots . \quad 50$

4.8 Heated Evaporation Rates as a Function of

Incident Energy Flux

4.9 Heated Evaporation Rates as a Function of Absorbed Energy

4.10 Total Incident Energy Requirements for Explosive Boiling as a Function of Healing Time and Droplet Composition

4.11 Dynamic Response as a Function of Heating Time:

$160 \mu \mathrm{m}$ diameter, $4 \%$ surfactant

4.12 Dynamic Response as a Function of Heating Time:

agglomerates of CWSF with $2 \%$ surfactant 
4.13 Dynamic Response as a Function of Heating Time: $43 \%$ carbon black, $97 \mu \mathrm{m}$ diameter, $0 \%$ surfactant

4.14 Mass Normalized Energy Requirements for Explosive Boiling of Slurry Droplets

4.15 Top:

Agglomerate Resulting from the Ambient Evaporation of a CWSF Droplet.

Bottom: Unusually Hollow CWSF Droplet Agglomerate $\quad . . . . .667$

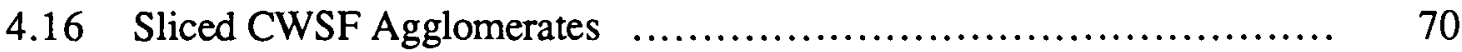

4.17 Carbon Black Slurry Agglomerates Revealing Their Hollow Structure... 72

4.18 Cross-Sections Showing the Concentration of Smaller Particles on the Outer Surface of CWSF Agglomerates

4.19 Variations in CWSF Agglomerate Shape

Following Droplet Fragmentation

4.20 Variations in Carbon Black Agglomerate Shape

Following Droplet Heating

4.21 Surface Detail of CWSF Agglomerates Resulting from Heated Droplets

4.22 Top View of Crucibles Containing Dried CWSF .................... 84

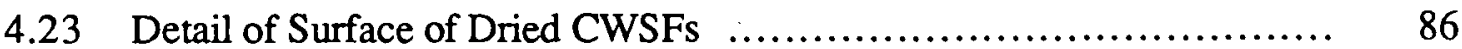

4.24 Detail of the Surface of a Carbon Black Agglomerate Shell ............ 88 


\section{LIST OF TABLES}

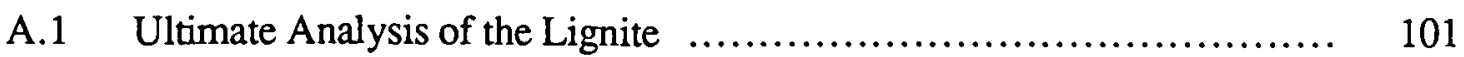

A.2 Particle Size Distribution of the Lignite CWSF ...................... 102

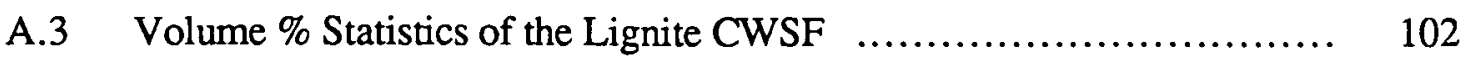

A.4 Ultimate Analysis of the Carbon Black ........................... 102

A.5 Particle Size Distribution of the Carbon Black Slurry $\quad . . \ldots \ldots \ldots \ldots \ldots . . . \ldots 3$

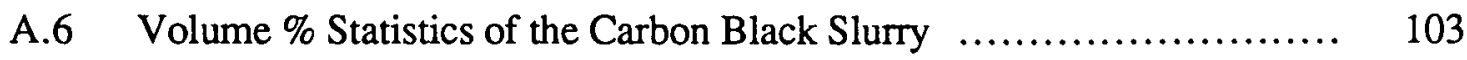




\section{ACKNOWLEDGMENTS}

I gratefully acknowledge the support and guidance of my thesis advisor, Dr. Alan Scaroni, and adjunct advisor at the Morgantown Energy Technology Center (M.E.T.C.), Dr. Daniel Maloney. Dr. Phuoc Tran at M.E.T.C. was instrumental with the experimental and theoretical work as well as a good friend. James Poston at M.E.T.C. performed some of the scanning electron microscopy. Discussions and friendship with fellow graduate students and colleagues at both Penn State and M.E.T.C. were valuable and rewarding. Greg Cutlip of M.E.T.C. generously opened his home to me during my many extended trips. My wife and family were always there providing love and support, especially during the numerous changes of residence.

Kurt Anast of AMAX Corporation supplied the coal-water fuel and additives, and Dr. Rod Taylor of Columbian Chemicals supplied the carbon black.

This work was funded by the U.S. Department of Energy under contract number DE-FG21-87MC24213. 
Chapter 1

INTRODUCTION

\subsection{General Introduction}

Introducing coal into the liquid fuels market would certainly increase the demand for coal. This may occur if coal's economic advantages can be maintained while incorporating the handling and combustion advantages associated with liquid fuels. Coalwater slurry fuel (CWSF) has great potential for replacing conventional liquid fuels in both retrofit and new applications. In retrofit applications CWSF is a compromise between the prohibitively expensive liquefaction of coal in order to yield a liquid replacement for petroleum oil, and pulverized coal, which requires the replacement of oil tanks and pumps with coal storage and pulverizing facilities as well as additional flue gas cleaning equipment. Slow speed diesel engines represent a potential new application of CWSF.

However, burning CWSF presents most of the same problems associated with the combustion phase of pulverized coal utilization plus additional considerations. Two of the main problems associated with the combustion of CWSFs are the ignition delay caused by the evaporation of the water component of CWSF droplets and the agglomeration of coal particles within the droplets, which produces combustion inefficiency. Dealing with these problems is especially important for heat engine applications because of the restrictions on residence time and erosion tolerance. Both of these problems are related to the initial or evaporative stage of the combustion of CWSF droplets. Limited atomization technology produces droplets that are many times larger than the size of the coal particles.

Consequently, as a CWSF droplet dries, an agglomerate of many coal particles is formed that is about the same size as the atomized droplet. 
Inducing the fuel droplets to boil explosively upon introduction to the combustion chamber (secondary atomization) is a potential mechanism for decreasing combustion time, increasing combustion efficiency, and reducing the erosiveness of the flyash. These benefits would result because explosive boiling would 1) increase the rate of vaporization of water away from the coal by greatly increasing the surface area available for water heating and evaporation, and 2) decrease heterogeneous combustion time and flyash particle size by separating the individual coal particles before a sturdy agglomerate could form.

Explosive boiling can be defined as the irreversible, rapid growth of vapor bubbles within a droplet resulting in the complete fragmentation of the droplet core. Droplets can boil explosively if vapor nuclei in the droplet interior attain a critical radius beyond which bubble growth is energetically favorable over bubble collapse. This condition requires that the droplet interior heat much faster than heat can be dissipated at the droplet surface. Whether the surfactant additives used to stabilize and modify the rheological properties of CWSFs influence the propensity for droplets to boil explosively, either by retarding the evaporation of the water from the droplet or by causing the formation of a fused, impermeable shell of coal particles on the droplet surface is the main subject of this study.

Chapter 2 reviews the thermodynamics of explosive boiling of droplets, the mechanisms of explosive boiling of both liquid and slurry fuel droplets, and the agglomeration and evaporation of slurry fuel droplets. Chapter 3 discusses the experimental apparatus and procedure. Chapter 4 presents the results and discusses their significance. Chapter 5 summarizes the conclusions and suggests avenues for further work. The appendix contains slurry preparation procedures and analyses as well as instrument calibrations and outlines of calculations. 


\subsection{Research Objectives}

The primary objective of this work was to determine the role and importance of coal type and fuel additives on the explosive boiling of CWSF droplets. Tests were performed on single CWSF droplets at the Morgantown Energy Technology Center using apparatus specifically designed to study explosive boiling phenomena. The evaporation behavior and explosive boiling thresholds as a function of heating time, droplet size, and droplet composition were to be determined for both a fine grind, low-rank CWSF and a carbonwater slurry, with and without stabilizing additives. The evaporation rates of CWSF droplets under different heating conditions were to be estimated and compared to surfactant concentration. All of this information could be useful in setting targets for CWSF preparation and combustor design. 
Chapter 2

SURVEY OF THE LITERATURE

\subsection{Scope of the Survey}

Three major sections comprise the literature survey. The first section covers the theories of explosive boiling phenomena. Three major reviews are referenced due to the vast amount of related literature. The next two sections cover reports of explosive boiling in fuel droplets. The first section is on liquid fuel droplets and the second section is on slurry fuel droplets. The last two sections cover the agglomeration and evaporation of slurry fuel droplets, respectively.

\subsection{Theory of Explosive Boiling}

Explosive boiling is the formation and rapid growth of the vapor phase within a droplet resulting in the droplet's violent fragmentation. Skripov (1) discussed the fundamental thermodynamics of explosive boiling of pure water droplets. Explosive boiling requires the formation of vapor nuclei within the droplet, which, in turn, requires that the interior of the droplet be superheated. The limit of superheat is reached when the vapor nuclei attain a critical radius beyond which the internal bubbles find it energetically favorable to grow rather than collapse. The work of bubble formation is a maximum, as is the Gibbs free energy of liquid-vapor bubble system, at the critical size. Therefore, the formation of a viable nucleus involves overcoming a barrier

$$
\mathrm{W}_{\mathrm{cr}}=\Delta \Phi_{\mathrm{b}}
$$


where $W_{c r}$ is the work of formation at the critical size and $\Phi_{b}$ is the Gibbs function at the critical size. Using the form of the fundamental equation of nucleation theory presented in (2), the work of formation of a spherical bubble is

$$
\mathrm{W}_{\mathrm{cr}}=\sigma \mathrm{A}-\left(\mathrm{P}_{\mathrm{G}}-\mathrm{P}_{\mathrm{L}}\right) \mathrm{V}_{\mathrm{G}}+\mathrm{x}\left(\mu_{\mathrm{G}}=\mu_{\mathrm{L}}\right)
$$

where $A$ is the bubble surface area, $\sigma$ is the surface tension of the gas-liquid interface, $x$ is the number of molecules, $V_{G}$ is the bubble volume, $P_{G}$ and $P_{L}$, and $\mu_{G}$ and $\mu_{L}$ are the pressures and chemical potentials of the gas and liquid phases, respectively. The first term in (2.2) represents the work of surface formation, the second term the volume work directed against the pressure forces, and the third term the "molecular" work. The conditions of mechanical and chemical equilibrium $\left(\mathrm{P}_{\mathrm{G}}=\mathrm{P}_{\mathrm{V}}\right)$ have the following respective forms:

$$
\begin{aligned}
& P_{V}=P_{L}+\frac{2 \sigma}{r} \\
& \mu_{V}\left(P_{V}, T\right)=\mu_{L}\left(P_{L}, T\right)
\end{aligned}
$$

where $\mathrm{T}$ is the temperature. At equilibrium (2.3) and (2.4) can be invoked to rewrite (2.2) for the critical-size bubble as

$$
\mathrm{W}_{\mathrm{cr}}=\frac{1}{3} \sigma \mathrm{A}_{\mathrm{cr}}=\frac{1}{2} \mathrm{~V}_{\mathrm{cr}}\left(\mathrm{P}_{\mathrm{V}}-\mathrm{P}_{\mathrm{L}}\right)
$$

Bubble nuclei are on the order of $10^{-7}$ to $10^{-6} \mathrm{~cm}$ in radius. The size dimension can be ormitted from (2.5) by rewriting the expression in the form

$$
\mathrm{W}_{\mathrm{cr}}=\frac{16 \pi \sigma^{3}}{3\left(\mathrm{P}_{\mathrm{V}}-\mathrm{P}_{\mathrm{L}}\right)^{2}}
$$


The critical bubble is in mechanical equilibrium with the liquid. Bubbles larger than the critical size grow spontaneously, while smaller bubbles tend to collapse. Since bubbles can only grow to $r_{c}$ from subcritical sizes, critical size bubbles must form by relatively improbable fluctuations over the energy barrier leading to $\mathrm{W}_{\mathrm{cr}}(2)$.

These principles of explosive boiling can be applied to multiple phase systems in terms of homogeneous and heterogeneous nucleation phenomena. Blander and Katz (2) and Cole (3) discussed homogeneous nucleation and heterogeneous nucleation from plane, glassy surfaces. Blander and Katz included heterogeneous nucleation at liquid-liquid interfaces. Cole elaborated on heterogeneous nucleation from cavities, vapor trapping, and nonuniform heating.

\subsubsection{Homogeneous Nucleation}

Homogeneous nucleation only occurs when the liquid reaches its limit of superheat (LOS). Blander and Katz (2) defined a kinetic LOS and a thermodynamic LOS. For a given ambient pressure, boiling initiation can happen over a range of temperatures, the median of which is the kinetic LOS. It is not a true limit. The thermodynamic LOS is the true LOS, and it follows that it is always higher than the kinetic LOS. The thermodynamic LOS corresponds to the temperature at which the liquid branch of a pressure-volume diagram for a fluid is at a minimum. There is no suitable equation of state for reliable calculation of the thermodynamic LOS.

The fundamental equation of homogeneous nucleation theory is the same as equation (2.2) above. Homogeneous nucleation occurs at LOS temperatures that are 88 to $90 \%$ of the critical temperature (2).

Cole (3) defined the LOS as "the maximum temperature in excess of the saturation temperature to which the liquid can be subjected without nucleation occurring." 
Accordingly, the LOS is predicted to be inversely proportional to the radius of the vapor nucleus,

$$
\mathrm{T}_{\mathrm{L}}-\mathrm{T}_{\mathrm{sat}}=\frac{2 \sigma \mathrm{T}_{\mathrm{sat}}}{\rho_{\mathrm{v}} \Delta \mathrm{H}_{\mathrm{vap} \mathrm{T}}}
$$

where $T_{L}$ is the liquid temperature, $T_{\text {sat }}$ is the saturated temperature, $\Delta H_{v a p}$ is the latent heat of vaporization of water, $\rho_{V}$ is the density of the vapor phase, and $r_{e}$ is what Cole called the equilibrium cluster radius. Since bubble nucleation occurs by the growth of activated clusters of molecules, $r_{e}$ is of molecular dimensions. Removing $r_{e}$ from this expression yields

$$
\mathrm{T}_{\mathrm{L}}-\mathrm{T}_{\text {sat }}=\frac{\mathrm{T}_{\text {sat }}}{\rho_{\mathrm{V}} \Delta \mathrm{H}_{\text {vap }}}\left[\frac{16 \pi \sigma^{3}}{3 k \mathrm{~T}_{\mathrm{L}} \ln \left(n k \mathrm{~T}_{\mathrm{L}} / h\right)}\right]^{1 / 2}
$$

where $n_{t}$ is the total number of molecules per unit volume, $k$ is the Boltzmann constant, and $h$ is the Plank constant.

\subsubsection{Heterogeneous Nucleation}

Heterogeneous nucleation is possible when the contact angle of the volatile fluid is greater than zero with a solid substrate. Therefore, "the better the wetting of the substrate by the fluid, the less probable is heterogeneous nucleation at the interface and the more probable is homogeneous nucleation in the interior of the fluid" (2). Heterogeneous nucleation occurs at lower temperatures than homogeneous nucleation. However,

even when the limit of superheat is not attained, the [vapor] explosion can be violent. Violence is a function of the total enthalpy involved in superheating the liquid before the metastable [stable under small, continuous thermodynamic variations; unstable if a competing phase forms] liquid is nucleated....A characteristic of these superheating explosions is the time lag until some portion of the volatile fluid is sufficiently superheated. This time 
lag permits a large amount of heat to be transferred to the fluid before boiling is initiated and obviates the need for unusual rates of heat transfer. The greater the time lag, the closer to the limit of superheat one gets in a given situation, and the greater the total energy of the initial explosion. Fragmentation after the initial explosive boiling will increase surface areas of the volatile fluid, enhancing the total heat transferred to the fluid in a later stage. (2)

Heterogeneous nucleation is intuitively the most probable mechanism for explosive boiling of rapidly heated slurry droplets. The solid particles within such a droplet should provide numerous sites for heterogeneous nucleation of vapor from the liquid phase. Both the smooth exterior surfaces and the interior surfaces of pores and cavities of the solid particles can be heterogeneous nucleation sites.

\subsubsection{Plane, Rigid Surfaces}

For calculating the work of bubble formation at plane, rigid surfaces, Blander and Katz (2) modified the first term of equation (2.2) to get

$$
\mathrm{W}=\sigma_{L G} A_{L G}+\left(\sigma_{S G}-\sigma_{S L}\right) A_{S G}-\left(P_{G}-P_{L}\right) V_{G}+x\left(\mu_{G}-\mu_{L}\right)
$$

where the subscripts LG, SG, and SL designate the liquid-gas, solid-gas, and solid-liquid interfaces, respectively. Cole (3) stated that when the contact angle is $0^{\circ}$, measured through the liquid phase, the liquid completely wets the surface and the liquid superheat is the same as for the homogeneous case. Also, when the contact angle is $180^{\circ}$ no superheat is possible.

\section{2,2.2.2 Liquid-Liquid Interfaces}

At the interface of two immiscible liquids, $a$ and $b$, the work of bubble formation is expressed by Blander and Katz (2) as 


$$
W=\sigma_{a} A_{a}+\sigma_{b} A_{b}-\sigma_{a b} A_{a b}-\left(P_{G}-P_{L}\right) V_{G}+x\left(\mu_{G a}-\mu_{L a}\right)
$$

An example of a system of this kind is oil with emulsified water as a combustion additive.

The tiny emulsified water droplets within an atomized droplet of the oil can boil explosively, causing secondary atomization of the oil droplet.

\subsubsection{Cavities, Vapor, and Gas}

Cole (3) concluded that cavities should serve as preferential nucleation sites over the bulk, plane surfaces, or surface projections. Systems characterized by poor wetting should promote nucleation significantly compared to well-wetted systems under the same conditions. Furthermore, the greatest chance of nucleation is from cavities that tend to trap gas and vapor. It then follows that most cases of nucleation on poorly wetted surfaces occur from a preexisting gas phase.

The presence of trapped gases depends on the morphology of the surrounding cavity and the solubility of the gases in the system. Certainly, the probability of nucleation from trapped gases will vary directly with temperature and inversely with pressure because of the corresponding effects on gas solubility. The probability of nucleation should increase with the ability of a cavity to entrap gas. Cole (3) stated that a reservoir-type cavity, shown in Figure 2.1, "represents an outstanding source of extremely low superheat bubbles, remaining available over extended periods of time through many thermal cycles of the heat transfer surface." This cavity shape could plausibly represent a pore in a coal particle. Cole gave the superheat for such a system as

$$
T_{L}-T_{\text {sat }}=\frac{T_{\text {sat }}}{\rho_{\mathrm{V}} \lambda}\left(\frac{2 \sigma}{r}-P_{G}\right)
$$




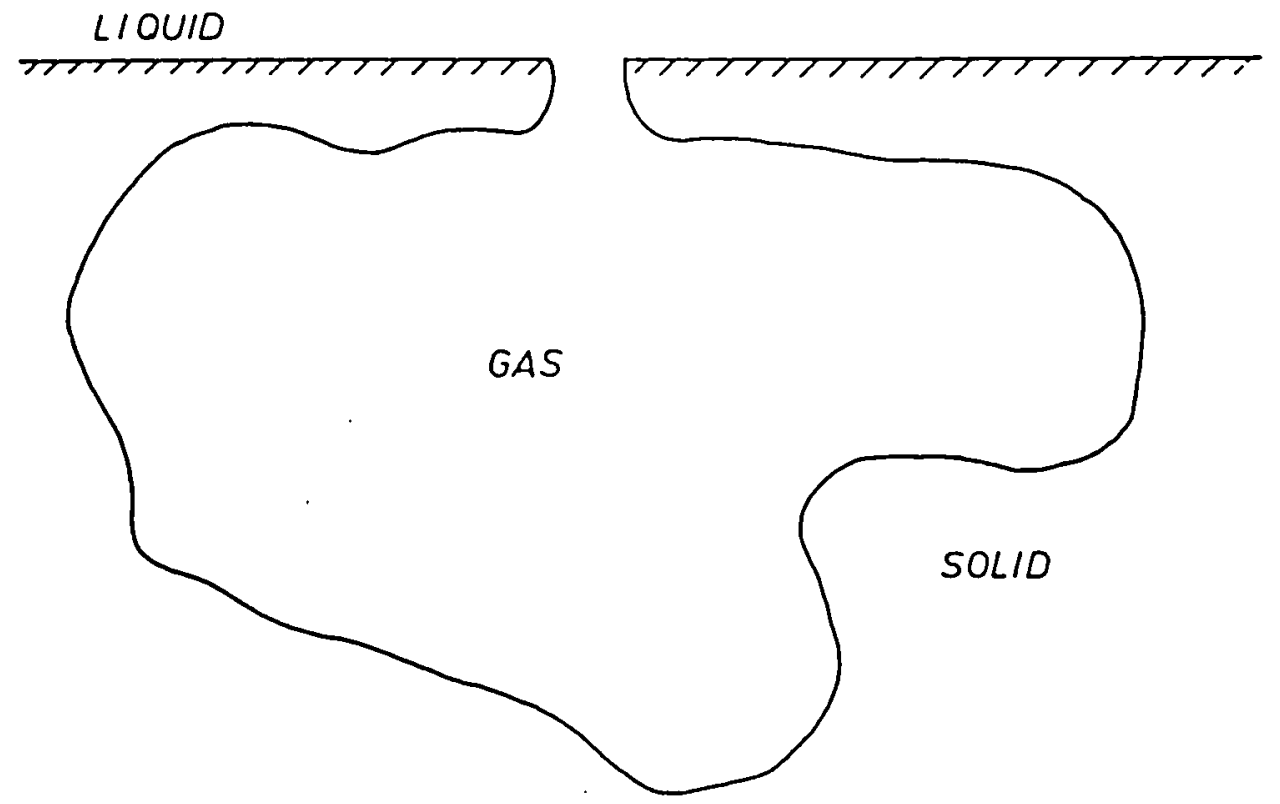

Figure 2.1 Reservoir-type Surface Cavity (3) 


\subsubsection{Nonuniform Heating}

Thus far it has been assumed that the liquid, walls, and gas are at the same temperature. Under these conditions of uniform superheat, "the criteria for [heterogeneous] boiling nucleation are that a surface cavity contains entrapped gas or vapor having a radius of curvature greater than or equal to the equilibrium cluster value, and that the superheat be sufficient for the nucleus to emerge from the cavity.... When the superheat varies spatially, the nucleation criteria are not as clear. The criteria specified for uniform temperature are no doubt necessary, but may not be sufficient" (3).

\subsection{Explosive Boiling of Liquid Fuel Droplets}

Studies of the heating and evaporation phenomena of droplets of multicomponent liquid fuels and water in fuel emulsions were performed both theoretically and in the postcombustion region of flat-flame burners. There are two main bodies of research, one headed by C. K. Law, the other by F. L. Dryer.

Law developed a model for the combustion of oil/water emulsion (4) and for the vaporization of binary liquid fuel (5) droplets. Later, with others, he supported his model with experimental data (6). In the first work he considered water emulsions of diesel fuels. He derived the following pressure sensitive criterion on droplet explosive boiling, or as he termed it, micro-explosion:

$$
T_{\text {Lir }}=\left[\frac{27}{32}\right]^{\frac{1}{n+1}}+\frac{P_{r}}{8(n+1)}
$$

where $0 \leq \mathrm{n} \leq 1, \mathrm{~T}_{\mathrm{Li}, \mathrm{r}}$ is the LOS in reduced form, and $\mathrm{P}_{\mathrm{r}}$ is the reduced pressure. He concluded that droplet temperature increases with increasing pressure and that a micro- 
explosion from vaporizing water can only occur for very high boiling point fuels or at pressures greater than one atmosphere. The experimental work (6) tied the theoretical combustion and vaporization models together by studying $250-300 \mu \mathrm{m}$ diameter multicomponent droplets in the postcombustion zone of a flat-flame burner. A three-staged combustion behavior was described with diffusion being the dominant liquid-phase transport mechanism. Niioka and Sato (7) found that the three combustion stages diminish as pressure is increased above atmospheric. Increasing pressure also suppressed droplet microexplosions. They suggest that lower and upper pressure limits exist for microexplosion by homogeneous nucleation.

The basic mechanism of explosive boiling for multicomponent droplets relies on the difference in volatility of the components and the relative difference in the rates of mass and thermal diffusion. As the droplet heats up the high volatile component preferentially vaporizes from the surface resulting in an outer layer of low volatile component and a core that still contains a significant quantity of high volatile component. For suitable initial concentrations, the inner core can be heated to the point of homogeneous nucleation of the low volatile component. The internal vaporization fragments the droplet $(6,8)$.

Lasheras et al. (9) developed a model that identified two characteristic modes of bubble growth during explosive boiling of multicomponent droplets. Inertial bubble growth is governed mainly by the inertia imparted to the liquid from the motion of the bubble surface and by the pressure difference between the superheated vapor and the liquid. Diffusion bubble growth is governed by heat diffusion from the liquid to the bubble. The model also indicated that bubble growth rate would be very fast in water-infuel emulsions and slow in multicomponent fuels. Finally, the model predicts that increasing the ambient pressure changes bubble growth from the fast inertially controlled mode to the slow diffusion controlled mode. 
Yap et al. (10) found that the results of their flat-flame droplet studies fit the quasisteady (toroidal) Hills vortex droplet model, Figure 2.2. Unlike the well-mixed, batch distillation model (5), the Hills vortex model allows explosive boiling under high relative gas-droplet velocities. Compositional gradients are only removed along the convective streamlines, while radial gradients are still possible.

\subsection{Explosive Boiling of Slurry Droplets}

Explosive boiling of slurry droplets has been directly observed in single droplet studies and indirectly in spray and combustion studies. Single droplet studies can provide a quick and economical determination of the differences between the qualitative behavior of slurry fuels in large scale combustion conditions (21). There are two basic methods of performing single droplet heating studies. The first and more common method employs a silica probe or thermocouple to hold the droplet. The advantages of this method are that the droplet can be heated by convective, radiative, or both modes of heat transfer and the droplet can be subjected to a laminar combustion gas stream. A significant disadvantage of this method is that the droplets are usually on the order of one millimeter in diameter. The second method does not require droplet intrusion. The advantages of this method are that the droplets are more comparable in size to commercially atomized droplets (of the order of $100 \mu \mathrm{m}$ ), the energy delivery to the droplet can be varied over several orders of magnitude, and the absorbed energy can be better quantified. The main disadvantage of this method is the restriction to radiative heat transfer. However, the advantages of the latter method are especially important for studying explosive boiling. Spray and combustor studies have the advantages of droplet-droplet interactions and more realistic environments, however explosive boiling phenomena must be inferred. 


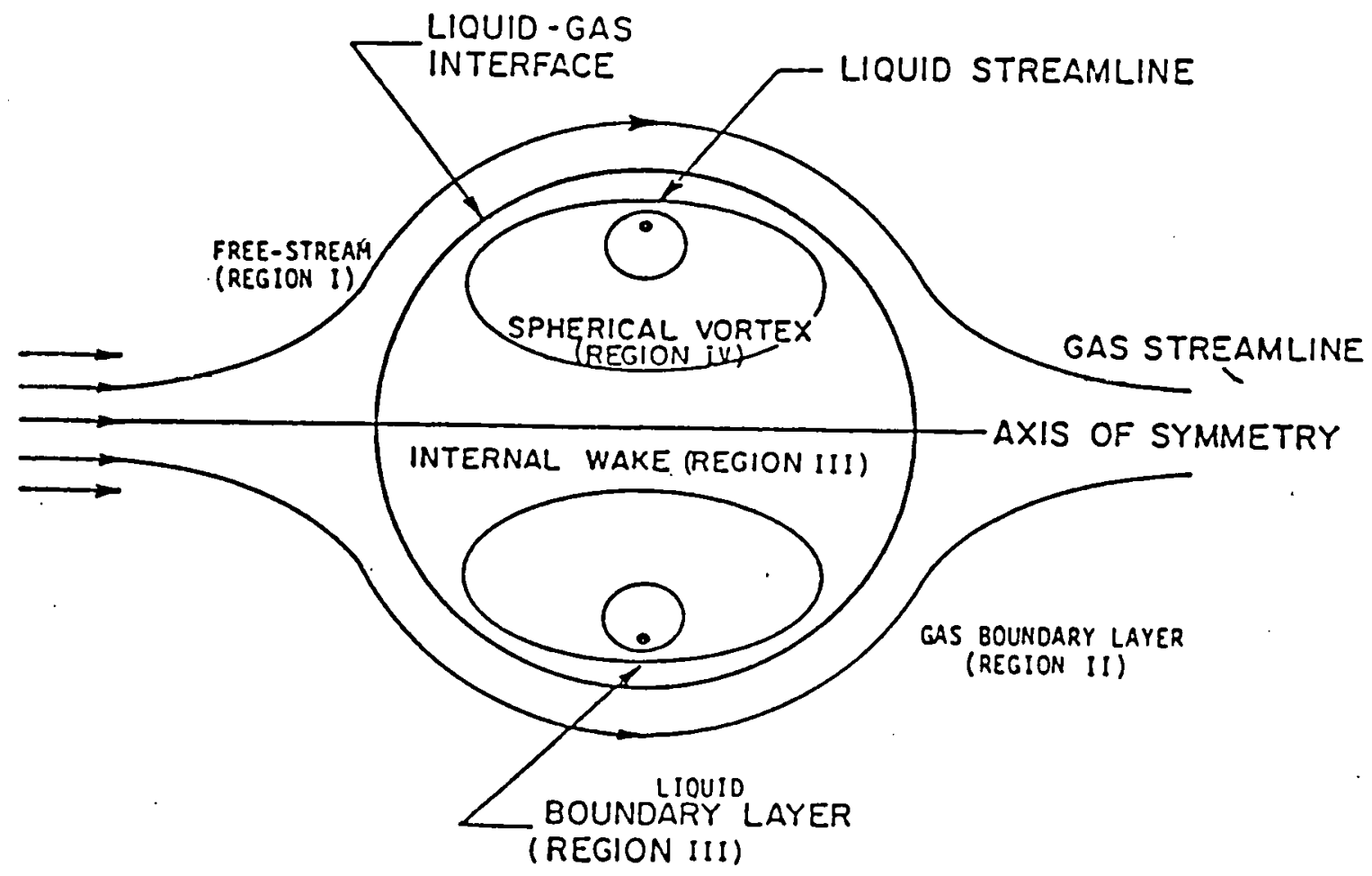

Figure 2.2 Toroidal Vortex Droplet Model (10) 


\subsubsection{Intrusive Single Droplet Studies}

\subsubsection{Coal-Oil/Methanol/Water Mixtures}

Saito et al. (12) studied the effect on combustion of water (W), methanol (M), or both as additives to coal-oil mixture (COM). Droplets of COM did not experience explosive boiling during convective heating. However, M-COM and W-COM droplets did boil explosively, with the W-COM droplets exploding more violently. The most violent explosions were exhibited by $10 \% \mathrm{~W}-20 \% \mathrm{M}-\mathrm{COM}$ droplets. It was concluded that water addition might be effective for secondary atomization, leading to shorter droplet combustion time, and methanol addition would be useful for shortening the ignition delay time. Law et al. (13) ignited droplets of COM and COWM by a spark discharge and found that COM droplets did explode, but 5\% water addition yielded much earlier, more violent explosions.

The above studies $(12,13)$ used bituminous coal for their slurries. Yao and Manwani (14) added kerosene to slurries of a bituminous coal and of a lignite. In both cases the kerosene addition enhanced what was referred to as "splattering," which was not as catastrophic as explosive boiling in other studies.

\subsubsection{Coal-Water Slurry Fuels}

Yao and Liu (15) suspended droplets of bituminous and lignite CWSF with no other additives in the hot stream over a bunsen burner. The bituminous CWSF droplets formed an agglomerate shell that trapped superheated water and volatiles. When the shell cracked from the increasing internal pressure, "the interior particles flushed out like popcorn." A schematic diagram of the mechanism of "popped swelling" is shown in 
Figure 2.3. No disintegration of the droplets was ever observed. Lignite CWSF droplets showed no agglomeration and burned out fast.

Zghoul and Essenhigh (16) radiatively heated droplets of four different bituminous CWSFs. All of the CWSFs showed some degree of bubbling and swelling. Two CWSFs exhibited blow holes followed by the sides of the droplets blowing away or a stream of gases. Another CWSF showed what was presumed to be an explosive release of volatiles. The authors questioned whether the slurry surfactants catalyzed pyrolysis.

\subsubsection{Other Slurry Fuels}

Wong and Turns (17) suggested that a proprietary surfactant could be binding the solid particles of aluminum in droplets of an Al/JP-10 slurry and forming a surface crust that promotes internal vaporization and pressure build-up, leading to violent fragmentation. Similar behavior was observed for freely falling boron/JP-10 slurry droplets by Takahashi et al. (18). It was also suggested (17) that the addition of submicron carbon particles to the Al/JP-10 slurry containing micron-sized aluminum particles might yield a much stronger crust, because of the ability of the smaller carbon particles to fill the voids between the larger aluminum particles. A stronger crust could enhance the explosive behavior.

\subsubsection{Nonintrusive Single Droplet Studies}

Maloney and Spann (19) electrodynamically suspended single droplets of a commercial bituminous CWSF and subjected them to a wide range of radiative energy fluxes. They determined that the droplets would boil explosively when the incident flux exceeded approximately $1000 \mathrm{~W} / \mathrm{cm}^{2}$. They also found that the surface of the droplet agglomerate fused prior to explosive disruption. It was suggested that the surface fusion resulted from a combination of plastic deformation of the coal particles and binding of the 


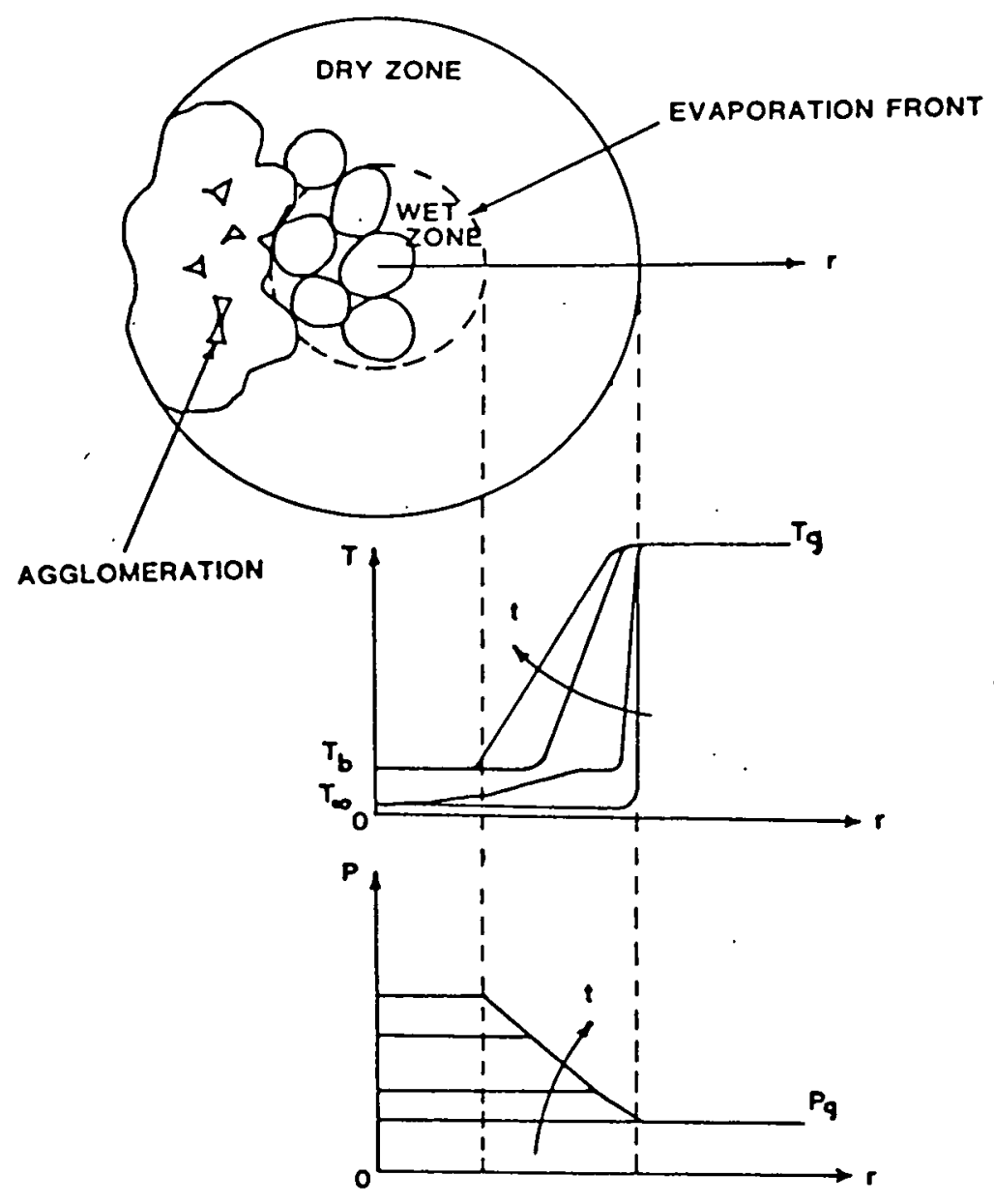

Figure 2.3 Schematic Diagram of the Mechanism of Popped Swelling (15) 
particles by the surfactants in the CWSF. The data in (19) suggested surface heat delivery to the droplets with the formation of an impermeable surface crust allowing heat to be conducted to the droplet interior, superheating the water trapped inside.

As stated in the previous section, Takahashi et al. (18) studied free boron/JP-10 droplets in hot combustion gases. At low solids loading the initial burnout was identical to that of pure JP-10 droplets and followed the diameter squared rule, i.e. $d^{2}-d_{o}{ }^{2}=-k t$, where $\mathrm{k}$ is the burning rate and $\mathrm{t}$ is time. As the solids loading increased, the solid particles concentrated at the droplet surface, forming a porous shell. At this point the $\mathrm{d}^{2}$ rule was no longer followed. As the liquid regressed into the shell, the shell could heat up. Physical binding or dense agglomeration of the particles, or both, rendered the shell impermeable. Internal vaporization could then occur at heterogeneous nucleation sites beneath the shell, causing droplet disruption. It was suggested that a high boiling point additive may contribute to the shell binding mechanism.

It is apparent that heating rate is an important factor in explosive boiling, especially for CWSF. The catastrophic explosions observed in (19), where the droplets were heated at rates of $10^{4}-10^{6} \mathrm{~K} / \mathrm{s}$, contrast greatly to the popping, swelling, and gaseous expulsions observed in (15) and (16), where the droplet heating rates did not exceed $10^{3} \mathrm{~K} / \mathrm{s}$. It is possible that the low heating rates cause devolatilization before they promote the formation of superheated vapor inside the droplet. However, Murdoch et al. (20) observed "explosive disruption" of freely falling bituminous CWSF droplets in a furnace at $1000^{\circ} \mathrm{K}$ but not at $1123^{\circ} \mathrm{K}$. It was suggested that the rate of droplet heating can influence the occurrence of explosion, but no further explanation was attempted. 


\subsubsection{Spray and Combustor Studies}

Three methods of promoting secondary atomization of CWSF droplets were investigated by Yu et al. (21): 1) heating CWSF under pressure to produce steam during the pressure drop at the atomizer nozzle, 2) dissolving $\mathrm{CO}_{2}$ gas in the CWSF to produce a similar effect, and 3) adding a thermally unstable chemical to the CWSF which causes microexplosions in the droplets upon heating. The efficacy of the methods follows the order in which they are listed. The methods were checked against their effect on spray particle size distribution (p.s.d.) and flame stability, carbon burnout, and flyash p.s.d. The effect of slurry viscosity change with higher CWSF temperature in the first method was not accounted for.

\subsection{Agglomeration of Slurry Droplets}

Agglomeration of slurry droplets upon drying is generally accepted as the rule rather than the exception, regardless of the application $(12,13,22-25)$. The causes of agglomeration are not usually clear. CWSF droplets agglomerate as they dry even under ambient conditions $(19,26)$. When the CWSF contains no additives the agglomeration must result from coal particle surface interactions. Because agglomerates of all ranks remain intact after the water evaporates, the mechanism binding the agglomerate is independent of coal rank (26). Monolayers of water adsorbed by the coal could serve to hold the particles together $(26,27)$.

Under heating conditions the reaction of the particles to the heat is expected to be a function of coal rank. CWSF droplets consisting of caking coals would be expected to form agglomerates with fused particles (28), whereas particles of noncaking coals would not be expected to fuse. Matthews and Street (11) found that fusion was less pronounced for low swelling coals than for high swelling coals. One group of authors (26) speculated 
that lignite could possibly exhibit "enough thermoplasticity to bind the agglomerate, but insufficient to show a molten surface structure." Others (29) simply suggest that lignite and subbituminous coal slurry agglomerates break up rather than fuse, as illustrated in Figure 2.4. The results of Yao and Liu (15) agree with the mechanisms shown in this figure.

Surfactants in the slurry have been shown $(17,30)$ or implicated $(18,19)$ to yield agglomerates with a surface crust of adhered particles. A bimodal particle size distribution can lead to agglomerates that are smoother and denser than agglomerates formed with a unimodal p.s.d. (31).

\subsection{Evaporation of Slurry Droplets}

The evaporation of slurry droplets has been modeled for mild, convective conditions (32) and for combustion conditions $(33,34)$. Under mild conditions a dilute slurry droplet will evaporate the same as a homogeneous liquid droplet, following a diameter squared $\left(d^{2}\right)$ relationship. As the liquid evaporates the solids reach a concentration that prevents further regression of the droplet surface. At this point evaporation becomes much more complex; the liquid must diffuse through the particle matrix. Under heating conditions steep temperature gradients can develop across the droplet (33) and the differences in the thermal properties of the liquid and solid phases govern the dynamic response of the droplet (32).

When the liquid phase is not combustible, e.g. water, the response of a slurry fuel droplet to a combustion environment can be divided into relatively distinct stages. Walsh, et al. (35) designated the response of CWSF droplets as: 1) heat to boiling, 2) drying, 3) ignition, 4) volatiles combustion, and 5) char burnout. Their droplet heating and drying times increased approximately as $\mathrm{d}^{1.7}$ over the range 10 to $100 \mu \mathrm{m}$. Also for CWSF 


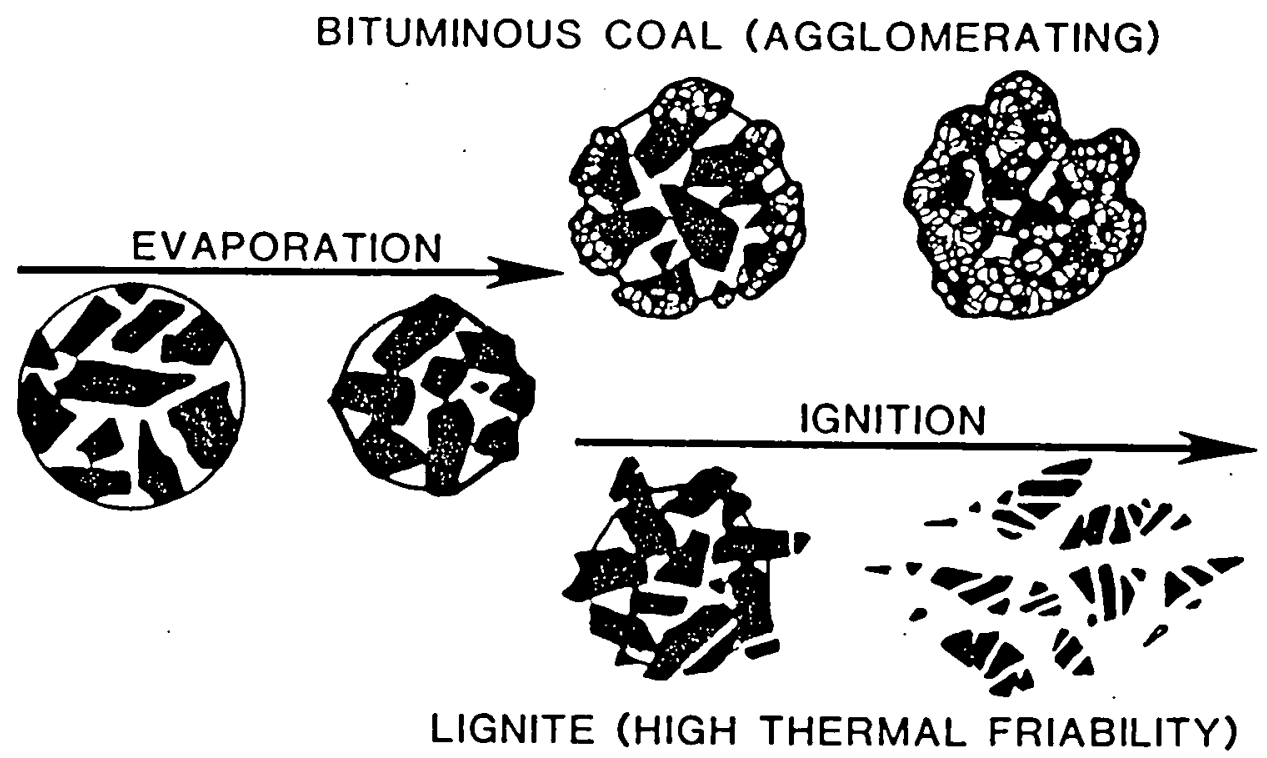

Figure 2.4 Rank Effect for the Evaporation and Ignition Sequence of CWSF Droplets (29) 
droplets during these same initial stages, Zghoul and Essenhigh (16) found that times were approximately proportional to $\mathrm{d}^{2}$ if conductive heat transfer dominates or $\mathrm{d}^{1}$ if radiation dominates. For combustion, the burning times were proportional to $\mathrm{d}^{2}(16)$.

Surfactant additives in CWSF have the potential for inhibiting the evaporation of the droplets. Surfactant molecules have the ability to align themselves as a monolayer on a droplet surface. The monolayer removes the liquid-gas interface at which evaporation normally occurs. Evaporation becomes limited by the ability of the liquid molecules to diffuse through the monolayer. Retardation of evaporation by monolayers has been studied extensively by La Mer (36) and others (37-39) and found to be effective under mild conditions, depending on the molecular structure of the monolayer. If surfactant monolayers on the surface of a slurry droplet can significantly inhibit the evaporation of the liquid during rapid heating, then the slurry droplet could boil explosively by a similar mechanism to the one discussed in section 2.3. This would mean that an analogy could be made between a slurry droplet with surfactant and a binary liquid fuel droplet consisting of low volatile and high volatile components. 
Chapter 3

\section{EXPERIMENTAL}

\subsection{Sample Selection}

The coal-water slurry fuel (CWSF) used in this study was prepared by AMAX Corporation and consisted of 31 percent by weight micronized, highly beneficiated, Velva lignite and the remainder water only. This work is a continuation of a study that used an AMAX bituminous CWSF; therefore, in order to study the effects of both coal rank and CWSF surfactant additives, it was both logical and convenient to obtain the lignite CWSF and surfactants from AMAX Corporation. Further information on the CWSF can be found in its preparation report (40) and the analyses in Tables A.1-3.

Carbon black, obtained from Columbian Chemicals, was selected to make a slurry with the intention that the effect of the coal volatile matter could be manifested when compared to experiments performed with the carbon black slurry. Tables A.4-6 contain data on the carbon black.

The additives were a Diamond Shamrock A-23 dispersant (the ammonium salt of naphthalene sulfonate in solution) and a Pfizer Flocon 4800 Xanthan stabilizer (85 percent biopolymer in water with about $3000 \mathrm{ppm}$ formaldehyde to prevent decomposition).

\subsection{Sample Preparation}

Preparation of the CWSF consisted of resuspending the settled solids on the bottom of the container to uniform distribution, diluting with deionized water to the desired solids loading, and mixing in the desired concentration of additives.

The CWSF was delivered in a five gallon bucket. Because there were no additives in the slurry, it was not surprising to find the solids hard packed on the bottom of the 
bucket. It required about an hour to cut up the hard pack with a table knife and work the solids back into suspension with manual mixing. The uniformly suspended mixture was then poured into one quart canning jars to allow easy mixing in the future. Separate jars of CWSF were mixed to contain the different amounts of surfactant that were to be tested in the study, the idea being that mixing the batches at once would yield greater consistency among the samples. However, when the slurries containing surfactant settled they could not be resuspended. The hard packs were harder than before adding surfactant. One batch was mixed again, this time including stabilizer, but its subsequent hard pack could not be resuspended; this hard pack did have a rubbery consistency compared to those without stabilizer. Therefore, it was decided to mix the slurries just prior to their use. The additive concentrations were all based on a solids loading of 50 percent by weight. This way the additive concentration was consistent relative to the coal regardless of the instantaneous solids loading. Slurries had to be diluted (with deionized water) to 20 percent solids or less to minimize plugging of the droplet generator. The appendix contains the methodology of adding the surfactant and dilution aliquots. All slurries were magnetically stirred for at least an hour before any data was ever taken on them.

The carbon black was delivered in jars in powder form. Deionized water and carbon black powder were slurried in an Oster kitchen blender. Details are provided in the appendix.

There are three sets of data that were taken with heat treated samples, two with CWSF and one with carbon black slurry. These sets were taken as a result of a minor mishap in which the heating element was accidentally activated on the magnetic stirrer and the CWSF, which contained additives, started to boil. Since the behavior of the droplets upon heating was noticed to be changing before the mishap was discovered, it was decided to perform controlled runs on heat treated batches of slurry containing surfactant. It was 
thought that the heat might have affected the additives because heating the slurry reservoir could not have had any effect on the temperature of the actual droplets (about $260 \mu \mathrm{m}$ in diameter) that got caught in the balance. Also, if a difference could be detected from heat treating a slurry with surfactant, the results could have implications for actual CWSF preheat operations. The slurries were boiled while being stirred on the magnetic stirrer for 15 minutes and allowed to cool to room temperature. The CWSF boiled at $103^{\circ} \mathrm{C}$ and the carbon black slurry boiled at $101^{\circ} \mathrm{C}$.

\subsection{Apparatus}

Slurry was contained in a half pint mason jar secured on a Sybron Thermolyne Type 1000 stir plate. Two hoses ran in and out of the lid. One was connected to a helium supply in order to prime the droplet generating system; the other carried slurry to the droplet generator, from which a monodisperse stream of droplets was ejected. The droplet generator works on the principle of an ink-jet printer and was developed specifically for use in this system. The device basically consists of a cylindrical piezoelectric transducer element with a capillary tube attached to one end and a fuel supply line attached to the other. Voltage pulses applied to the transducer cause sudden volume contractions which force fuel through the capillary orifice. The extruded fuel forms a monodisperse stream of droplets of uniform composition with the droplet size being determined by the capillary diameter and the amplitude and duration of the voltage pulses. Details of the design and operating characteristics of the droplet generator are provided in the literature (41). The droplet stream passed through a small hole in a copper disk maintaining a potential of about -900 volts, supplied with a Keithly Instruments model 240 regulated high voltage supply. After having a positive charge induced on them, the droplets fell into the electrodynamic balance. 
The heart of the system is the electrodynamic balance, sometimes referred to as a quadrupole trap, that was designed and built based on the work of Davis and Ray (42). This cylindrical balance contains a ring electrode around the center while two hyperbolic endcap electrodes enclose the balance from above and below. When an AC voltage is applied to the ring, the resulting electric field has a well-defined null point. A charged droplet in this field is subjected to a time-averaged force directed toward the null point. Applying a potential ( 0 to $\pm 150 \mathrm{VDC}$ ) across the endcap electrodes counterbalances gravitational forces acting on the droplet. The balance position is located at the geometric center of the trap, which serves as the focal point for the droplet irradiation and monitoring systems. The AC power was 0 to 2400 VRMS and was varied with a Wavetek model 143 $20 \mathrm{MHz}$ function generator.

The droplet mass to charge ratio is directly proportional to the DC voltage required to bring the droplet to the null point. As water evaporates from CWSF droplets the mass (and so the mass to charge ratio) continuously decreases, and the DC balance voltage must be adjusted to maintain the droplet at the null point during an experiment. A droplet imaging system (DIS) was employed to facilitate droplet position control and to provide accurate and precise measurements of changes in droplet size and mass. The DIS utilizes a Panasonic WV-1850 TV camera detector to monitor droplet position and size. The droplet appears on a Panasonic WV-5410 monitor as a shadow image created by backlighting the droplet with an LED. A microprocessor scans the video signal every 17 milliseconds and image processing techniques are employed to determine the droplet size and location. A control signal is then generated to hold the droplet position at the balance null point. Digital values corresponding to droplet cross-sectional area and balancing voltage (proportional to droplet mass) are generated at a rate of $60 \mathrm{~Hz}$. The droplet size information is used to trigger a high-speed camera and to activate a pulsed radiation (laser) source. Droplet 
diameter, mass, and solids loading are determined from the droplet size and balance control data, as detailed in the appendix. The confidence interval for droplet size resolution with the DIS is $\pm 3 \mu \mathrm{m}$ for droplets ranging from 50 to $200 \mu \mathrm{m}$ in diameter. The confidence interval for mass resolution is \pm 50 nanograms. Further details on the DIS are available in Maloney et al.(43).

The experimental configuration is presented in Figure 3.1. The pulsed radiation source was a Lasag type KOS (class IV) Nd:YAG laser powered by a Lasag KLS 016 impulse generator. Droplet backlighting for the Photec IV $16 \mathrm{~mm}$ high-speed motion picture camera was provided by a Spectra Physics 155 (class II) helium-neon laser. Calibrations were taken with Laser Precision RJP 735 detectors and registered on a Laser Precision $\mathrm{Rj}$ - 7200 energy ratiometer.

\subsection{Calibration Procedures}

\subsubsection{Characterization of the Laser Pulse}

The droplets in these experiments would be irradiated on two opposite sides. This required that the single pulse emitted from the Nd:YAG be split into three beams, other than the two fractions split off simply to reduce the overall intensity. The first beam split off was aimed at detector $A$. This beam was 5 percent of the energy incident upon the splitter and was simply a reference beam. The remaining 95 percent of energy that passed through the splitter would be split in half such that the two resultant beams would meet head-on at the null point in the electrodynamic balance. Figure 3.2 shows the schematic for the laser characterization. To ensure uniform energy flux upon the droplets, the counterpropagating beams had to be focused to equal intensity at the focal (null) point in the electrodynamic balance, and the radial energy distribution within the beams had to be measured. Both of these issues were addressed by using pinholes. 


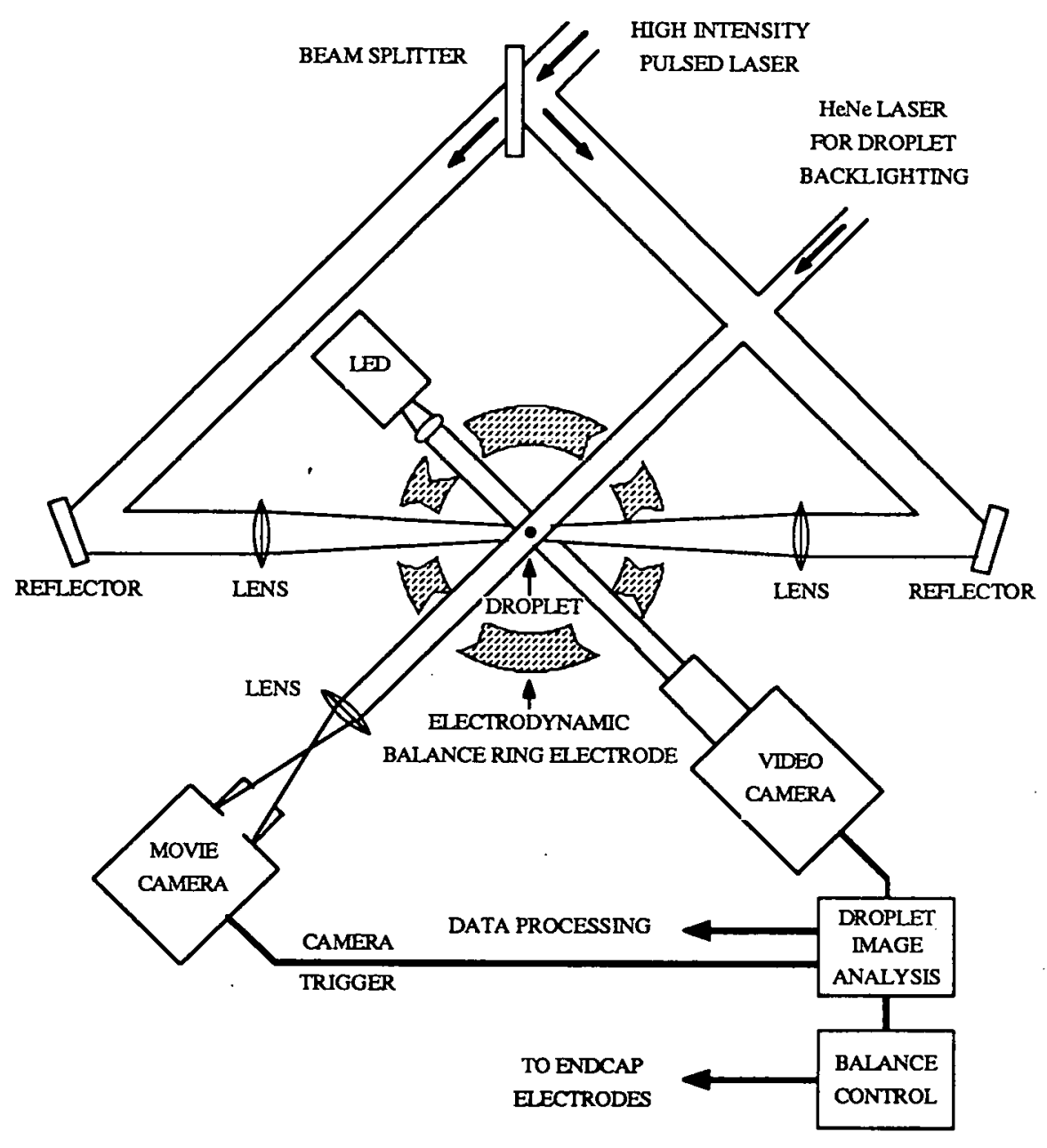

Figure 3.1 Experimental Configuration for Droplet Studies 


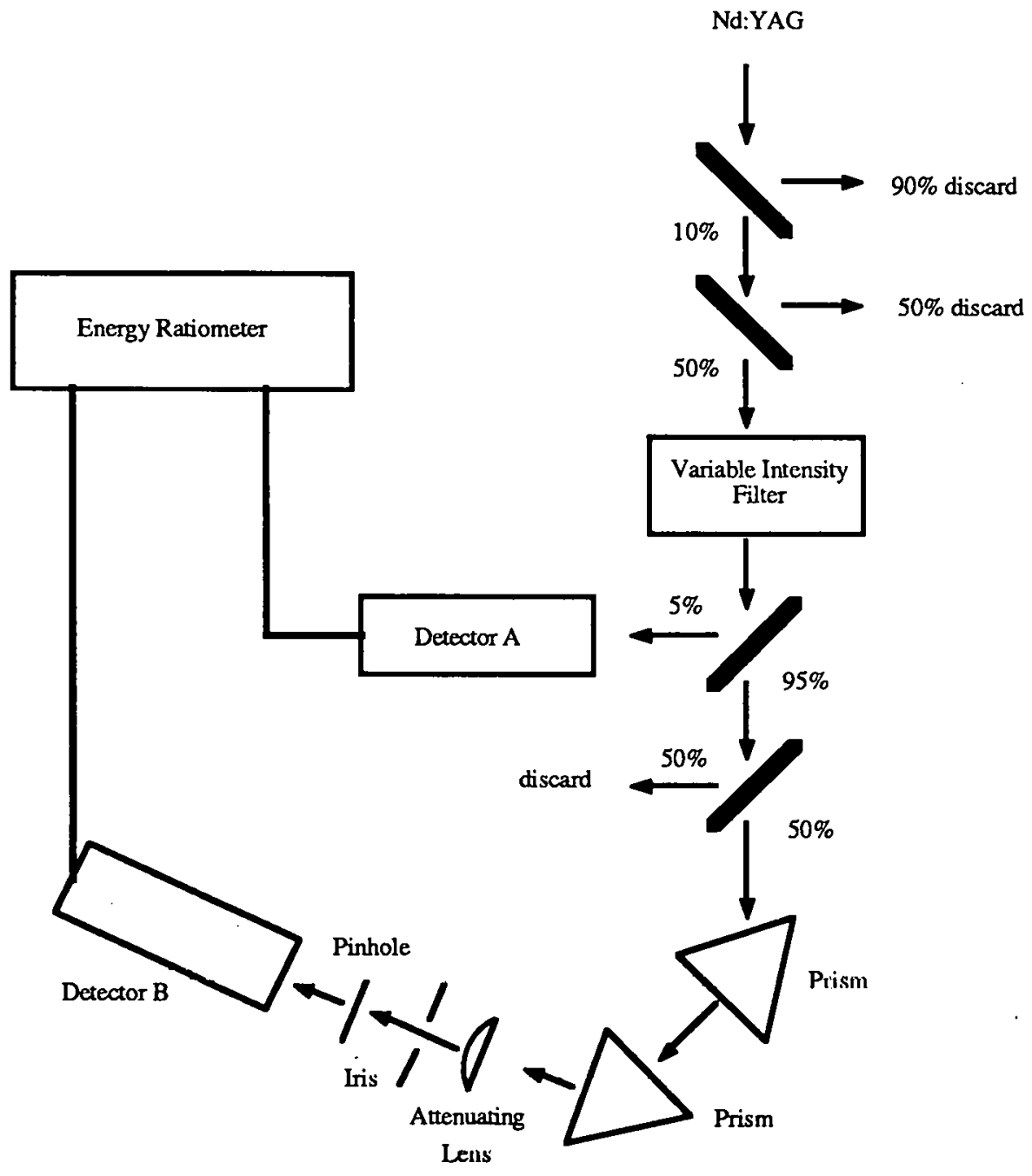

Figure 3.2 Schematic Diagram for Laser Characterization 
Two focusing lenses, one for each beam, were used to equalize the beams' intensities at the focal point in the electrodynamic balance. The focal lengths were measured for the monochromatic radiation emitted by the laser. This was done by blocking one of the beams, removing the electrodynamic balance and placing detector $\mathrm{B}$ at the location of the focal point, and putting a pinhole in the path of the unblocked beam between the focusing lens and detector B, as shown in Figure 3.3. The pinhole was moved along the beam path until the energy incident on detector $B$ was a maximum. The distance between the center of the lens and the pinhole was recorded as the focal length for that lens. The energy ratiometer gave the readings for both detectors $\mathrm{A}$ and $\mathrm{B}$ in $\mathrm{mJ}$, and the ratio B/A. Both focusing lenses had a focal length of $230 \mathrm{~mm}$ for the $1.06 \mu \mathrm{m}$ wavelength radiation.

The radial energy distribution within the beam was measured by maintaining a constant pinhole position, but varying the diameter of the pinhole. Pinholes of 1000,800 , 600,400 , and $200 \mu \mathrm{m}$ in diameter were used. The energy could then be measured in terms of the percent of beam cross-sectional area, varying uniformly from the beam center. The distribution was essentially Gaussian, but it was determined that the center 57 percent of the beam could be considered to be of uniform intensity. This translated into a central diameter of about $910 \mu \mathrm{m}$ at the focal point of the electrodynamic balance when the focusing lenses were $165 \mu \mathrm{m}$ distant from the focal point. Therefore, the largest droplets in this study, $170 \mu \mathrm{m}$ in diameter, had five droplet diameters of positional latitude in which the incident energy flux could safely be assumed to be uniform.

Interfacing detector B with an oscilloscope showed that the Nd:YAG laser produced a pulse that was approximately square in intensity over the 10 millisecond duration. 


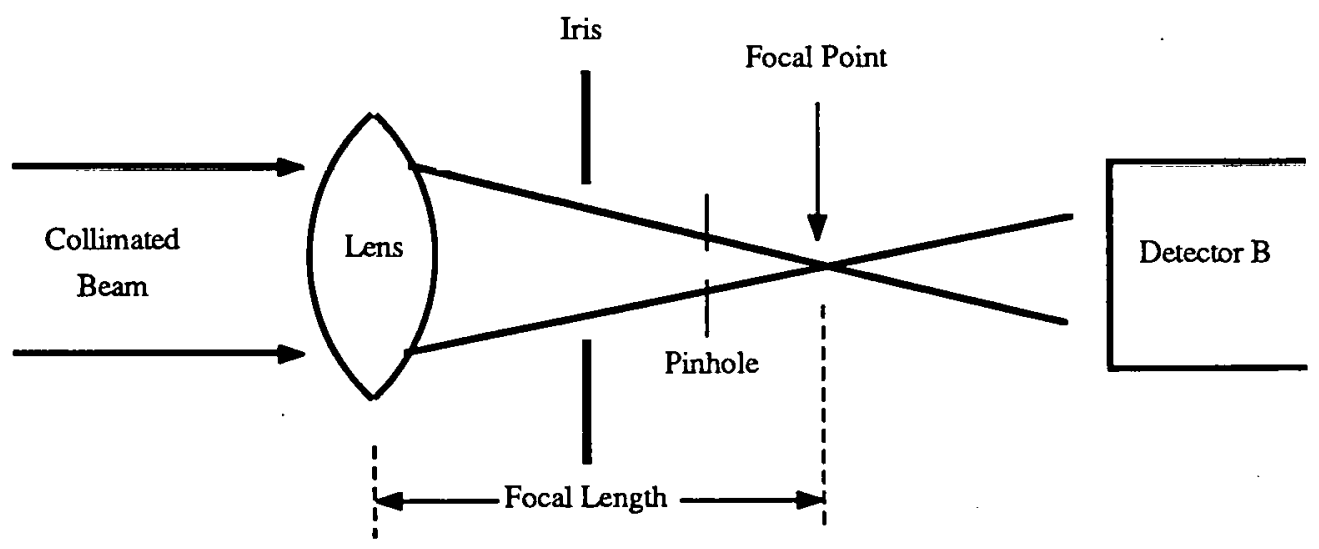

Figure 3.3 Schematic Diagram for Focusing Lens Focal Length Determination 
Therefore, when analyzing the high-speed movies, it could be assumed that the energy flux was equal in every one of the 50 frames exposed during the pulse.

The energy measured by detector $B$, which was located at the same position that would be occupied by the null point in the electrodynamic balance, divided by the energy measured simultaneously by detector A yielded a constant. When performing experiments detector $\mathrm{B}$ was no longer in place, but the readings from detector $\mathrm{A}$ were multiplied by the constant B/A so the incident energy upon the droplets could be determined. The expression for converting A to energy flux is given in the appendix.

\subsubsection{Calibration of the Droplet Imaging System}

Three parameters of the DIS were calibrated. They were the image size, the DC balance control voltage, and the DIS output control voltage (which is the signal that is amplified to become the DC balance control voltage).

The image size calibration was performed so that the digital value representing the size of the shadow image of a droplet on the monitor could be converted accurately into the real droplet size. Polystyrene DVB microspheres were statically charged and caught in the electrodynamic balance. The DIS was activated long enough to record at least 100 size measurements. The average and standard deviation of the 100 measurements were computed. If the standard deviation was less than two (the digital measurement values ranged from 500 to 2000 ), then the average DIS value was recorded. The microsphere was retrieved and placed on a glass slide for measurement under an optical microscope; microspheres were measured at three magnifications for averaging. The process was repeated for many microspheres over a range of sizes. 'I he DIS values were plotted against the actual sizes determined with the microscope. Curve fits were made over the range of sizes encompassing the sizes of the droplets to be studied. A second order fit corresponded 
to DIS data plotted against microsphere diameter, while a linear fit corresponded to DIS data plotted against microsphere cross-sectional area.

The calibration for the DC balance control was performed by, first, keeping the amp gain constant, and then inputting integer values between 0 and 4096 into a BASIC control program. (These values represent the range of possible outputs produced by the DIS position control D/A converter when video scans sense the droplet shadow image rising due to decreasing mass to charge ratio). After each value was entered, the voltage was measured off the top endcap of the electrodynamic balance with a Fluke 8840A Multimeter. The calibration for the voltage control signal, which is amplified to become the DC balance control voltage, is identical to the above procedure except the resultant voltages are measured from the DIS output that leads to the balance control amp. The relationships between the digital signal and the resultant DC voltages were linear.

The relationships from these three calibrations are presented in the appendix.

\subsection{Procedure}

The first step in performing droplet evaporation and explosive boiling experiments was getting a steady production of droplets from the droplet generator. All slurry supply lines were purged with helium for 15 minutes. The gas connection was switched with the supply line at the reservoir such that the gas pressure forced the liquid through the supply line and out the droplet generator. When the system was primed the high voltage pulses that operate the droplet generator were engaged. The droplet generator was then secured in place, and the gas was shut off. The droplet generator had to be at or below the level of the fluid in the reservoir in order to remain primed. The voltage and pulse width were varied in order to optimize the droplet stream out of the droplet generator. Once the droplet stream was entering the port in the electrodynamic balance and falling through the region of the 
focal point, the charging orifice was placed in the stream, 1 to $3 \mathrm{~mm}$ from the face of the droplet generator. Between 800 and 1000 negative volts were applied to the induction disk. Next, the AC current was turned on to the electrodynamic balance at a frequency of about $40 \mathrm{~Hz}$. When droplets could be seen oscillating on the monitor, the top endcap was put in place and the DC voltage was applied. The DC voltage was adjusted to position the droplet at the null point, and then the DIS was engaged.

Obtaining evaporation data would simply involve letting the droplet evaporate, saving the DIS data (size and mass changes), and recording the temperature and relative humidity in the electrodynamic balance. For an explosive boiling study, the evaporation file would be analyzed to determine how the droplet composition varied with decreasing size. A droplet size corresponding to a desired composition would be chosen and entered into the DIS as a trigger value. When an evaporating droplet reached the trigger size, a light on the control panel would go on and the high-speed camera would be started manually. Then, when the film attained a speed of 5000 frames per second, the laser fired automatically.

The particles that were still caught electrodynamically could be extracted with a charged probe inserted into the electrodynamic balance. Many droplet agglomerates from evaporative and non-explosive runs and fragments from explosive events were retrieved from the electrodynamic balance to be studied by scanning electron microscopy.

An image analysis system (IAS) was employed to measure the area of the shadow image on individual frames of movie film. The IAS takes a video image through an optical microscope focused on the film and uses brightness thresholds to count the number of pixels contained within the image. Because the starting droplet diameter is known, the relative change in cross-sectional area measured from the film can be converted into real size changes, which can then be used to calculate the droplet evaporation rates. 
Chapter 4

\section{RESULTS AND DISCUSSION}

\subsection{Energy Analyses}

\subsubsection{Droplet Energy Absorption}

The energy flux incident upon the droplets in these experiments was measured directly in terms of the power per unit cross-sectional area of the droplet. The quantity of energy that the droplets absorb is important for relating the experimental results to combustion conditions. Because the droplets were heated radiatively, the convective heat losses from the droplets also need to be estimated in order to determine the energy stored in the droplets as a function of time.

The amount of energy absorbed by a droplet was determined by measuring the size change and, therefore, the mass of water evaporated as a direct result of a pulsed heating event. Figure 4.1 illustrates the effect of a nonexplosive heating event on droplet evaporation. The cross-sectional area of the droplet decreases linearly as the droplet evaporates under ambient conditions. At time zero the heating pulse was initiated and the droplet was heated for 10 milliseconds. The open squares represent ambient evaporation data taken with the DIS, and the solid squares represent the rapid evaporation data taken with the IAS. Shortly after the cessation of the energy pulse, the droplet thermally equilibrated and resumed ambient evaporation. Because the ambient rates before and after droplet heating are essentially the same, which can be inferred because the lines through the respective points are parallel, all of the size change between these two periods must have been caused by the energy that the droplet absorbed during the rapid heating stage. This procedure normalizes the effects of variation in room temperature and relative humidity 


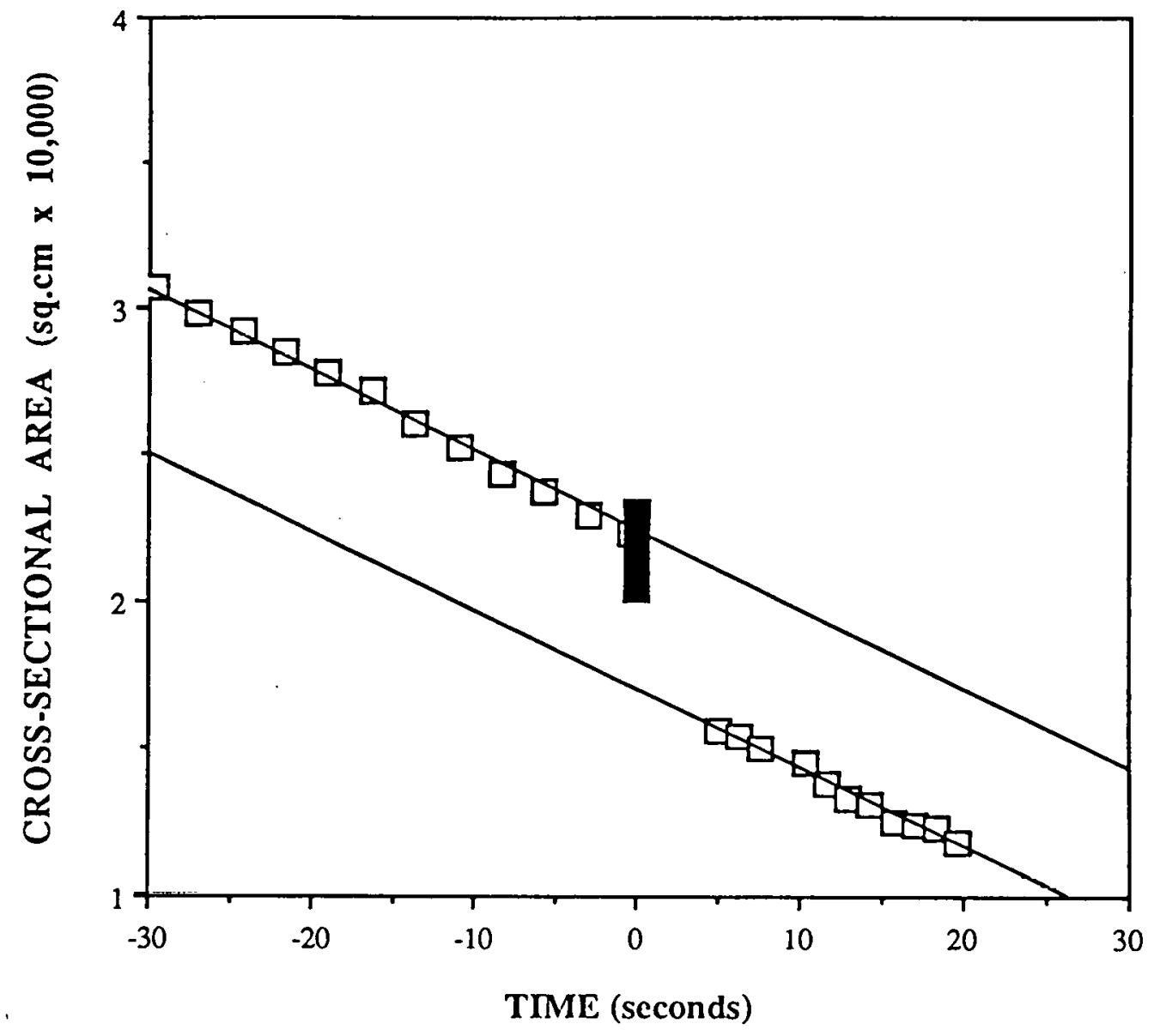

Figure 4.1 Ambient versus Heated Evaporation:

$50 \%$ lignite, $170 \mu \mathrm{m}$ diameter, $0 \%$ surfactant, $1090 \mathrm{~W} / \mathrm{cm}^{2}$

$\square$ DIS data corresponding to ambient evaporation

- IAS data corresponding to heated evaporation 
when comparing different droplets. Since the change in size could only be from water loss, the vertical distance between the parallel lines was used to calculate the mass of water evaporated. The energy required to raise this quantity of water to its boiling temperature and vaporize it was compared to the total incident energy.

This comparison was performed for six droplets ranging from 160 to $170 \mu \mathrm{m}$ in diameter, 25 to $50 \%$ solids, 0 to $4 \%$ surfactant, and 410 to $1330 \mathrm{~W} / \mathrm{cm}^{2}$ incident flux. The absorbed energy dissipated by evaporation accounted for between 42 and $50 \%$ of the incident energy, with $46 \%$ being the average. The conduction/convection heat loss from the droplets during the time period between the initiation of the heating pulse and thermal equilibration was estimated to be about $5 \%$. In the subsequent analyses all droplets were assumed to absorb $50 \%$ of the incident energy.

\subsubsection{Heat Losses}

Before the temperature of heated droplets can be estimated, a heat balance must be performed in order to identify significant avenues of heat loss in addition to sensible and latent heat. Unlike droplets in a combustion chamber, the experimental droplets were surrounded by cool gas as they were heated radiatively. Radiative heat loss from the droplets was assumed to be negligible. Convective losses were estimated as follows. The Reynolds number for motionless conditions is zero. Therefore, for spherical geometry, the Nusselt number is equal to 2 (44). Solving the definition of the Nusselt number, Nu, for the convective heat transfer coefficient, $h$, gives

$$
h-\frac{\mathrm{Nuk}_{\mathrm{f}}}{\mathrm{d}}
$$

where $\mathrm{k}_{\mathrm{f}}=0.0286 \mathrm{~W} / \mathrm{mK}$ is the thermal conductivity of the fluid, air, at the film temperature, which is the average of the ambient temperature, $\mathrm{T}_{\infty}=20^{\circ} \mathrm{C}$, and the droplet 
surface temperature at its boiling point, $\mathrm{T}_{\mathrm{s}}=100^{\circ} \mathrm{C}$. Next, the convective energy loss during the heating period, $E_{c}$, could be approximated by using the definition

$$
E_{c}=h t S\left(T_{\infty}-T_{s}\right)
$$

where $S$ is the surface area of the droplet. $E_{c}$ was about $0.02 \mathrm{~mJ}$ for the droplets while the total energy absorbed averaged about $2 \mathrm{~mJ}$. The time, $\mathrm{t}$, is $10 \mathrm{~ms}$ for droplets that survive the heating period; otherwise $t$ corresponds to the time of droplet disruption. Because $E_{c}$ was two orders of magnitude lower than the total absorbed energy, except at incident fluxes below about $450 \mathrm{~W} / \mathrm{cm}^{2}$ where it was one order of magnitude, convective losses were neglected when estimating droplet temperatures.

\subsubsection{Estimate of Droplet Temperature at Explosive Boiling}

Rigorous thermodynamic analysis of heated droplets is beyond the scope of this work. However, estimates of the temperatures achieved by droplets prior to explosive boiling are useful in determining the energy requirements of explosive boiling and some of the limiting factors in the transfer of heat to the droplets. The following simplifying assumptions were made for these estimates: 1) The entire droplet reached $100^{\circ} \mathrm{C}$ before the onset of rapid (over equilibrium) evaporation. Therefore, at least some initial portion of the heating period was attributed soley to droplet heat-up. 2) $50 \%$ of the incident energy was absorbed. 3) Heat losses were only from an amount $\Delta m$ of water evaporated, either measured or, in most cases, estimated from a linear fit to the measured evaporation rates, which is detailed in section 4.2.2. 4) Thermal properties were constant and evaluated at $100^{\circ} \mathrm{C}$. 5) Fluctuations in droplet size were did not significantly affect evaporation or energy absorption. This final assumption was tested for two droplets, one that received $2930 \mathrm{~W} / \mathrm{cm}^{2}$ and one that received $9350 \mathrm{~W} / \mathrm{cm}^{2}$. In the former case the resulting 
temperature was only $3^{\circ} \mathrm{C}$ less than the calculated temperature without considering changing droplet size, while in the latter case the result was $42{ }^{\circ} \mathrm{C}$ less. Therefore, the assumption is more valid at lower energy fluxes.

Step I: Time for Droplet to Reach its Boiling Point

The energy absorbed by a droplet is

$$
\begin{gathered}
\mathrm{E}_{\mathrm{ab}}=\frac{1}{2}[\mathrm{Ft}(2 \mathrm{~A})] \\
\mathrm{E}_{\mathrm{ab}}=\mathrm{FtA}
\end{gathered}
$$

where $F$ is the incident energy flux, $t$ is time, and $A$ is the cross-sectional area of the droplet. Substituting equation 4.3 into the heating expression $E=m C_{p} \Delta T$, solving for $t$ and designating this time as ti yields

$$
\mathrm{t}_{\mathrm{I}}=\frac{\mathrm{m}_{\mathrm{d}} \mathrm{C}_{\mathrm{pd}}\left(\mathrm{T}_{\mathrm{BP}}-\mathrm{T}_{\mathrm{d}}\right)}{\mathrm{FA}}
$$

where $m_{d}$ is the droplet mass, $C_{p, d}$ is the droplet heat capacity, $T_{B P}$ is the boiling temperature of $100^{\circ} \mathrm{C}$, and $\mathrm{T}_{n}$ is the temperature of the droplet before heating, about $18^{\circ} \mathrm{C}$. The droplet heat capacity was determined as the weighted average of its components, $C_{p, d}=\sum y_{i} C_{p, i}$, where $y$ is the weight fraction and $i$ represents coal or water. The value of the heat capacity employed for lignite was $1.5 \mathrm{~J} / \mathrm{g} \cdot \mathrm{K}(45,46)$.

Step II: Energy Absorbed Between Heat-up and Explosion

Designating the total amount of energy absorbed by the droplet between heat-up to boiling and explosion as $\mathrm{E}_{\mathrm{II}}$,

$$
E_{I I}=F A\left(t-t_{1}\right)
$$

where $t$ is the total irradiation time. 


\section{Step III: Water Evaporated Before Explosion}

The amount of water evaporated before explosion, $\Delta \mathrm{m}$, can be estimated from a linear fit to a plot of evaporation rate against incident flux.

$$
\Delta \mathrm{m}=\mathrm{R}\left(\mathrm{t}-\mathrm{t}_{\mathrm{I}}\right) \mathrm{A}
$$

where the experimentally determined evaporation rate, $R=0.02569 \mathrm{~F}-11.61$. (See section 4.2).

Step IV: Latent Heat Required to F.vaporate $\Delta \mathrm{m}$ of Water

$$
\mathrm{E}_{\Delta \mathrm{m}}=\Delta \mathrm{m} \Delta \mathrm{H}_{\mathrm{vap}}
$$

where $\Delta \mathrm{H}_{\text {vap }}$ is the latent heat of vaporization of water at $100^{\circ} \mathrm{C}$.

Step V: Energy Available for Superheat

$$
\mathrm{E}_{\mathrm{S}}=\mathrm{E}_{\mathrm{II}}-\mathrm{E}_{\Delta \mathrm{m}}
$$

Step VI: Average Droplet Temperature at Time of Explosion

$$
T_{f}=\frac{E_{S}}{m_{d} C_{p d}-\Delta m C_{p w}}+T_{0}
$$

where $C_{p, w}$ is the heat capacity of water.

These calculations were repeated for the three cases where $\Delta \mathrm{m}$ was measured with the IAS. Two of these results were in excellent agreement with the result using the estimated $\Delta \mathrm{m}$. The third result using the measured $\Delta \mathrm{m}$ was about $60^{\circ} \mathrm{C}$ lower than when $\Delta \mathrm{m}$ was estimated because the measured $\Delta \mathrm{m}$ was more than twice the estimated $\Delta \mathrm{m}$. There is no apparent cause for this discrepancy. This third droplet had $25 \%$ solids, while the 
other two had $50 \%$ solids, but the difference in droplet heat capacity caused by different solids loading was taken into account in the temperature calculation.

Figure 4.2 shows the estimated temperatures that droplets achieved just prior to explosive boiling. The diagonal reference line divides the order-of-magnitude heating rate regimes. The horizontal reference lines define the region in which explosive boiling is expected to occur.

It is physically impossible for a CWSF droplet to exist in whole at a bulk temperature above the maximum superheat of water. Therefore, droplets indicated at temperatures above this line must contain high thermal gradients between the coal particles and the water phase. The coal particles were expected to be hotter than the water since the water did not absorb the incident radiation. However, if the bulk droplet temperature is much higher than the maximum superheat temperature of approximately $300^{\circ} \mathrm{C}$, then the coal particles would have to be near or above their devolatilization temperature. As indicated earlier, the temperatures are slightly overestimated at the higher heating rates, but not enough to account for droplet temperatures much greater than $350^{\circ} \mathrm{C}$. There were five instances in which small clouds of volatiles were apparent following droplet heating and disruption; however, for the numerous other fragmentation and explosive boiling events, there was no visual evidence of release of volatile matter.

The lignite had been hot-water dried at $334^{\circ} \mathrm{C}, 2455$ psig for 15 minutes, so most of the low temperature release of $\mathrm{CO}_{2}$ and $\mathrm{H}_{2} \mathrm{O}$ had already occurred. If the lignite particles exceeded $350^{\circ} \mathrm{C}$, which they would have if the high droplet temperatures are at all accurate, then the evolution of tars and light volatiles should be occurring as a droplet boils explosively. Indeed, for a few of the CWSF droplets heated by energy fluxes around 9000 $\mathrm{W} / \mathrm{cm}^{2}$ volatile clouds and combustion were apparent on the high speed films. The explosive growth of water vapor bubblcs must still be responsible for the complete 


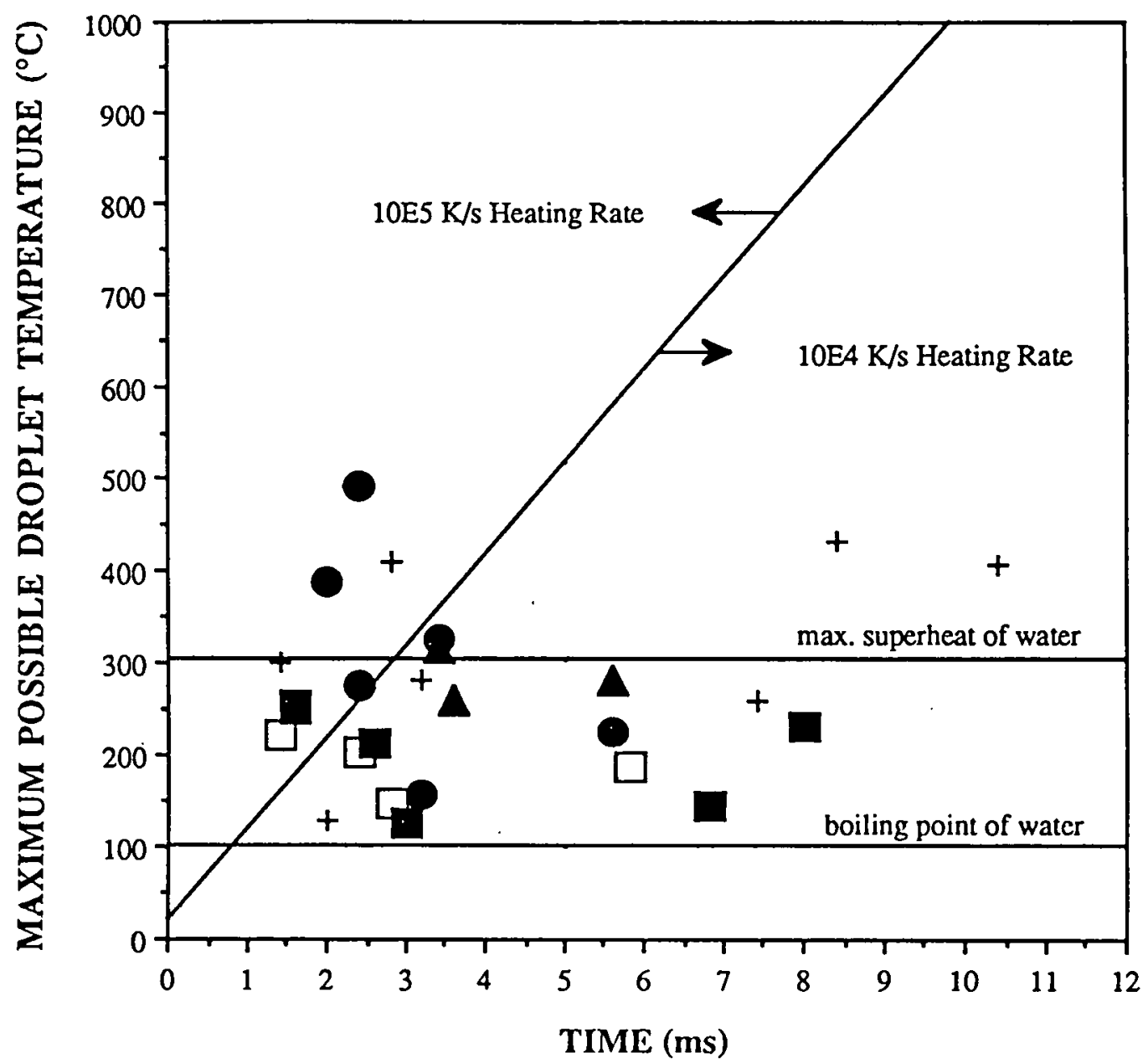

Figure 4.2 Heat Capacity Normalized Energy Requirements for Explosive Boiling

$\square \quad 50 \%$ lignite, $170 \mu \mathrm{m}$ diameter, $0 \%$ surfactant

D $25 \%$ lignite, $170 \mu \mathrm{m}$ diameter, $2 \%$ surfactant

- 50\% lignite, $120 \mu \mathrm{m}$ diameter, $2 \%$ surfactant

- $35 \%$ lignite, $170 \mu \mathrm{m}$ diameter, $2 \%$ surfactant

$+\quad 50 \%$ lignite, $160 \mu \mathrm{m}$ diameter, $4 \%$ surfactant 
destruction of the droplet and the dispersion of the particles as seen in the films. Devolatilization clouds were never seen to expand as quickly and as far as the droplet fragments.

The CWSF containing $4 \%$ surfactant, denoted by the plus signs in Figure 4.2, demonstrated the most erratic behavior of all of the CWSF compositions. The two plus signs above the maximum superheat line and in the $10^{4} \mathrm{~K} / \mathrm{s}$ region are anomalous, and could be the result of a measuring error. Particularly unusual is the droplet that exploded at 10.4 milliseconds, 0.4 millisecond after the termination of the heating pulse. There is no tenable explanation for this observation. Perhaps the surfactant can prevent heterogeneous nucleation during heating and the 0.4 millisecond is a delay for heat transfer from the particles to the water.

The only CWSF without surfactant in Figure 4.2 is represented by the open squares. This CWSF and the CWSF with only $25 \%$ solids and $2 \%$ surfactant boiled explosively at the lowest temperatures. The most plausible explanation is that these fuels have the greatest probability for heterogeneous nucleation. This could indicate a slight inhibition of explosive boiling by the surfactant.

\subsection{Evaporation}

\subsubsection{Ambient Evaporation}

Droplets evaporate at a rate proportional to the diameter squared. This was evident in Figure 4.1, where the CWSF droplet's cross-sectional area diminished linearly during ambient evaporation. Once the particles within the droplet reach their maximum packing density, the droplet stops shrinking and the $\mathrm{d}^{2}$ rule is no longer valid, which is illustrated in Figure 4.3. Here, the energy absorbed during the heating pulse (at time zero) caused 


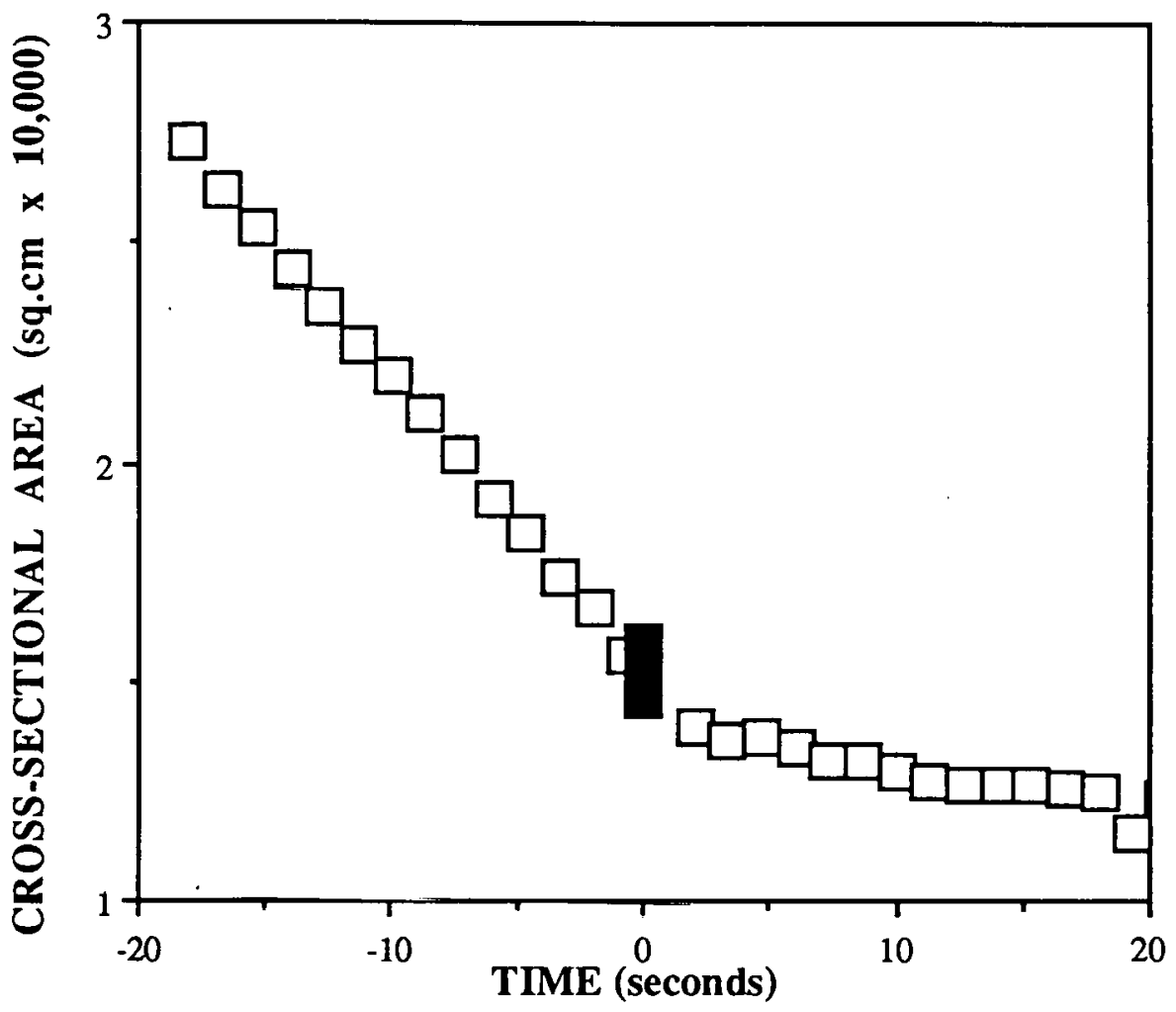

Figure 4.3 Ambient versus Heated Evaporation:

$50 \%$ lignite, $140 \mu \mathrm{m}$ diameter, $0 \%$ surfactant, $1030 \mathrm{~W} / \mathrm{cm}^{2}$ 
sufficient water to evaporate that the droplet could hardly shrink further as it continued to evaporate at equilibrium temperature.

Evaporation data for the CWSF droplets with $4 \%$ surfactant and with no surfactant were compared to a droplet evaporation model that considers the inhibition of evaporation by a surface monolayer, as well as energy balance, relative humidity, and other parameters. It was determined that the surfactant cut the evaporation rate in half for room temperature (47).

\subsubsection{Evaporation Under Heating Conditions}

Measuring the evaporation rates during droplet heating were made using high speed film and an image analysis system. The IAS measures the relative change in droplet crosssectional area by measuring the size of the droplet shadow image on each frame of film. These data are then superimposable with the DIS data, as was already seen in Figures 4.1 and 4.3. In these figures the IAS data appear as a step because the sharp increase in the evaporation rate during heating is not resolvable on the time scales shown in the plot. Figures 4.4-6 detail the rapid evaporation data. The arrows point out the 10 millisecond heating period in each case. The data terminate at either explosive boiling or the initiation of thermal equilibration. Complete thermal equilibration was not achieved within the time frame of Figures 4.4-6. For example, the droplets in Figure 4.5 that were heated at fluxes of 480 and $1330 \mathrm{~W} / \mathrm{cm}^{2}$ had bulk temperatures of about 40 and $60^{\circ} \mathrm{C}$, respectively, at the maximum time shown for each. The data in Figure 4.6 are unusually scattered compared to those in Figures 4.4 and 4.5. It might be possible that, since the droplets in Figure 4.6 had no surfactant, trapped gas (not vapor) bubbles disturbed the heated droplets.

Pulsed droplet heating apparently involves three stages: heat up, rapid evaporation, and either thermal equilibration or explosive boiling. At the onset of the pulse the droplet 


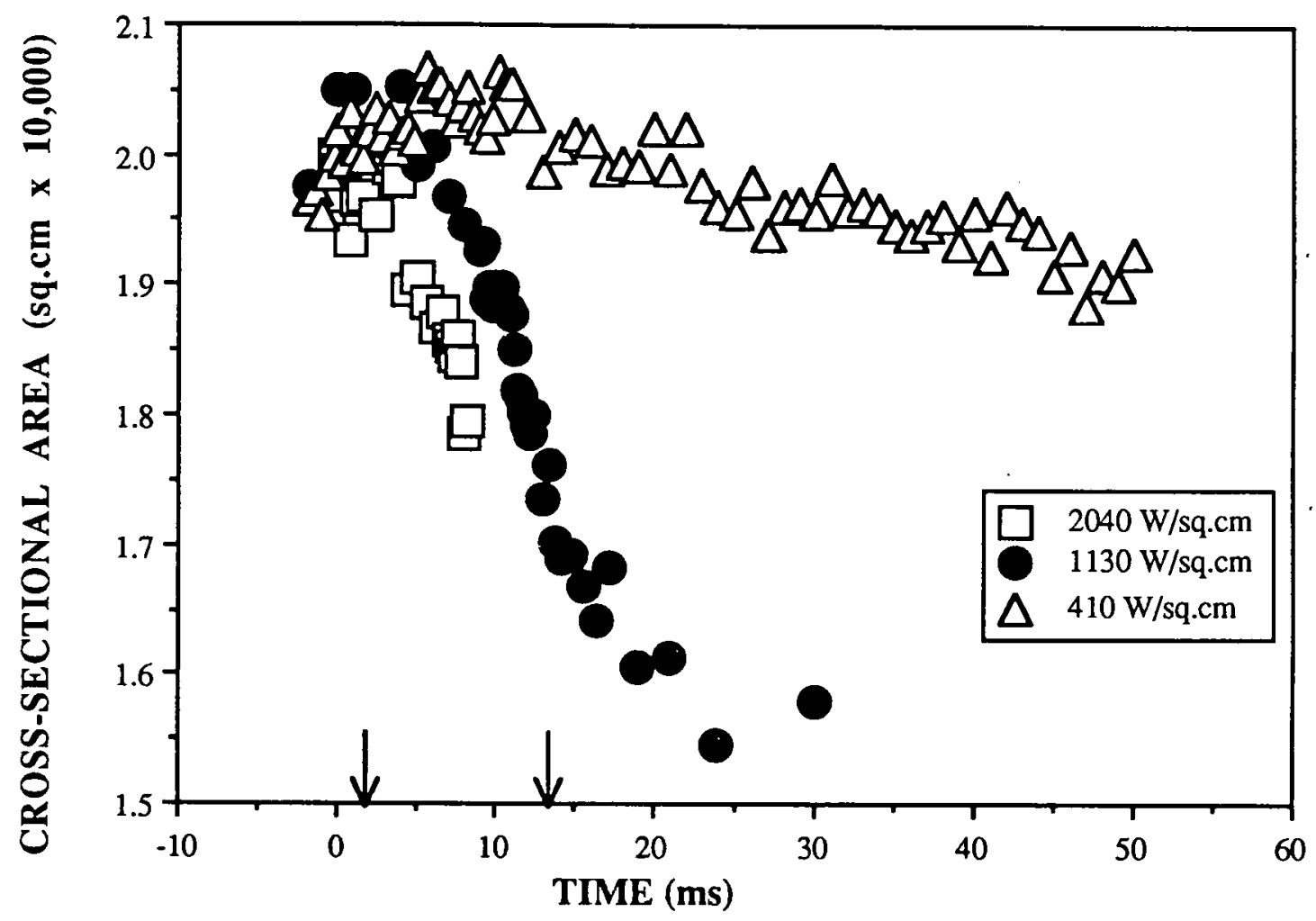

Figure 4.4 Change in Cross-Sectional Area for Heated CWSF Droplets: $50 \%$ lignite, $160 \mu \mathrm{m}$ diameter, $4 \%$ surfactant 


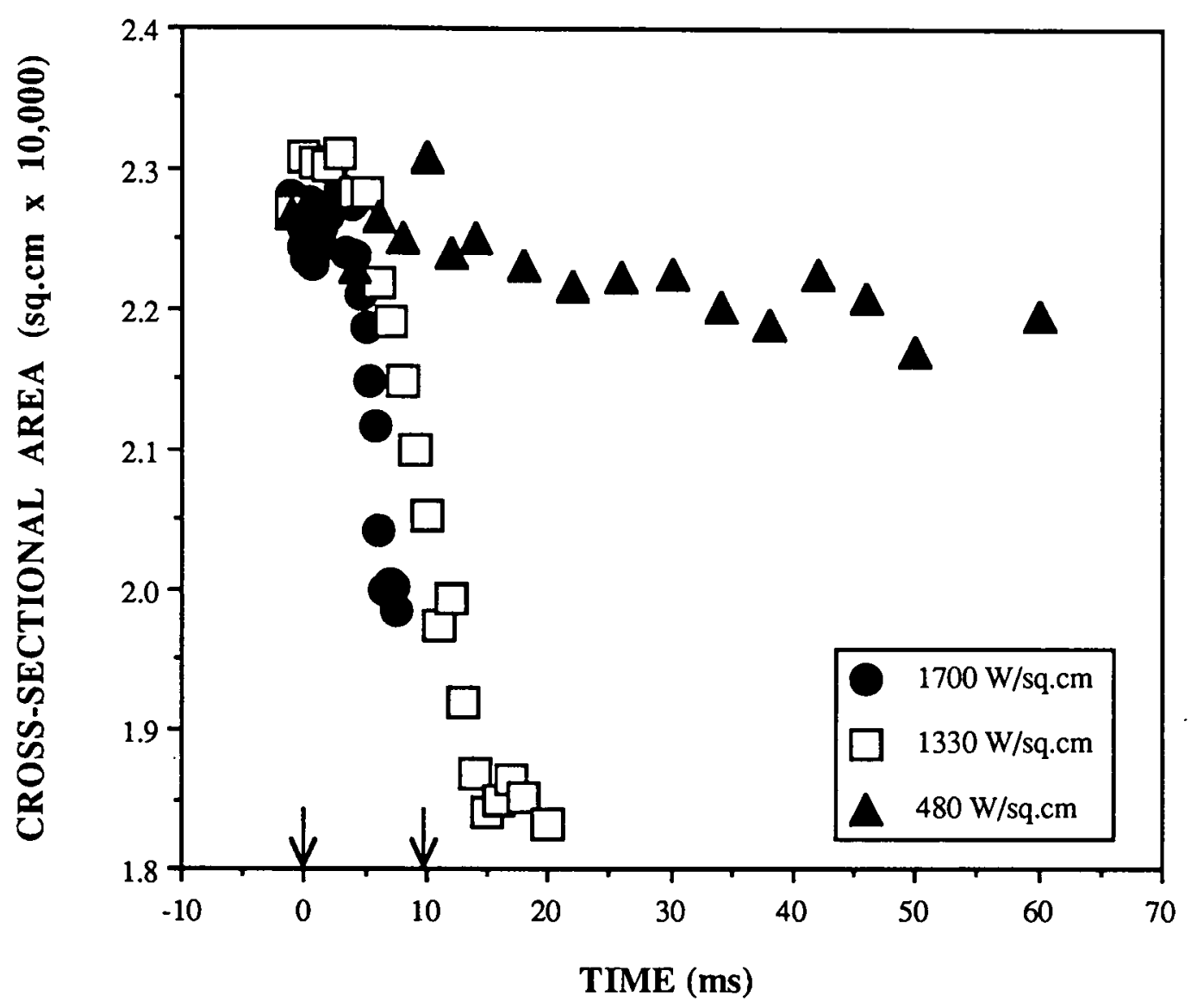

Figure 4.5 Change in Cross-Sectional Area for Heated CWSF Droplets: $25 \%$ lignite, $170 \mu \mathrm{m}$ diameter, $2 \%$ surfactant 


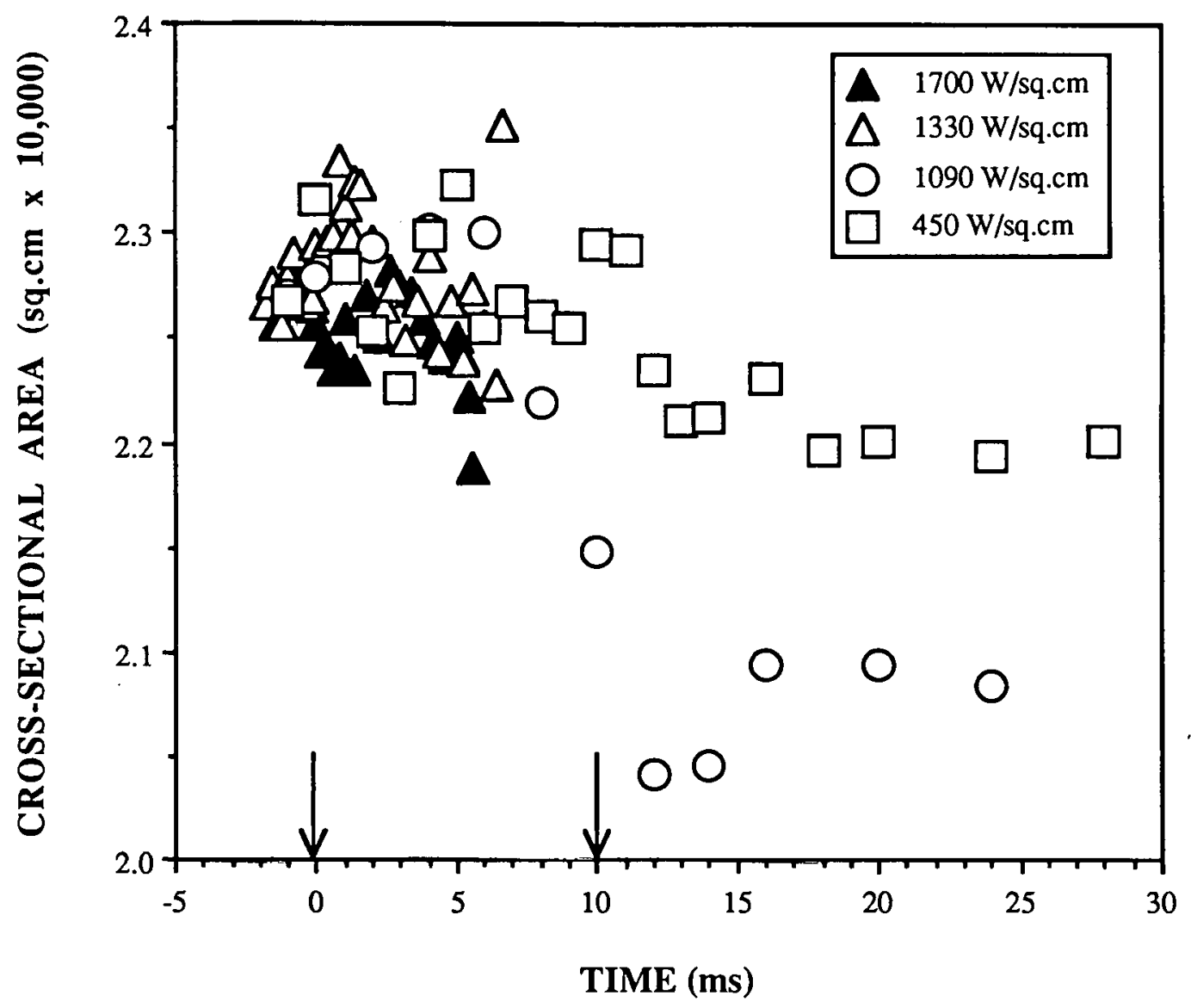

Figure 4.6 Change in Cross-Sectional Area for Heated CWSF Droplets: $50 \%$ lignite, $170 \mu \mathrm{m}$ diameter, $\mathbf{0 \%}$ surfactant 
heats up, causing thermal expansion and, most likely, increased evaporation of the water. Early in the pulse the thermal expansion is either maximized or is no longer dominant over evaporation in changing the droplet size. Rapid evaporation causes rapid reduction in droplet size. If interior superheat develops and reaches its limit or initiates heterogeneous nucleation, the droplet boils explosively. If not, the rapid size reduction continues throughout the pulse life. At the termination of the heating pulse, the surviving droplet thermally equilibrates and eventually evaporates at its original, ambient rate, unless the particles have already achieved their maximum packing density. The data in these figures show how the rate of size reduction, or evaporation, increases with increasing energy flux.

The droplets in Figures 4.4 and 4.5 heated by 410 and $480 \mathrm{~W} / \mathrm{cm}^{2}$, respectively, evaporated at an accelerated rate (relative to ambient) for more than $\mathbf{4 0}$ milliseconds after the end of the heating period. The droplets heated at the next higher energy fluxes showed sudden decreases in their rapid evaporation rates at about 5 milliseconds after the pulse. The subsequent evaporation rates were still greater than the ambient rates because the droplets had not yet thermally equilibrated.

A common feature in Figures 4.4-6 is that the droplets that exploded (data corresponding to the highest energy flux in each figure) decreased in size less than droplets that did not explode at the next lower energy flux. This illustrates the dependency of explosive boiling on heating rate. Figure 4.7 further supports this point. Each of the droplets represented in this figure originally consisted of at least $50 \%$ water by weight. However, none of the droplets lost as much as $20 \%$ of its weight before boiling explosively. This means that explosive boiling occurred within a significant quantity of water, which has an important practical implication; in addition to preventing the formation of a sturdy agglomerate, explosive boiling of CWSF droplets could accelerate the evaporation of the water by increasing the surface area from which to evaporate. 


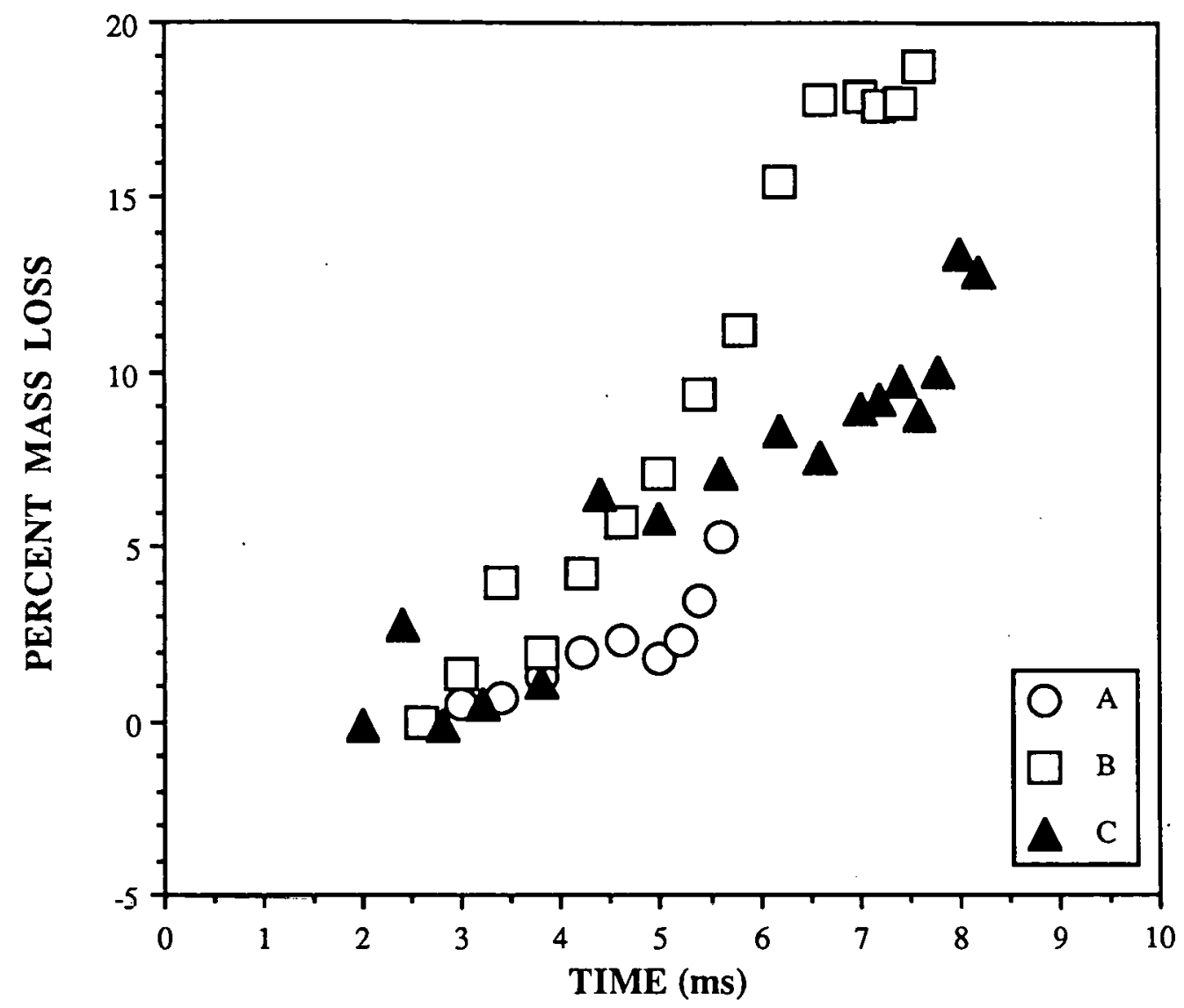

Figure 4.7 Percent Mass Loss by Evaporation Before Explosive Boiling

A: $50 \%$ lignite, $170 \mu \mathrm{m}$ diameter, $0 \%$ surfactant, $1700 \mathrm{~W} / \mathrm{cm}^{2}$

B: $25 \%$ lignite, $170 \mu \mathrm{m}$ diameter, $2 \%$ surfactant, $1700 \mathrm{~W} / \mathrm{cm}^{2}$

C: $50 \%$ lignite, $160 \mu \mathrm{m}$ diameter, $4 \%$ surfactant, $2040 \mathrm{~W} / \mathrm{cm}^{2}$ 
In Figure 4.7 droplet $\mathrm{A}$ lost about $6 \%$ of its total mass, which translates into a solids loadings of $53 \%$ when it boiled explosively. Droplet $C$, having lost about $13 \%$ of its mass, had a final solids loading of 57\%. The pour point of the CWSF, the solids concentration at which the particles begin to pack, is less than $56 \%$ coal (40). This would imply that explosive boiling is most probable when the particles become close-packed. At this point there could no longer be a film of water covering the droplet surface, and the surface area available for evaporation would suddenly be drastically reduced. Meanwhile, the coal on the surface of the droplet would be absorbing the incident energy directly and conducting it toward the interior, superheating the remaining water to the point of vapor nucleation. However, even though droplet $B$ lost almost $20 \%$ of its mass before explosive boiling, its final solids loading was only $30 \%$. The above argument is not valid in this case. The heating rate was sufficient for droplet $B$ to cause internal superheating and bubble nucleation.

Droplet $C$, with $4 \%$ surfactant, lost more than twice the relative amount of water before explosive boiling than the droplet with no surfactant (A), even though droplet $\mathrm{C}$ was heated under a higher incident energy flux and both droplets have the same heat capacity. This could be the result of earlier, heterogeneous nucleation in droplet $A$; however, more cuimparisons should be done in the future to determine if the higher surfactant concentration would consistently allow greater water loss before explosive boiling.

The data in Figure 4.7 begin at the point of maximum expansion and were based on a droplet temperature of $100^{\circ} \mathrm{C}$. Beginning at the point of maximum expansion, the data could underestimate the final value by not more than $5 \%$. Basing the calculations on 100 ${ }^{\circ} \mathrm{C}$ could overestimate the final value not more than $5 \%$ if the actual droplet temperature had been $250^{\circ} \mathrm{C}$. The two simplifications tend to offset error. 
Rapid droplet evaporation rates can be estimated by plotting the droplet mass divided by the droplet surface area against time and taking the slope of the curve. These plots look like Figures 4.4-6, except the ordinate is of a different scale. For this purpose linear approximations were used between the peak droplet expansions and the onset of equilibration. Some data, especially for the droplets without surfactant and for explosive boiling events, were too scattered or nonlinear to be used for these estimations. The evaporation rates during heating are presented in Figures 4.8 and 4.9. The evaporation rates show good linear proportionality to both the incident energy flux and the rate of energy absorption, respectively. This linear proportionality is expected at the lower energy fluxes (and, therefore, lower droplet temperatures) because the energy is considered to be consumed only by mechanisms associated with the latent heats and heat capacities of the droplets (49). No heats of pyrolysis reactions are incorporated into the heat balance. A linear regression through the points in Figure 4.8 was used to estimate the effect of evaporation on droplet temperature, as previously outlined.

These rates are a little low since thermal expansion beyond $100^{\circ} \mathrm{C}$ was not considered even though it was shown earlier that the droplets did get hotter. However, what is important for this study is the relative difference among the droplet compositions. Since the surfactant reduced the evaporation of droplets under room conditions, the question to be addressed is how does it affect evaporation under heating conditions. If the surfactant significantly suppresses droplet evaporation during heating, then the reduced evaporation rate would have to be considered in combustion calculations. In Figures 4.8 and 4.9 there is no apparent influence on evaporation rates by the surfactant. The surfactant used in this study should not affect the evaporation of CWSF droplets in a combustor. 


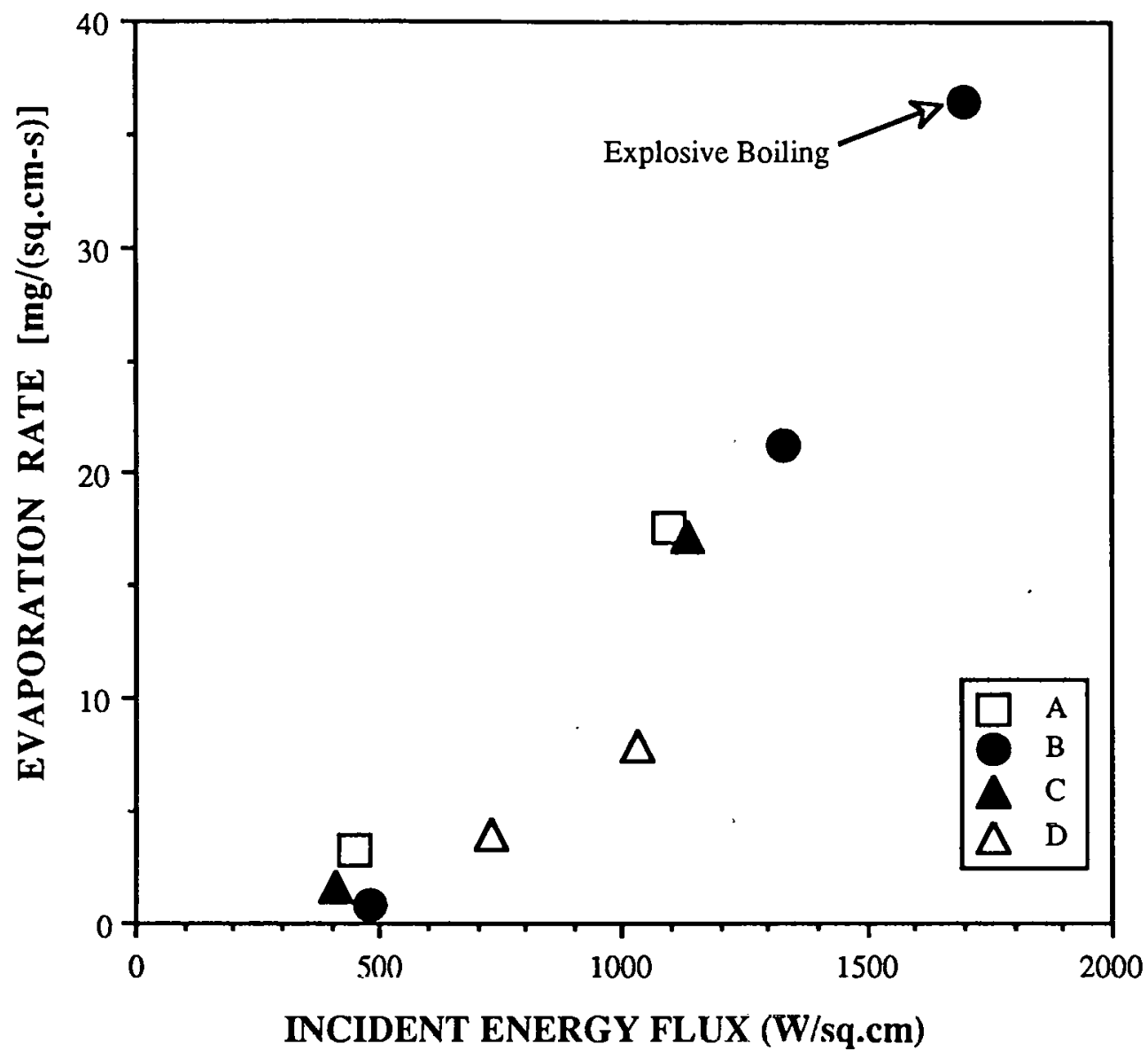

Figure 4.8 Heated Evaporation Rates as a Function of Incident Energy Flux
A: $50 \%$ lignite, $170 \mu \mathrm{m}$ diameter, $0 \%$ surfactant
B: $25 \%$ lignite, $170 \mu \mathrm{m}$ diameter, $2 \%$ surfactant
C: $50 \%$ lignite, $160 \mu \mathrm{m}$ diameter, $4 \%$ surfactant
D: $\mathbf{5 0 \%}$ lignite, $140 \mu \mathrm{m}$ diameter, $0 \%$ surfactant 


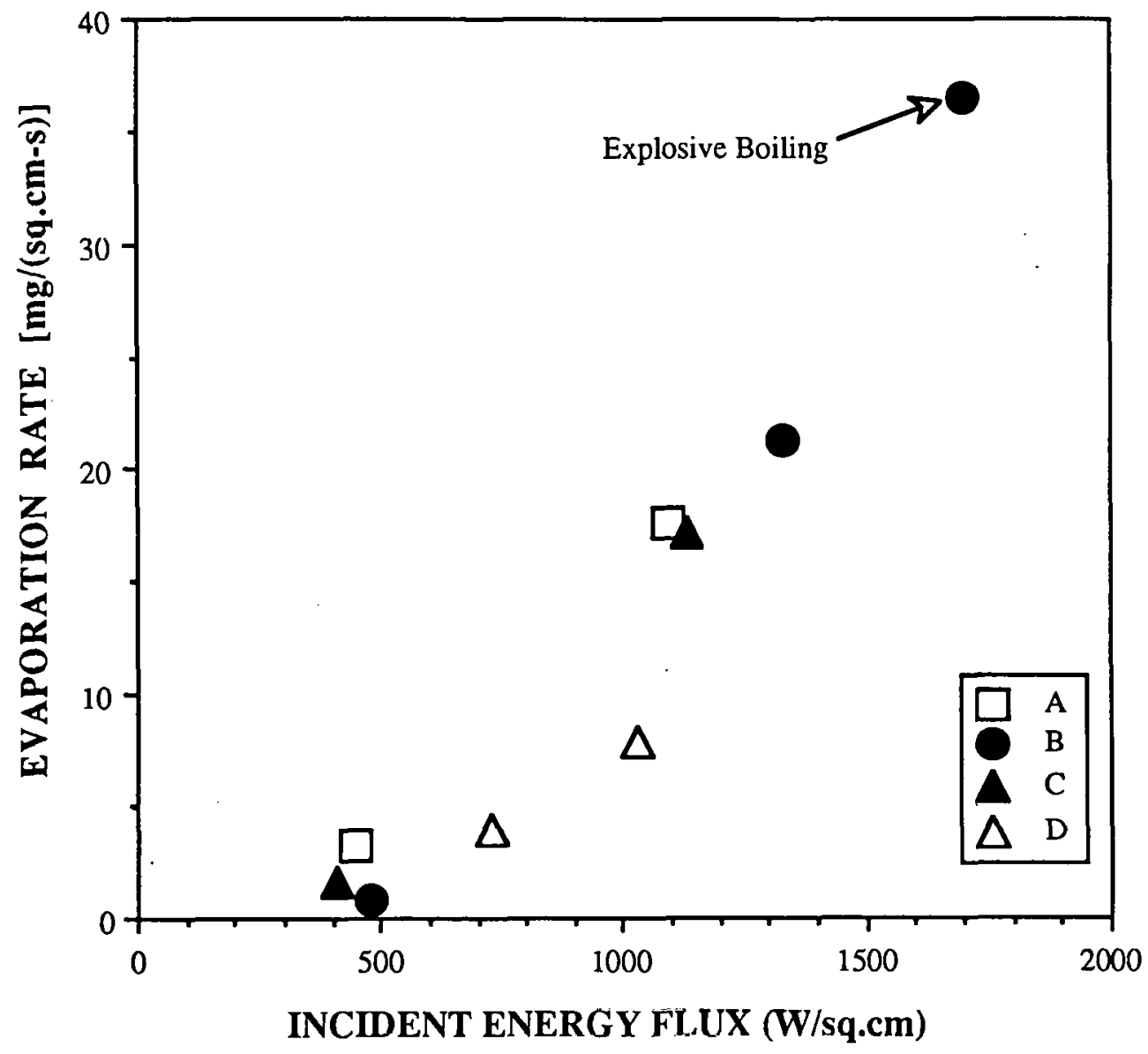

Figure 4.8 Heated Evaporation Rates as a Function of Incident Energy Flux

A: $50 \%$ lignite, $170 \mu \mathrm{m}$ diameter, $0 \%$ surfactant

B: $25 \%$ lignite, $170 \mu \mathrm{m}$ diameter, $2 \%$ surfactant

C: $50 \%$ lignite, 160 j.m diameter, $4 \%$ surfactant

D: $50 \%$ lignite, $140 \mu \mathrm{m}$ diameter, $0 \%$ surfactant 


\subsection{Explosive Boiling}

With increasing heating intensities, droplet responses to heating varied from accelerated evaporation, to minor fragmentation, to violent disruption with ignition of some of the coal particles. Based on the observations of the high speed films, the threshold for explosive boiling was defined as the minimum incident energy flux at which the droplet core would disrupt, achieving significantly fine atomization. Heating intensities just below this threshold often resulted in a few small fragments being ejected from the droplet surface. These minor disruptions will be referred to as fragmentation events. The finer atomizations were achieved by the more violent explosions at the higher incident fluxes. Many times droplets would experience one or more surface fragmentations before the core disrupted.

Surface fragmentations alone at low energy fluxes or a succession of surface fragmentations prior to core explosion at higher fluxes strongly suggest that the droplets were absorbing most of the energy near the droplet surface. Many times a thin cloud was seen in a single frame of the high speed films to surround the droplet just prior to explosive boiling. Matthews and Street (11) saw a similar response in their droplet heating experiments. They suggested that this cloud was water vapor. A sudden vaporization of the water from the surface of a CWSF droplet would indicate that the coal particles near the droplet surface were very hot and, because this is seen soon before explosive boiling, could imply that the droplets had little water at their surface at the time of explosive boiling. Further evidence of the surface heating mechanism has already been discussed (19). That the droplets are absorbing most of the radiant energy near the surface indicates that the experimental method of heating the droplets is more relevant to combustion conditions than it is sometimes credited. In both the experimental and combustion conditions the droplets absorb heat at their surface, and then conduct heat to the interior. 
The incident energy requirements for explosive boiling of slurry droplets as a function of time until explosive boiling are summarized for the various droplet compositions in Figure 4.10. Data acquisition involved varying the incident flux and recording the elapsed time until explosive boiling. The irradiation period is from 0 to 10 milliseconds. The data manifest a 1 to 2 millisecond thermal induction period during which explosive boiling did not occur. This indicates a practical lower time limit for explosive boiling for these droplets. Just beyond the induction period, between 2.5 to 4 milliseconds, the time until explosive boiling was relatively insensitive to the incident energy. After 4 milliseconds is a plateau region where increases in the incident flux tended to result in decreases in the time for explosive boiling. The plateau region shows the effect of the competition of heat loss by evaporation. Explosive boiling has an upper time limit because of the heat loss by evaporation at the droplet surface and the net energy input requirements for internal superheating. Having a higher surface area to mass ratio and, hence, greater relative heat loss, the smaller droplets have a shorter time domain for explosive boiling. For example, none of the $120 \mu \mathrm{m}$ diameter droplets in Figure 4.10 boiled explosively beyond 6.4 milliseconds, while most of the larger droplets could last 7 milliseconds or more before boiling explosively at the lower fluxes.

There is nu significant propensity for one CWSF composition to boil explosively at lower fluxes than another. The threshold incident energy flux is about $1500 \mathrm{~W} / \mathrm{cm}^{2}$ for all of the CWSFs. This is in contrast to the results of Maloney and Spann (19), which show a marked proportionality between the droplet size and explosive threshold. The reason for this contrast could be related to the size range of droplets studied. Maloney and Spann studied CWSF droplets from 74 to $158 \mu \mathrm{m}$ in diameter, while the size range of CWSF droplets in this study is 120 to $170 \mu \mathrm{m}$. The threshold energy flux for the $158 \mu \mathrm{m}$ droplets in the previous study is about the same as the threshold energy flux determined for the 


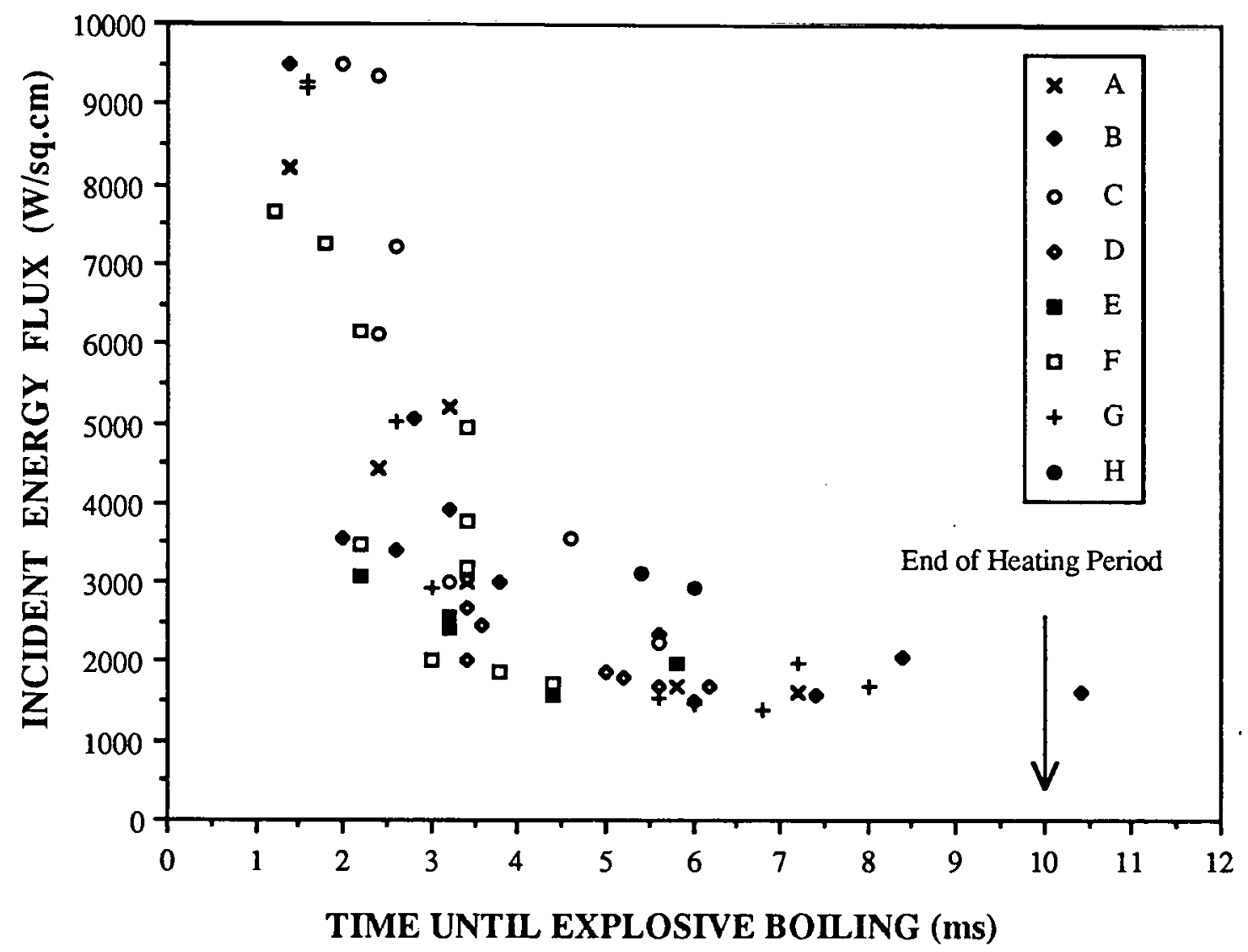

Figure 4.10 Total Incident Energy Requirements for Explosive Boiling as a Function of Heating Time and Droplet Composition
A: $50 \%$ lignite, $170 \mu \mathrm{m}$ diameter, $0 \%$ surfactant
B: $50 \%$ lignite, $160 \mu \mathrm{m}$ diameter, $4 \%$ surfactant
C: $35 \%$ lignite, $170 \mu \mathrm{m}$ diameter, $2 \%$ surfactant
D: $50 \%$ lignite, $120 \mu \mathrm{m}$ diameter, $2 \%$ surfactant
E: $55 \%$ lignite, $135 \mu \mathrm{m}$ diameter, $0 \%$ surfactant
F: $60 \%$ lignite, $120 \mu \mathrm{m}$ diameter, $0 \%$ surfactant
G: $25 \%$ lignite, $170 \mu \mathrm{m}$ diameter, $2 \%$ surfactant
H: $43 \%$ carbon black, $97 \mu \mathrm{m}$ diameter, $0 \%$ surfactant 
droplets in the present study. Therefore, below $120 \mu \mathrm{m}$ diameter the threshold could be more sensitive to droplet size.

The threshold incident energy flux does not directly translate into a minimum combustor energy flux for secondary atomization. The experimental method heated the droplets on two sides, with an absorbing area of $2 \pi r^{2}$, whereas the entire $4 \pi r^{2}$ of the droplet would be heated in a combustor. Furthermore, only $50 \%$ of the incident energy was absorbed in the experiments. Because of this uncertainty, the threshold energy requirement for explosive boiling is better expressed as the droplet heating rate. From Figure 4.2 it is evident that explosive boiling of CWSF droplets becomes probable above a heating rate of $2 \times 10^{4} \mathrm{~K} / \mathrm{s}$.

The CWSF with $4 \%$ surfactant had the longest explosive time domain, from 1.4 to 10.4 milliseconds. The high concentration of surfactant might have allowed the heated droplets to hold heat longer without nucleating internal boiling. The explosive event at 10.4 milliseconds, which is 0.4 millisecond after the end of energy input, implies a significant heat transfer limitation between the particles and the water for this case. However, this case is unique, so generalizations should not be drawn from it. In general, the surfactant had no significant effect on the energy requirements for explosive boiling.

CWSFs are often preheated to improve atomization and ignition, but heating the

- CWSF may be deleterious to the additive and, consequently, the CWSF (48). Some of the CWSF with $4 \%$ surfactant was thermally preconditioned by boiling for 15 minutes to see if it would alter the propensity for explosive boiling. Figure 4.11 presents the comparison between the original and thermally preconditioned CWSFs. The explosive boiling trends are identical. The significance of this result is twofold. First, the mild thermal preconditioning of the CWSF with $4 \%$ surfactant did not alter the energy requirements for 


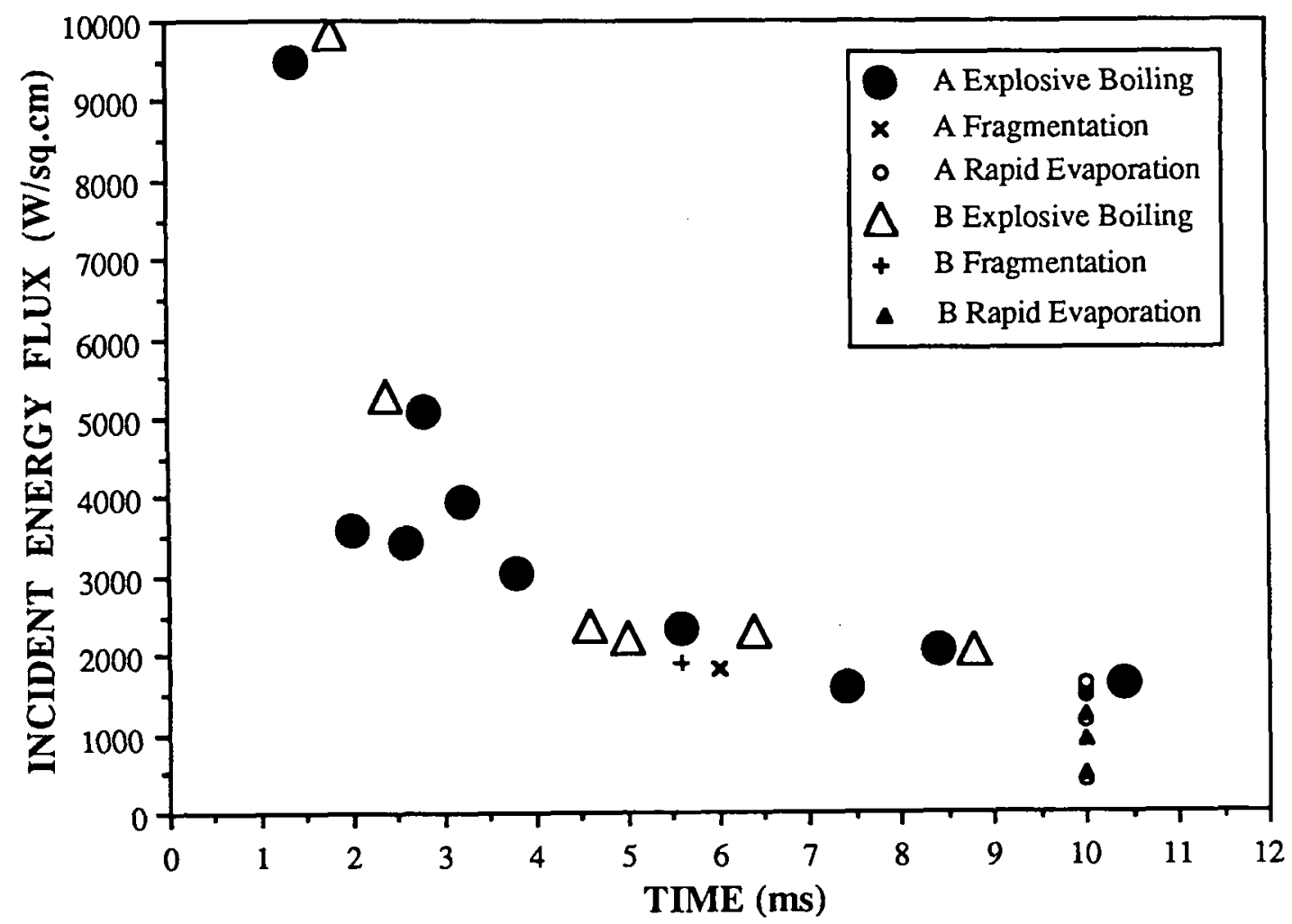

Figure 4.11 Dynamic Response as a Function of Heating Time:

$160 \mu \mathrm{m}$ diameter, $4 \%$ surfactant

A: $50 \%$ lignite

B: $45 \%$ lignite, thermally preconditioned 
explosive boiling. It should be noted, however, that the thermal preconditioning did slightly change the rheological behavior of the CWSF, resulting in a 5\% decrease in the solids loading for droplets of the same size as the unpreconditioned droplets. Second, reproducibility of the experimental method was demonstrated.

Figure 4.11 also illustrates the complete range of droplet responses to the heating events. In addition to explosive boiling, fragmentation and accelerated evaporation events are presented. The small symbols at 10 milliseconds in the figure represent droplets that were heated for the full 10 milliseconds and only experienced accelerated evaporation. These points highlight the subthreshold heating responses. Once the incident flux was higher than about $1500 \mathrm{~W} / \mathrm{cm}^{2}$, the droplets would boil explosively.

Three CWSF droplets were allowed to dry for five minutes, and the resulting agglomerates were irradiated. Figure 4.12 indicates that the CWSF agglomerates disrupted faster than CWSF droplets, although the threshold does not appear to be lower. Because of their lower heat capacity than the droplets, the agglomerates heated faster than the droplets. Devolatilization could not have caused the disruptions so fast. The results imply that there was sufficient moisture adsorbed on the coal particles inside the agglomerates to cause explosive boiling.

Figure 4.13 presents the data on the carbon hlack slurry droplets without surfactant. Of these droplets, only two boiled explosively and one fragmented. None of the carbon black slurry with $2 \%$ surfactant ever exploded or fragmented. The carbon black slurry droplets were very sensitive to the heating pulse. As the incident flux approached 1000 $\mathrm{W} / \mathrm{cm}^{2}$, the droplets would shoot out of the balance position without any indication of fragmentation. The open circles in Figure 4.13 illustrate the inverse relationship between droplet stability within the electrodynamic balance null position and increasing energy flux. Uneven droplet heating could be a cause for the droplet instability. Rapid evaporation from 


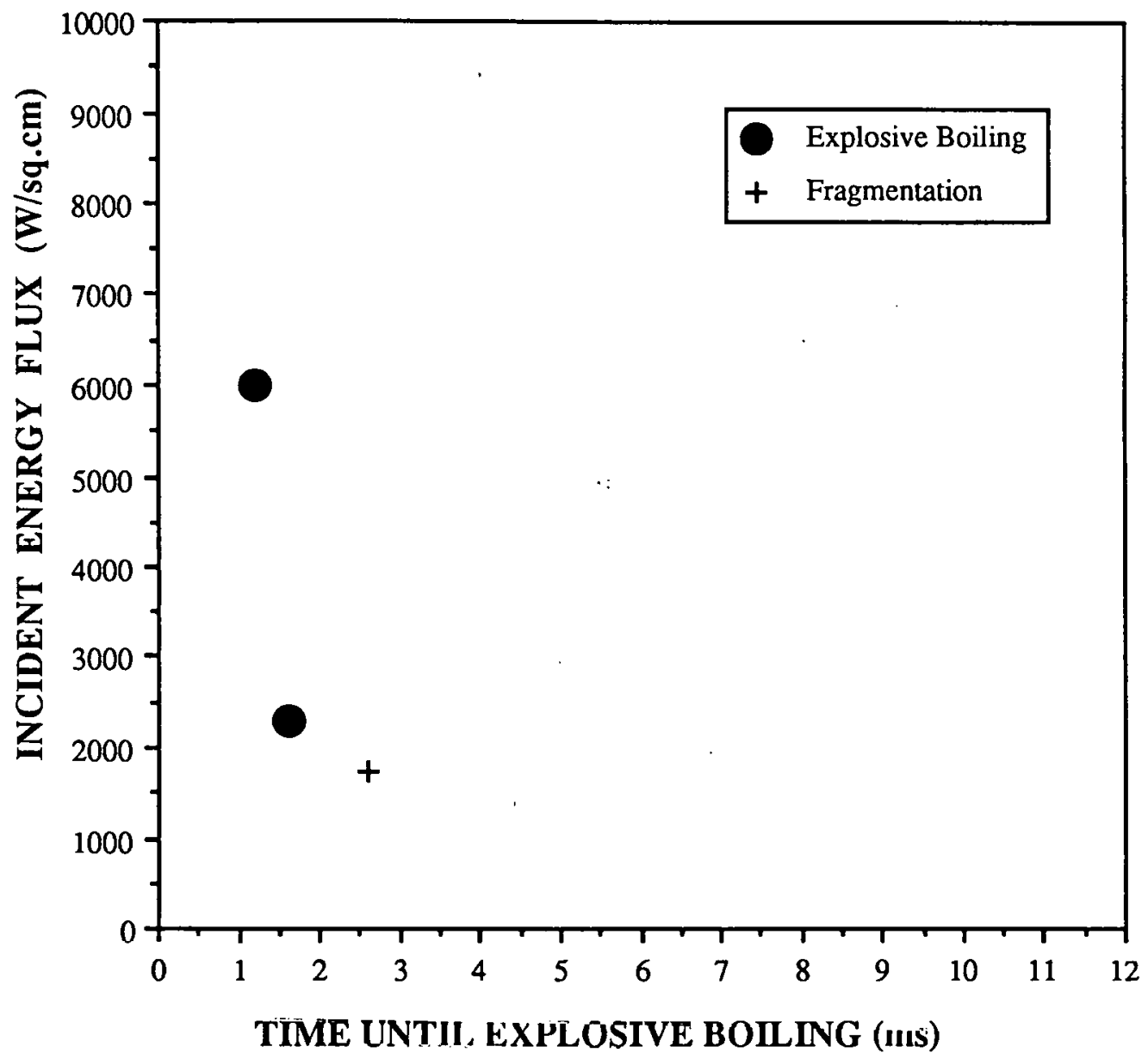

Figure 4.12 Dynamic Response as a Function of Heating Time: agglomerates of CWSF with $2 \%$ surfactant 


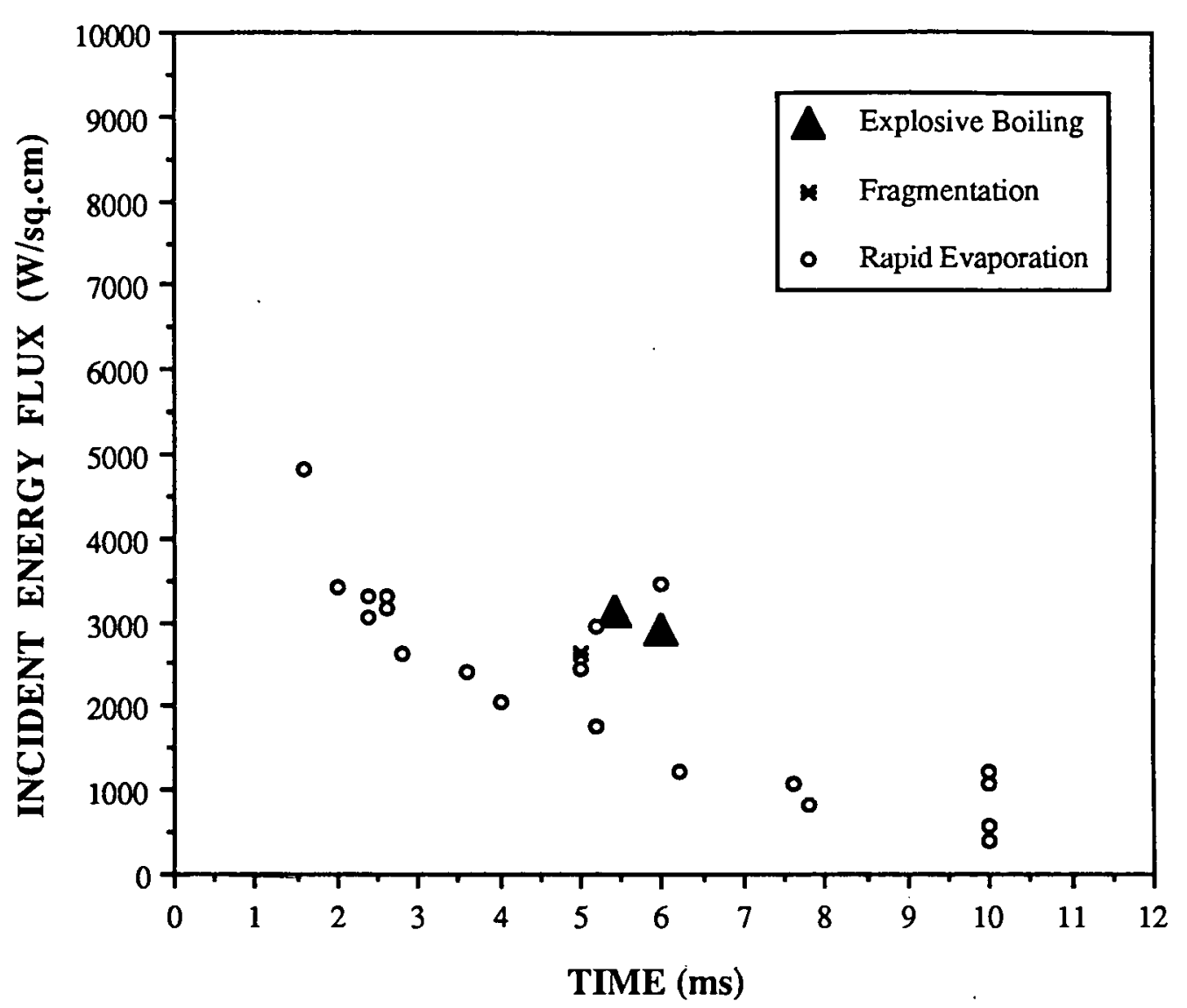

Figure 4.13 Dynamic Response as a Function of Heating Time: $43 \%$ carbon black, $97 \mu \mathrm{m}$ diameter, $0 \%$ surfactant 
just a relatively small section of the droplet surface could propel the droplet in a direction opposite of the localized evaporation.

The mass normalized energy requirements for explosive boiling for the slurry droplets are presented in Figure 4.14. These data are comparable to those in the equivalent figure in Maloney and Spann (19), where it was shown that the energy requirement in the plateau region was proportional to the mass of the droplets with equivalent coal loadings. This proportionality is less clear for the present data, possibly for the same reason that the energy requirement was less sensitive to droplet size than it was in the previous work. Part of the obscurity is because the present data fall into the region of most scatter for the previous work. Nevertheless, the present CWSF data fall in about the same energy per unit mass range for the same time domain. The two points for the carbon black slurry show a higher energy requirement. This could result if the carbon black slurry droplets had a lower energy absorption efficiency compared to the $50 \%$ absorption capability of the CWSF droplets.

\subsection{Agglomerate Morphology}

\subsubsection{Method}

Whole agglomerates and agglomerate fragments were recovered from the electrodynamic balance. The charged agglomerate particles were captured on a charged probe inserted into the balance. The particles were then transferred onto a scanning electron microscope (SEM) stage that was covered with double-stick tape. The objective was to determine if particle fusion was occurring and to infer the influence of the agglomerate morphologies on the evaporative mechanisms of the droplets.

Three SEMs were used to obtain micrographs: an ETEC Autoscan, which produced micrographs with the micron har on the left edge; an ISI-SX-40, which produced 


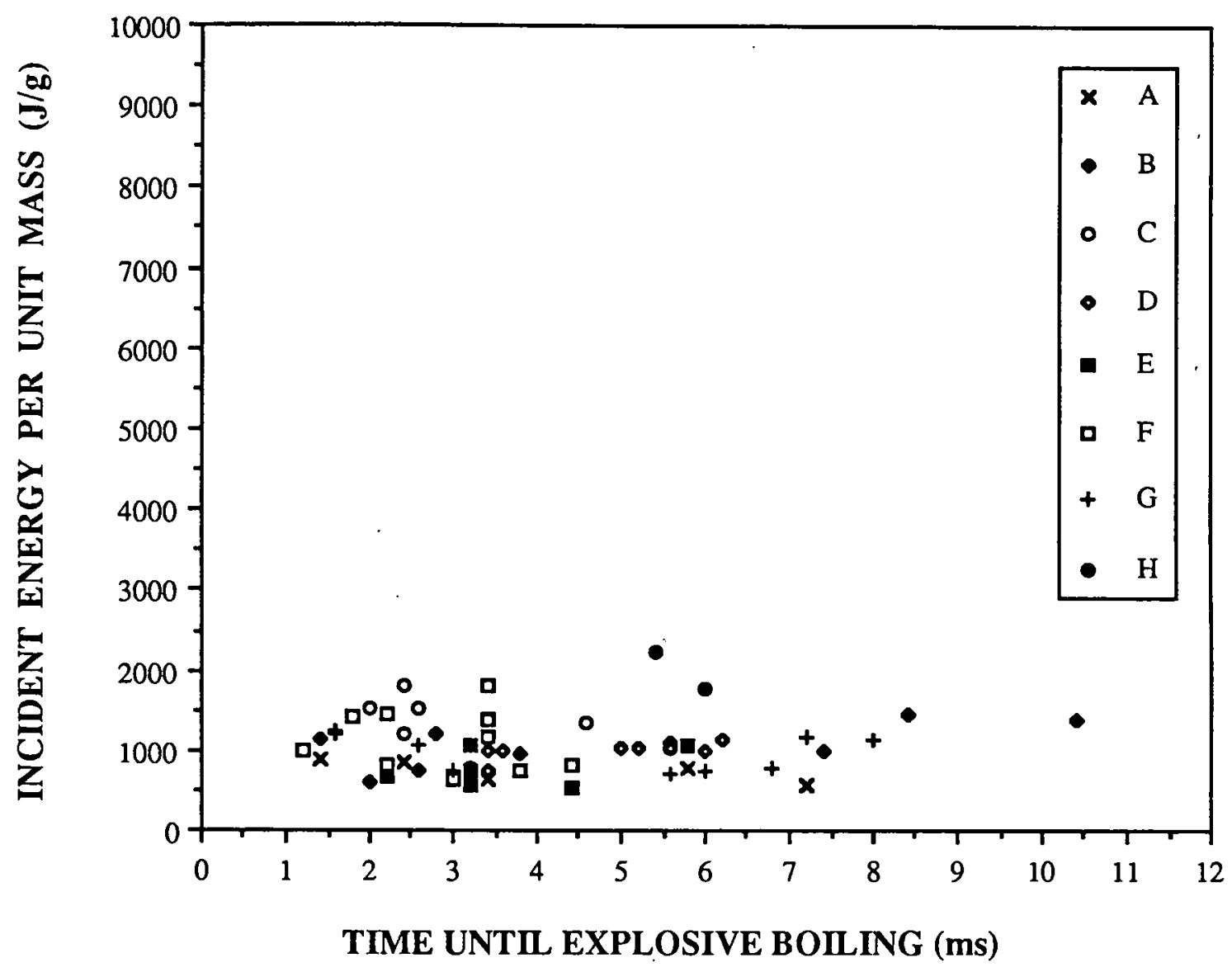

Figure 4.14 Mass Normalized Energy Requirements for Explosive Boiling of Slurry Droplets
A: $50 \%$ lignite, $170 \mu \mathrm{m}$ diameter, $0 \%$ surfactant
B: $50 \%$ lignite, $160 \mu \mathrm{m}$ diameter, $4 \%$ surfactant
C: $35 \%$ lignite, $170 \mu \mathrm{m}$ diameter, $2 \%$ surfactant
D: $50 \%$ lignile, $120 \mu \mathrm{m}$ diamcter, $2 \%$ surfactant
E: $55 \%$ lignite, $135 \mu \mathrm{m}$ diameter, $0 \%$ surfactant
F: $60 \%$ lignite, $120 \mu \mathrm{m}$ diameter, $0 \%$ surfactant
G: $25 \%$ lignite, $170 \mu \mathrm{m}$ diameter, $2 \%$ surfactant
H: $43 \%$ carbon black, $97 \mu \mathrm{m}$ diameter, $0 \%$ surfactant 
micrographs with a thick, $1 \mathrm{~cm}$ long micron bar; and an ISI Super-IIIA, which produced

micrographs with dashes rather than numerical designations accompanying the micron bar.

Over 230 micrographs were taken in this study. The following micrographs were chosen for their ability to illustrate representative features, unless otherwise noted.

\subsubsection{Discussion of the Micrographs}

Most whole agglomerates were somewhat oblate, rather than perfectly spherical, because of minor collapse in one area. Figure 4.15, top, shows a typical CWSF agglomerate. The collapse was gravitationally induced and could be witnessed on the DIS monitor as the shadow image curved inward from the top. The ability of the agglomerates to collapse reflects the mechanism of agglomerate formation. The droplets were generated at low solids loading to prevent clogging of the droplet generator. Most droplets were initially about $4 \%$ by weight solids. Depending on its initial size and solids loading, a droplet would evaporate between 15 and 90 seconds before it attained the desired size and solids loading. The particles within a droplet were drawn toward the droplet periphery. Offering the least resistance, many of the smallest particles could reach the droplet surface. Furthermore, the presence of the smallest particles at the droplet surface would allow the droplet to minimize its surface arca. $\Lambda \mathrm{s}$ the droplet diameter decreased during evaporation of the water, the solid particles were drawn together tangentially as well as receding radially. The particles could reach their maximum packing density in the tangential direction prior to reaching it in the radial direction. The resulting agglomerate would be spherical with a central, water-filled void. As the evaporation front proceeded into the agglomerate, water from the void would be absorbed into the agglomerate shell by capillary action. The diminishing water level in the void removed the buoyant force maintaining the upper portion of the shell, resulting in its collapse. 
Figure 4.15 Top: Agglomerate Resulting from the Ambient Evaporation of a CWSF Droplet.

Bottom: Unusually Hollow CWSF Droplet Agglomerate

Micron bar (long bar followed by two dashes) represents $10 \mu \mathrm{m}$ 


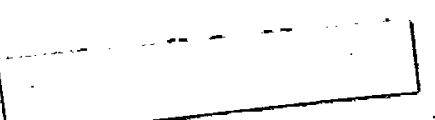

\section{DO NOT MICROFHLM THIS PAGE}


$\hat{\sigma}$
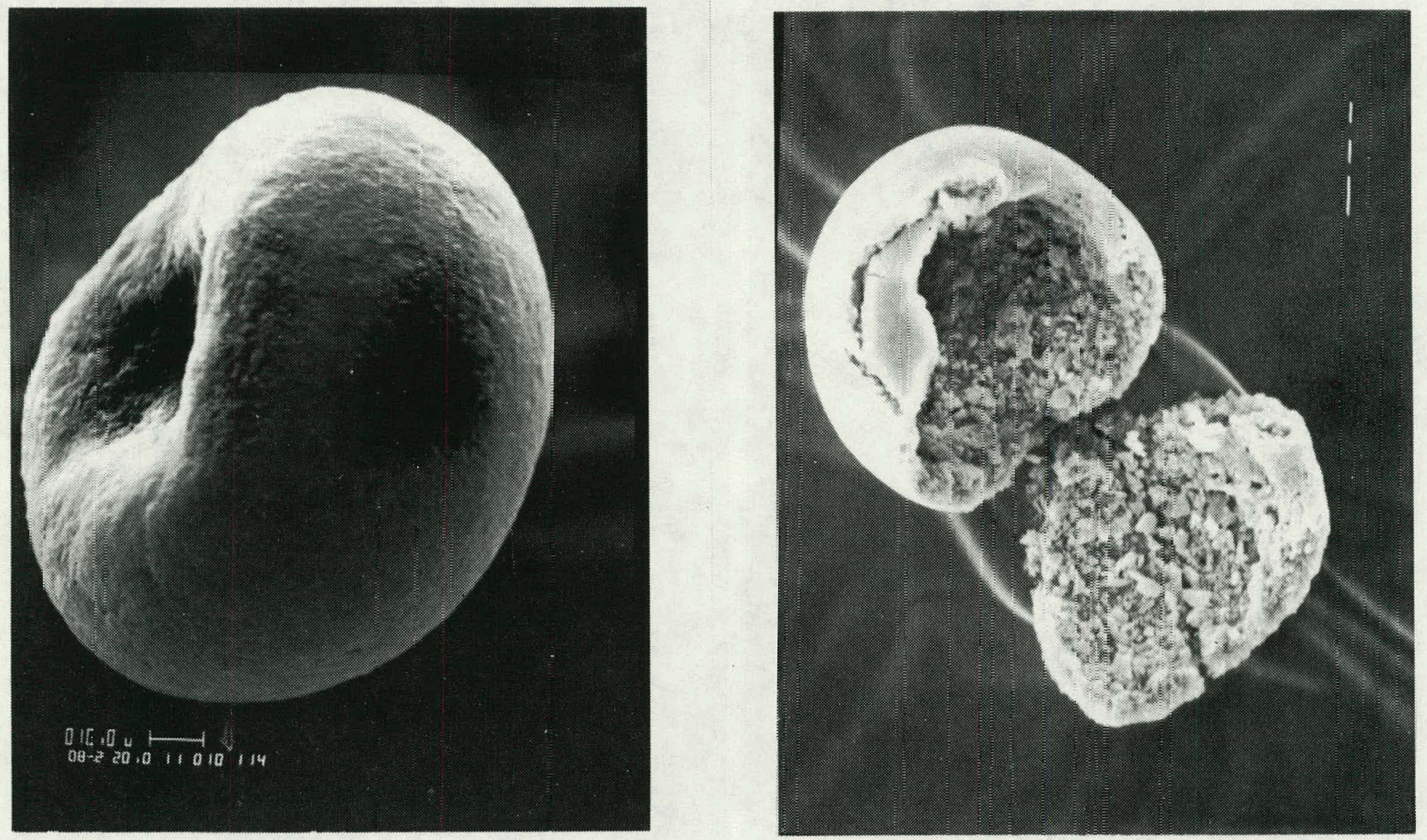
Figure 4.15, bottom, shows a CWSF agglomerate that did not completely collapse, although it did split when it was applied to the SEM stage. This CWSF agglomerate is unusual in that it apparently has significant central void volume. The central voids of most CWSF agglomerates were negligibly small on a volumetric basis, regardless of surfactant concentration or heating rate. The agglomerates in Figure 4.16 are more typical in that their cross-sections reveal that their voids were negligible compared to the volume of internal coal particles. However, the central voids of the carbon black agglomerates were extremely large, as can be seen in Figure 4.17. The reason is that the carbon black particles were much smaller than the lignite particles; therefore, the carbon black droplets had much less solids on a volumetric basis and would form a much thinner shell upon evaporation. The lumps lining the interiors of the agglomerate halves in the bottom of Figure 4.17 are fallen pieces of the shell.

Figure 4.18 shows the concentration of the fines to the periphery of the agglomerates. It is obvious that the majority of the particles in the outer shell of the agglomerates are submicron (upper right of the top agglomerate and left side of the bottom agglomerate in Figure 4.18). Both of the agglomerates in this figure contain no surfactant, but similar morphology was seen for agglomerates with surfactant. It is possible that the densified shell of fines at the droplet surface could be bound together more tightly than the larger interior particles because of the greater surface area of the fines. The densified shell could hold the agglomerate together and form a more tortuous path compared to the agglomerate interior for the escape of water vapor, thereby enhancing explosive boiling.

The effect of droplet heating on the subsequent agglomerate morphology was variable and depended on the dynamic response of the droplet. CWSF droplets that were heated but did not fragment yielded agglomerates that usually looked identical to agglomerates from droplets that evaporated ambiently. Agglomerates from droplets that 
Figure 4.16 Sliced CWSF Agglomerates

Top: With $4 \%$ surfactant

Bottom: Without surfactant 


\section{DO NOT MICROFHLM THIS PAGE}



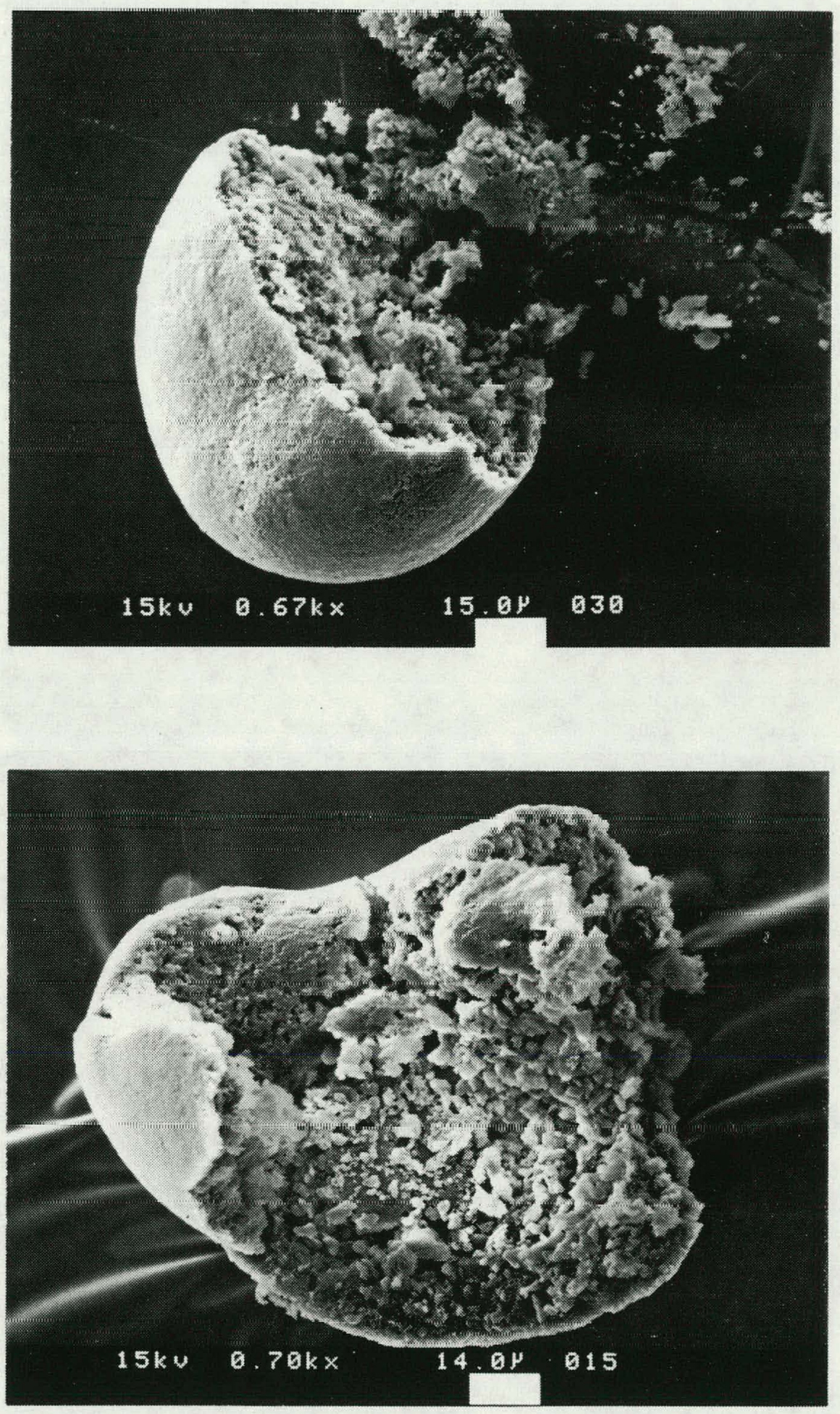
Figure 4.17 Carbon Black Slurry Agglomerates Revealing Their Hollow Structure 

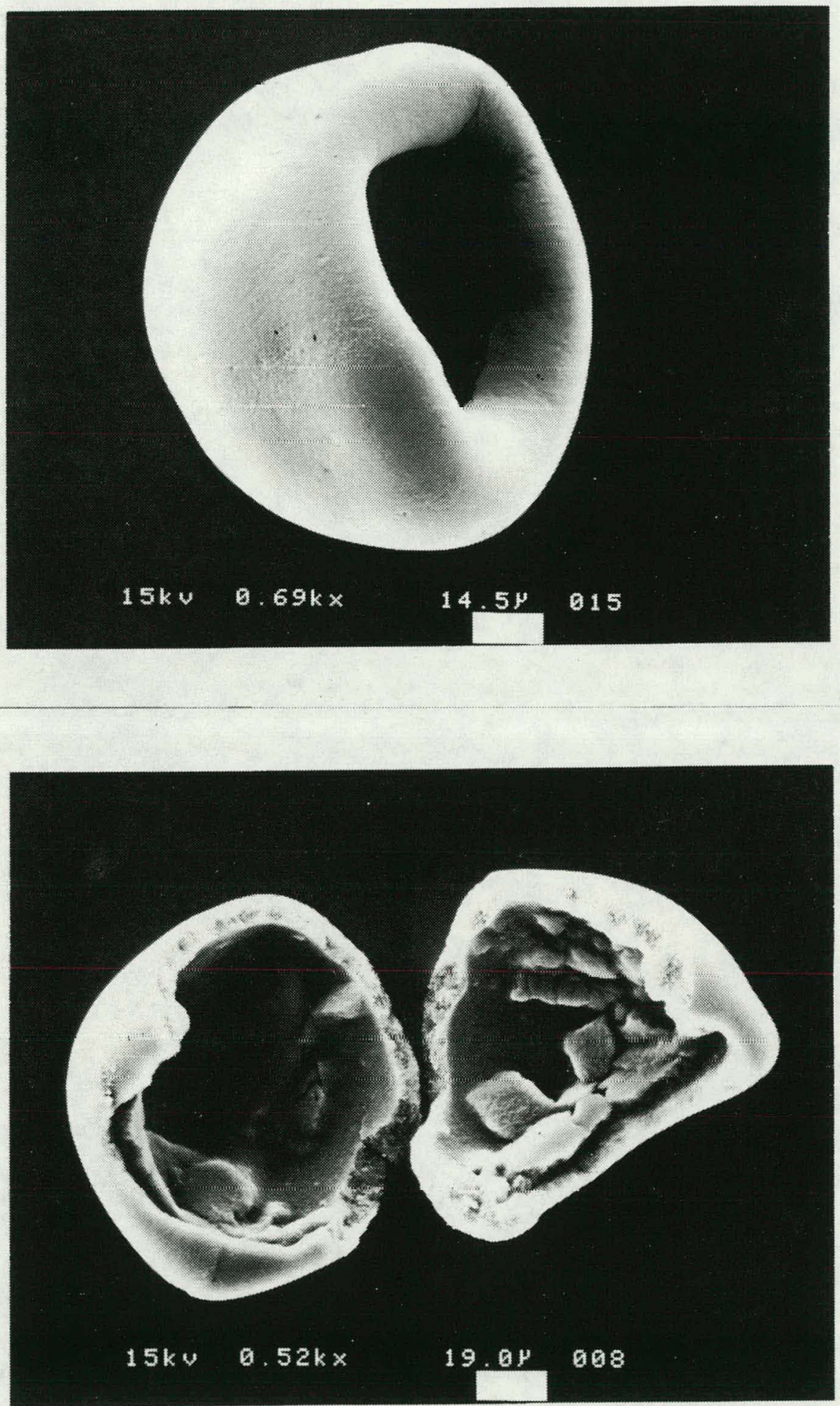
Figure 4.18 Cross-Sections Showing the Concentration of Smaller Particles on the Outer Surface of CWSF Agglomerates

Micron bar (left bar) in bottom micrograph represents $1 \mu \mathrm{m}$ 

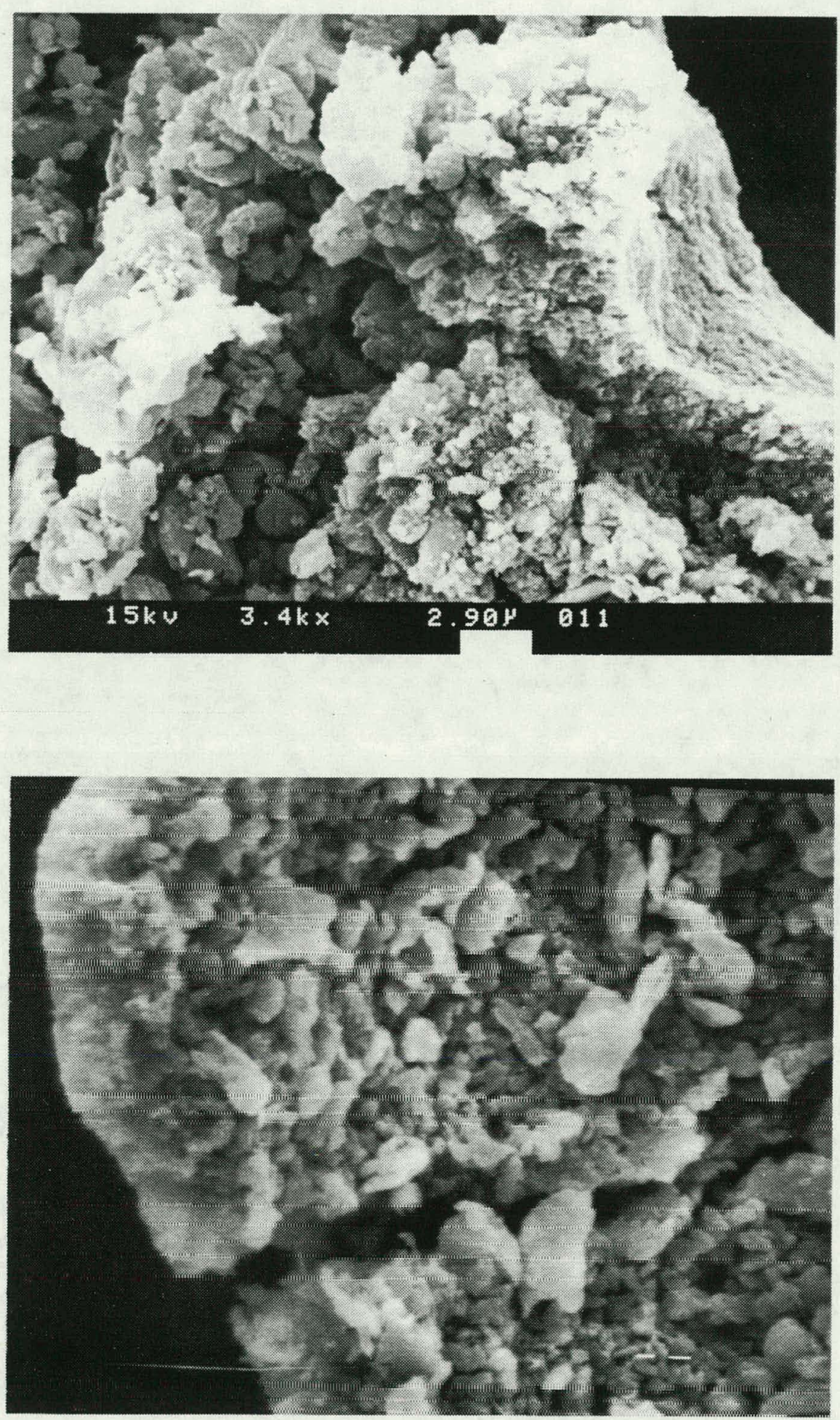
fragmented could show no differences (Figure 4.19, top) or drastic differences (Figure 4.19 , bottom). The morphology depended on whether the droplet fragment had enough water to regain sphericity. Uneven heating could explain why some droplets fragmented, yielding both round and angular fragments. Heated carbon black slurry droplets often yielded strangely shaped agglomerates without experiencing droplet fragmentation, but the stranger shapes usually resulted from more severe heating. Both of the agglomerates in Figure 4.20 were from droplet heating events. The top agglomerate, which is apparently perfectly spherical, resulted from a droplet that experienced $410 \mathrm{~W} / \mathrm{cm}^{2}$ incident energy flux. The bottom agglomerate resulted from a $1690 \mathrm{~W} / \mathrm{cm}^{2}$ heating event. The ability of the carbon black agglomerates to severely deform might have inhibited explosive boiling. Water vapor might have been able to escape from the droplet interior without disrupting the droplet.

Close examination of the agglomerate surfaces showed that the lignite particles were not fusing like those of a bituminous CWSF under essentially identical conditions (19). One or two micrographs of the lignite CWSF agglomerates indicated that some particle fusion (transformation) might have occurred during heating, but these were the exception. Overall, even the droplets with surfactant did not manifest any differences in the appearance of the particles. Figure 4.21 shows the agglomerate surface detail of a droplet with surfactant that fragmented at $1110 \mathrm{~W} / \mathrm{cm}^{2}$ (top) and a droplet without surfactant that deformed without fragmenting at $1310 \mathrm{~W} / \mathrm{cm}^{2}$ (bottom). The surface morphologies are identical and typical of all of the CWSF agglomerates, including those formed upon ambient evaporation. Note that most particles on the surface are submicron while the mass median diameter of the lignite particles is over $4 \mu \mathrm{m}$. Fragments from explosive boiling events were too small to reliably retrieve and examine. 
Figure 4.19 Variations in CWSF Agglomerate Shape Following Droplet Fragmentation 

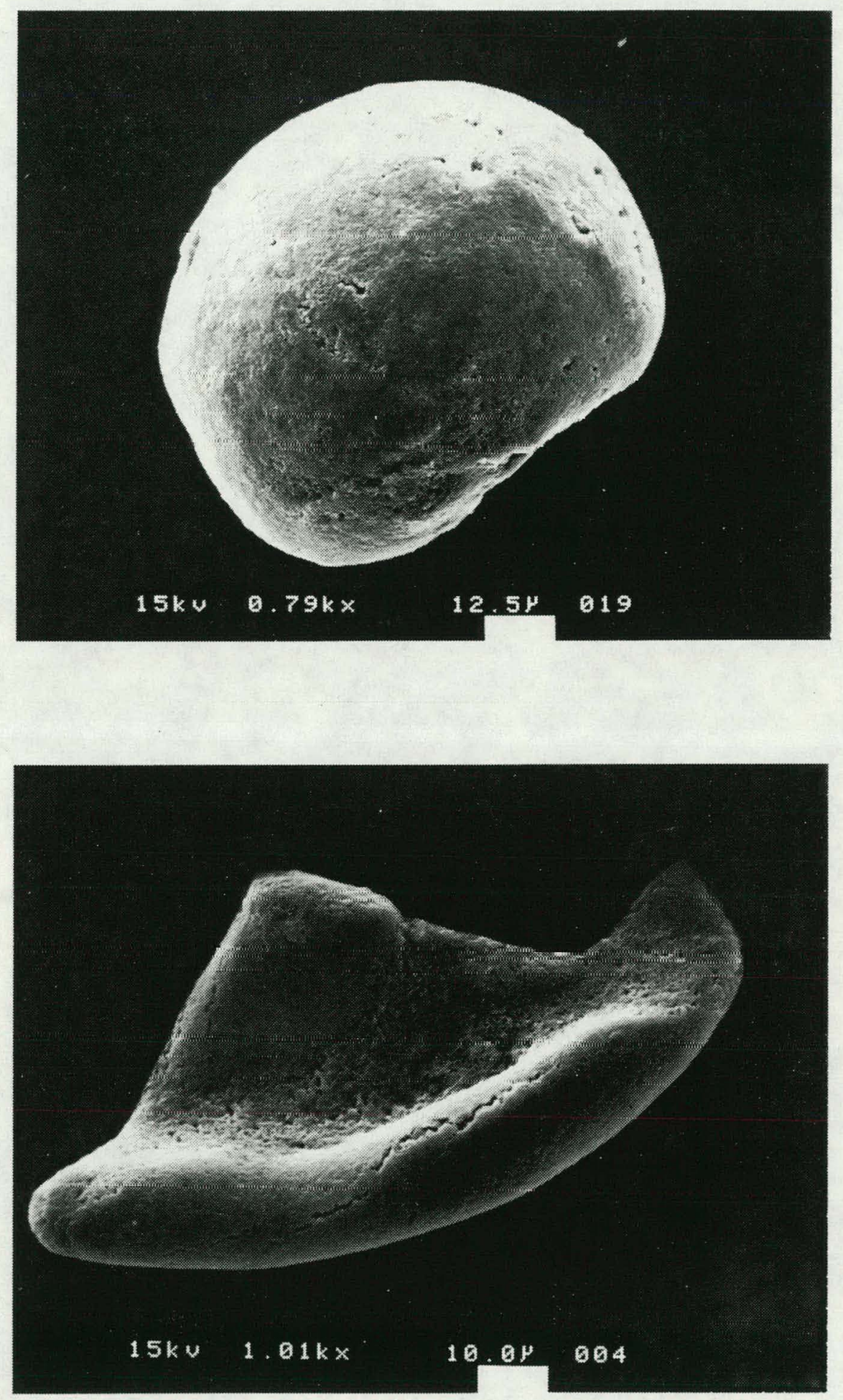
Figure 4.20 Variations in Carbon Black Agglomerate Shape Following Droplet Heating

Top: $\quad 410 \mathrm{~W} / \mathrm{cm}^{2}$ incident energy flux

Bottom: $1690 \mathrm{~W} / \mathrm{cm}^{2}$ incident energy flux 

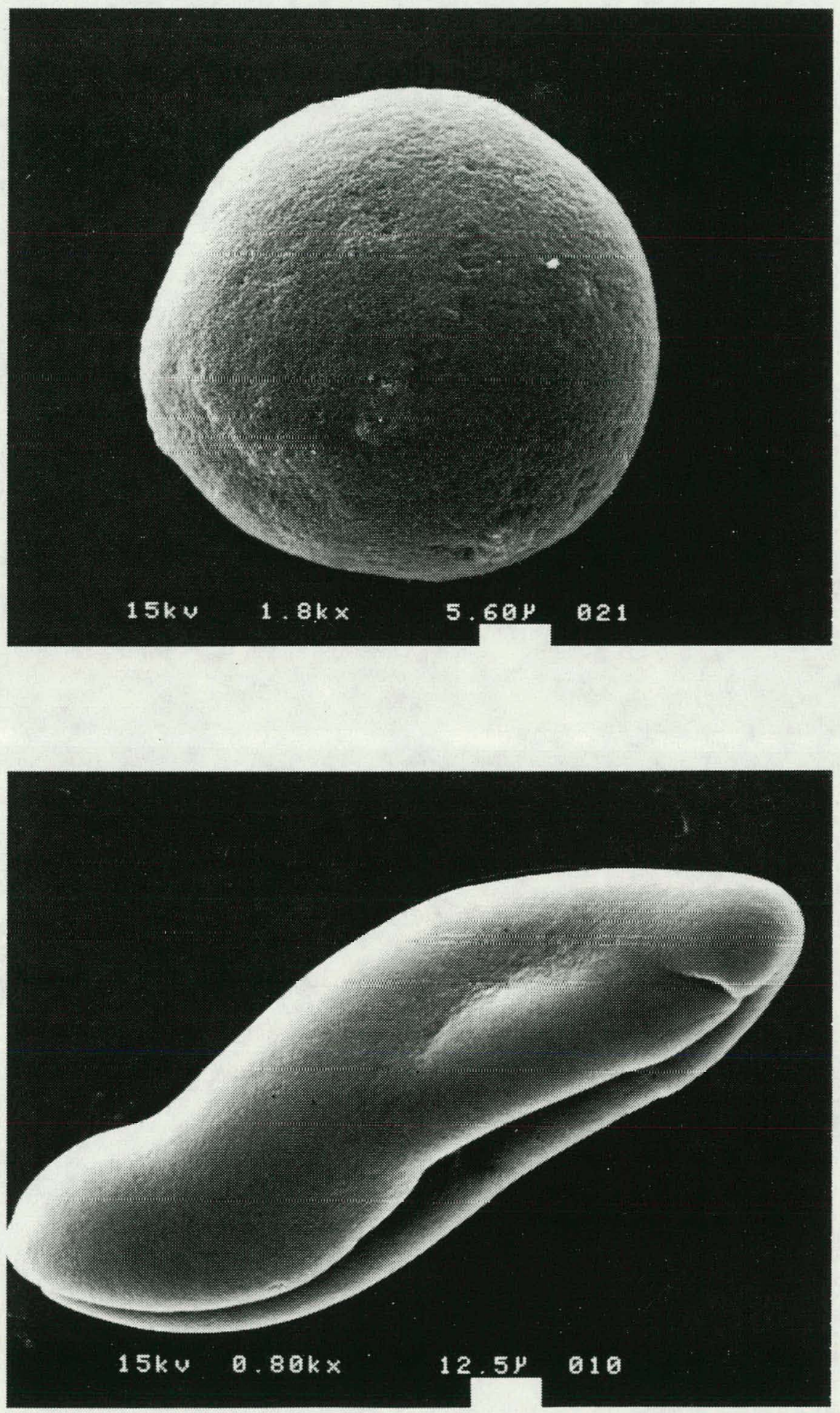
Figure 4.21 Surface Detail of CWSF Agglomerates Resulting from Heated Droplets

Top: Droplet with $4 \%$ surfactant that fragmented at $1110 \mathrm{~W} / \mathrm{cm}^{2}$ incident energy flux

Bottom: Droplet without surfactant that deformed into a rice grain shape at $1310 \mathrm{~W} / \mathrm{cm}^{2}$ incident energy flux 

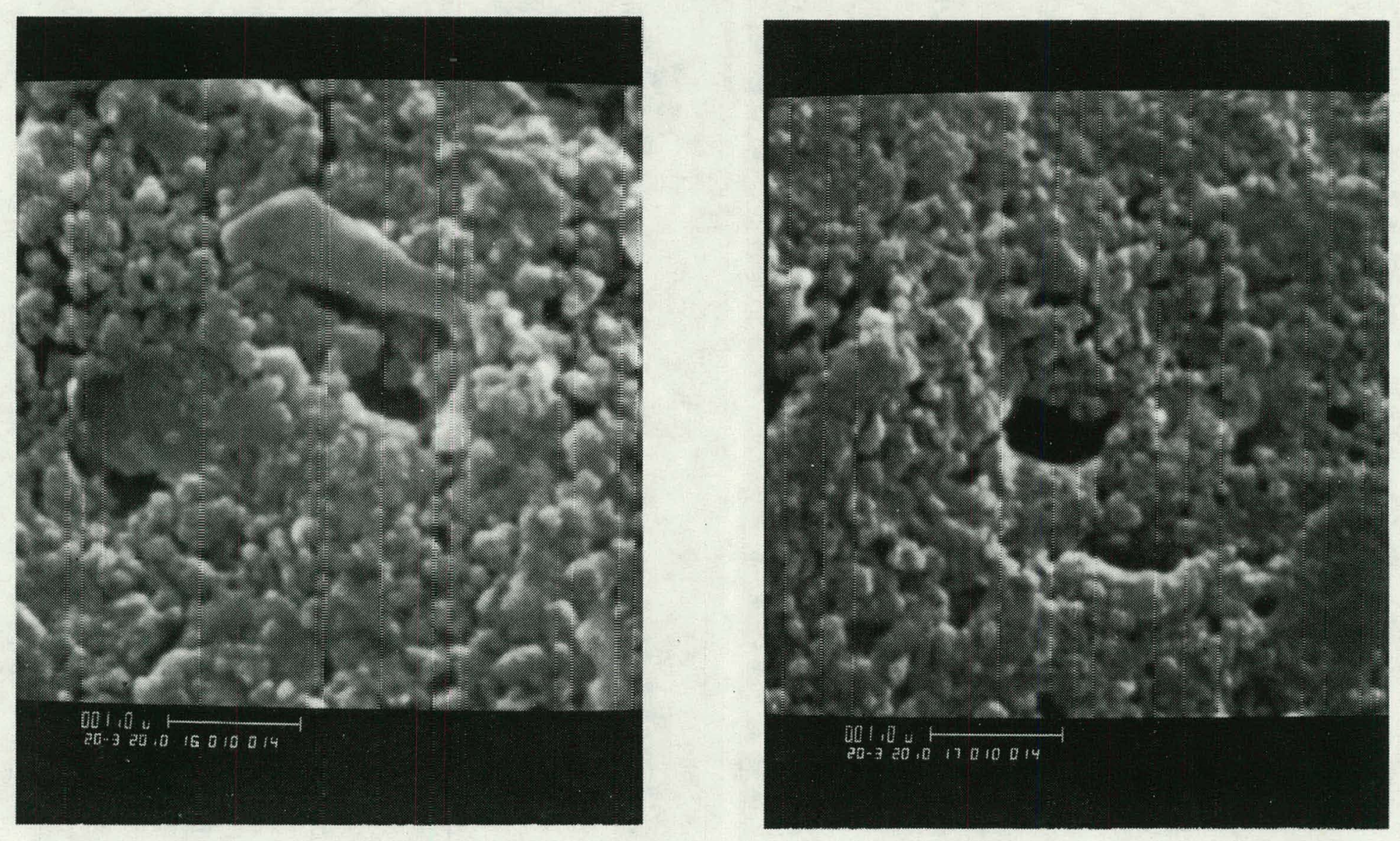
The properties of the the solid substrate must be very important in agglomerate morphology. Because lignite is non-caking, little, if any, particle transformation occurred. The bituminous CWSF agglomerates (19) did show significant particle transformation caused by heating. This transformation must result with contributions from the thermoplasticity of the coal particles.

Although there was never any obvious particle fusion on the lignite CWSF agglomerates, the surfactant could possibly bind the particles without manifestation under SEM. Figure 4.22 shows photographs of two batches of dried CWSF. The top batch consisted of only lignite and water, and it looks like parched mud. The bottom batch contained $4 \%$ surfactant solution and $0.02 \%$ stabilizer, and it has a shiny, curved crust. Therefore, the surfactant can concentrate at the water-air interface and may have a binding effect on the particles. However, this binding effect is not evident in the micrographs. Figure 4.23 shows the surface of dried batches of CWSF. There is no difference in the textures between the surface without surfactant (top) and with $4 \%$ surfactant (bottom). There was also no evidence of particle fusion on any of the carbon black agglomerates. Both the interior (top) and exterior (bottom) surfaces of the carbon black (with surfactant) agglomerate shell in Figure 4.24 are porous.

Other evidence for the ability of the surfactant to cover a droplet surface comes from the tendency for a droplet to charge. Charged droplet streams were balanced by adjusting the voltage between two parallel plates. Droplets of CWSF with surfactant required much less balancing voltage, indicating that the polar surfactant molecules on the droplet surface facilitated the induction of a surface charge.

Relatively large particles in the carbon black were only seen on the interior surfaces of the agglomerate shells, as in Figure 4.24, top. These observations are consistent with those in Figure 4.18, discussed above. 
Figure 4.22 Top View of Crucibles Containing Dried CWSF Top: $\quad$ No surfactant Bottom: $\quad 4 \%$ surfactant, $0.02 \%$ stabilizer 

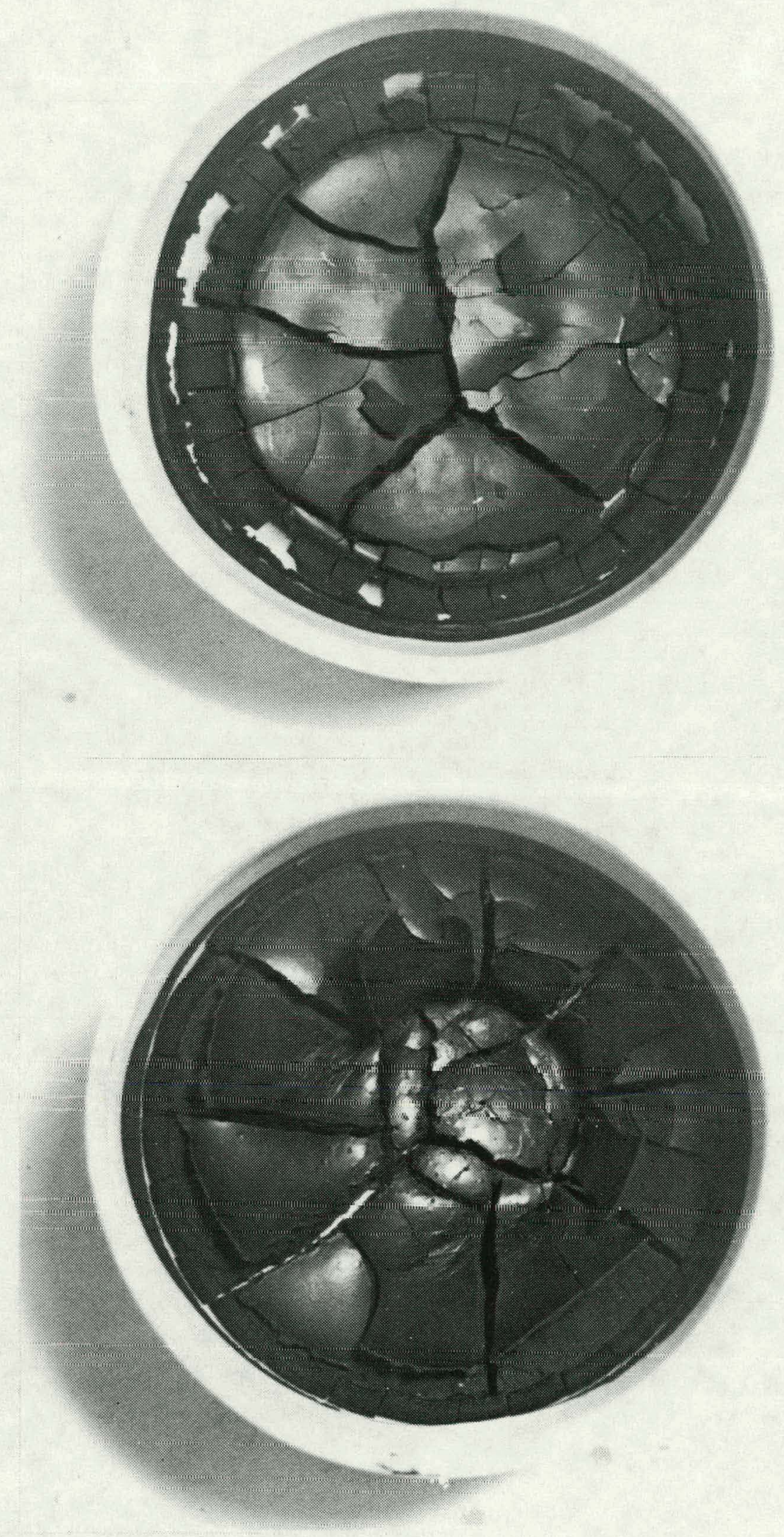
Figure 4.23 Detail of Surface of Dried CWSFs

\section{Top: No surfactant}

Bottom: $\quad 4 \%$ surfactant, $0.02 \%$ stabilizer 

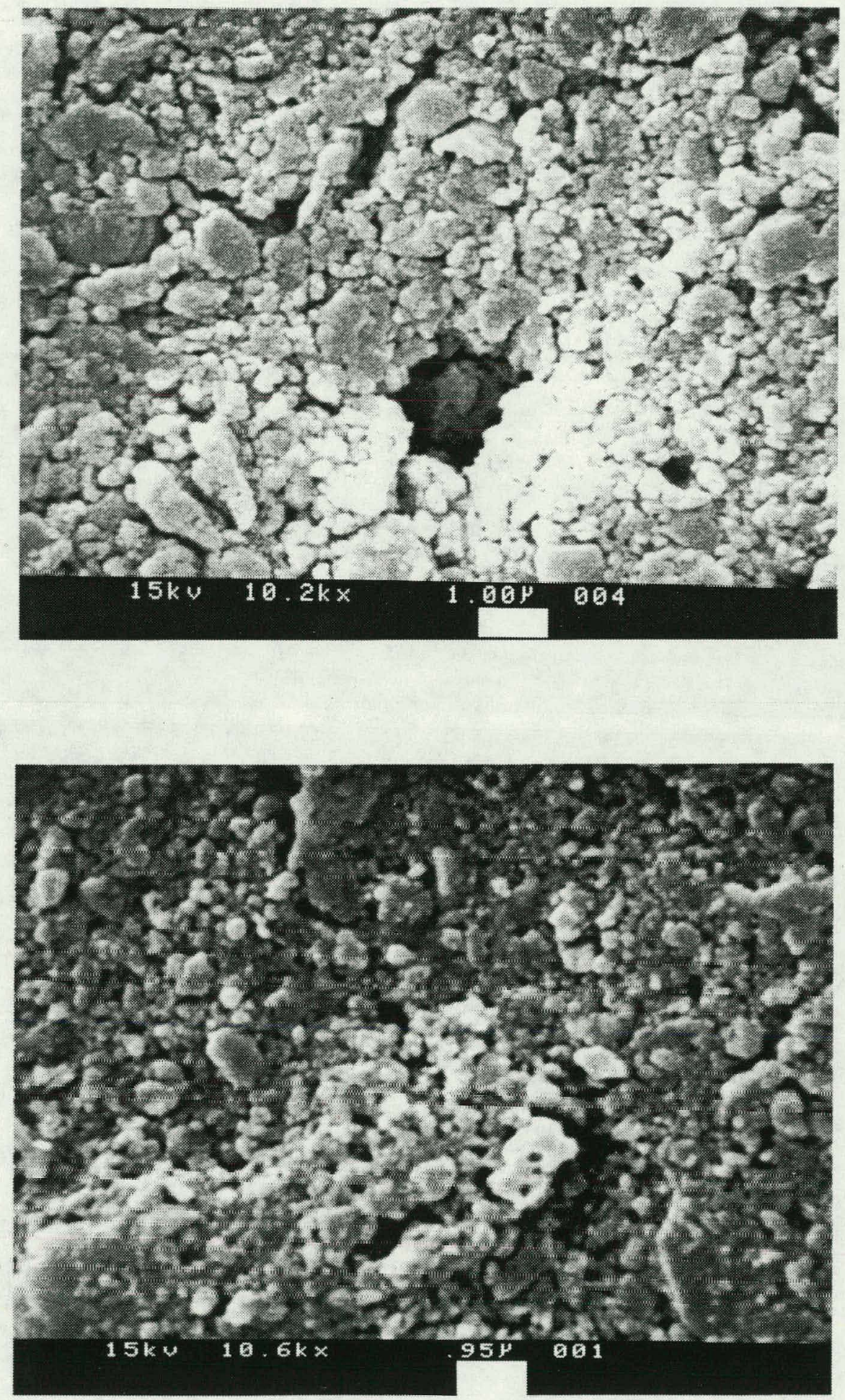
Figure 4.24 Detail of the Surface of a Carbon Black Agglomerate Shell Top: Interior (water side), with large particle resting on it

Bottom: Exterior (droplet-air interface) 

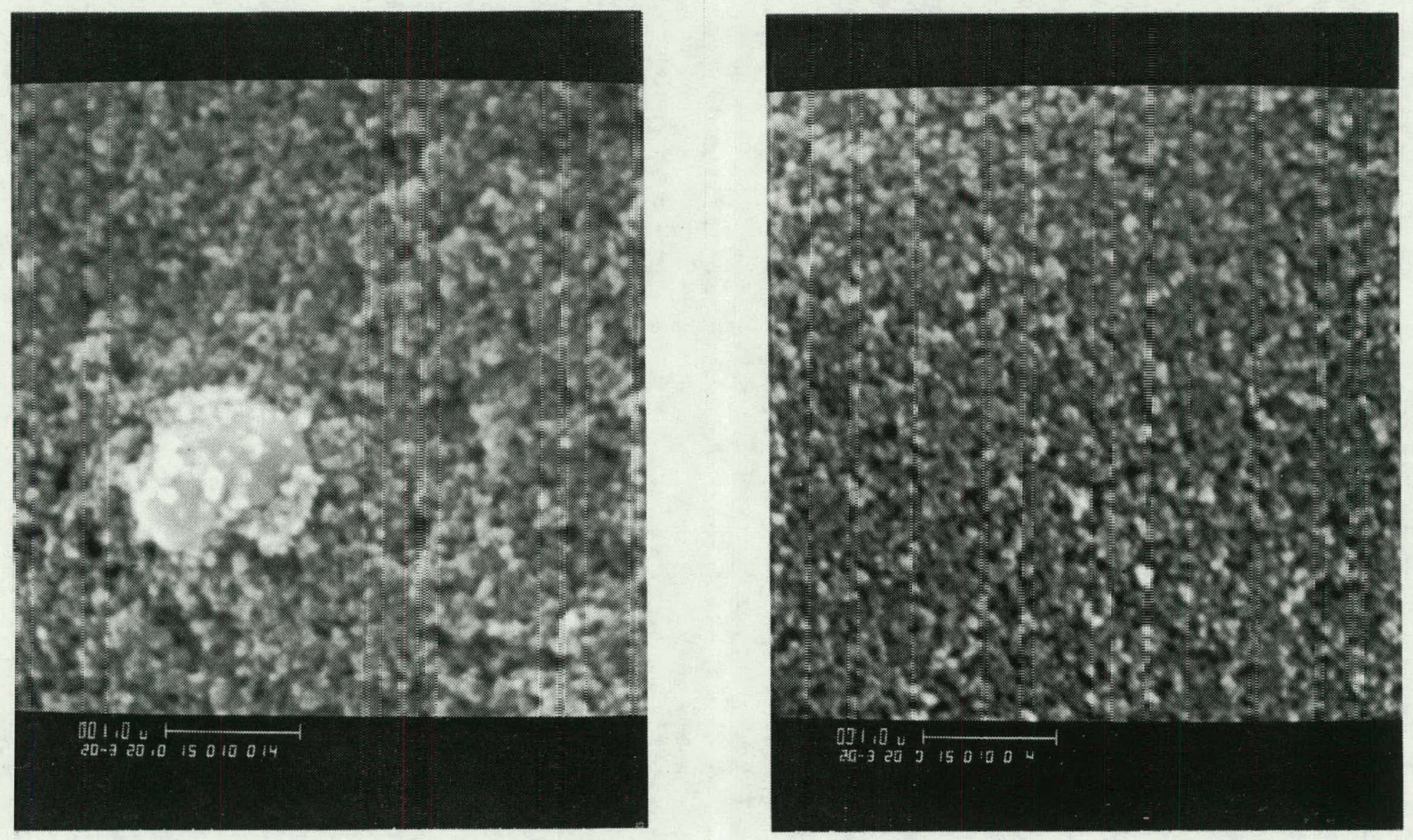
Since particle binding by the surfactant, if it existed, was not directly detectable by SEM, agglomerate integrity was checked by slicing a number of whole agglomerates. If agglomerates with surfactant crumbled easier than agglomerates without surfactant, then particle binding by the surfactant could be inferred. Again, however, there was no apparent effect by the surfactant. In Figure 4.16 the top agglomerate contained $4 \%$ surfactant, while the bottom agglomerate had no surfactant. Both agglomerates could be sliced without crumbling. 
Chapter 5

\section{CONCLUSIONS AND SUGGESTIONS}

\subsection{Conclusions}

The major conclusions of this study can be summarized as follows. The surfactant additives did inhibit the ambient evaporation of CWSF droplets and increase droplet stability during heating, but did not lower the explosive boiling energy threshold, reduce droplet evaporation rates during heating, or show any clear evidence of causing agglomerate surface fusion. These conclusions are discussed below.

The surfactant additive did not manifest any of the gross effects on droplet heating behavior and agglomerate morphology previously seen or suggested $(16-19,30)$. It is not possible to determine by comparison to most of the related literature why the surfactant did not have these effects because the experimental conditions varied greatly among the other studies and the surfactant was usually not characterized.

In the present study, the surfactant did have some minor effects on CWSF droplet heating responses. It was seen that the surfactant may cause heated CWSF droplets to evaporate more water and reach higher temperatures prior to explosive boiling than CWSF droplets without the surfactant. On the one hand, these effects by the surfactant could be considered to reduce the efficacy of secondary atomization because less water would be dispersed for vaporization. On the other hand, these effects indicate that more energy was stored before explosive boiling, which implies that the violence of explosive boiling would be enhanced. Unfortunately, the explosive boiling efficiency could not be measured.

However, these effects are minor and should not be weighed against the major influence of surfactant concentration on CWSF rheology when formulating a CWSF. 
The evaporation rates for pulse heated lignite CWSF droplets were proportional to the rate of energy absorption and were not significantly affected by surfactant concentration. Barring any reactions between the surfactant on a droplet surface and combustion gases, once the rheology of a CWSF has been optimized with the naphthalene sulfonate and Xanthan surfactant package used in this study, the surfactant concentration can be ignored in combustion calculations.

The image analysis system served as a second means of obtaining useful information from the high speed films. The dimensional response of the droplets was measured and used to estimate droplet evaporation rates and bulk droplet temperatures, with reasonably consistent results. The estimated maximum droplet temperatures were within the expected range, between the normal boiling point and the maximum superheat limit, for most of the explosive boiling events. Some droplet temperatures were calculated to be greater than the superheat limit, implying that heat was being absorbed by the coal particles faster than it could be conducted to the surrounding water. This mainly occurred at very high energy fluxes. Since the incident radiation is not absorbed by water, the coal particles can attain temperatures much higher than the superheat limit for water when the incident intensity is very high. At these very high energy fluxes, the relevance of the experimental heating method to heat transfer in a combustor is lost. However, at less severe energy fluxes and for droplets of practical solids loading, the experimental heating method is comparable to practical droplet heating. For these conditions, which represent the bulk of the experimental conditions, the outer film of water is quickly lost because the coal particles close-pack after only a minor fraction of the water has vaporized. From this point onward in time, the droplet is heated at its surface regardless if heat is transferred by radiation or convection. Now, the main difference between the heat transfer to the droplet 
for experimental and combustor conditions is that the energy absorption area is only $2 \pi \mathrm{r}^{2}$ for the former and $4 \pi r^{2}$ for the latter.

The threshold energy requirements for explosive boiling of the range of lignite CWSF droplet sizes and compositions in this study was approximately $1500 \mathrm{~W} / \mathrm{cm}^{2}$, which corresponds to a droplet heating rate of $2 \times 10^{4} \mathrm{~K} / \mathrm{s}$. This means that CWSF droplets $170 \mu \mathrm{m}$ in diameter or less should have a high probability of experiencing secondary atomization in a combustor if they can be heated at a rate of $2 \times 10^{4} \mathrm{~K} / \mathrm{s}$ or more in the furst 10 milliseconds of residence time.

Explosive boiling of CWSF droplets has the potential of significantly reducing the droplet evaporation time, as well as the heterogeneous burnout time and the size of flyash particles. The droplets can disrupt while still containing the bulk of the original water content. Disrupting the droplet would suddenly greatly increase the surface area available for heat-up and evaporation of the remaining water.

Minute quantities of water within a droplet agglomerate may cause explosive boiling in less time compared to normally loaded droplets at the same incident energy flux. Because the volume increase associated with the rapid formation of water vapor is so high, a tiny amount of water within a droplet agglomerate could plausibly expand sufficiently upon vaporization to disrupt the agglomerate. Since water has a heat capacity that is about three times greater than that of coal, the almost dry agglomerate would heat up quicker than a normally loaded droplet.

Particle binding on the surface of droplet agglomerates by the surfactant was insignificant. The fusion of the bituminous coal particles on the surface of the resulting agglomerates of heated droplets (19) must have significant contributions from thermoplastic transformations, which also indicates that pyrolysis was occurring on the agglomerate surface. Because the interior of the bituminous shell fragments were not fused, pyrolysis 
reactions had not progressed deeply into the agglomerate. The water inside the droplet must boil explosively before the interior coal particles pyrolyze since the superheat temperature limit of the water is less than the temperature associated with the initiation of pyrolysis. Therefore, expanding water vapor within the heated CWSF droplets is the most plausible cause of their disruption. If devolatilization did occur at the time of explosive boiling, then it most probably occurred at the droplet surface and did not contribute to the disruption of the droplet core.

Using carbon black slurried with water in order to gain some insight into the effect of particle devolatilization on explosive boiling was not very successful because the droplets would usually shoot out of the focal volume of the electrodynamic balance when heated. It is not certain whether this behavior is related to the low volatile matter content or some other property of the carbon black.

\subsection{Suggestions for Future Work}

More films should be studied with the IAS. Lignite CWSF, bituminous CWSF, and carbon black slurry droplet films should be compared to determine if the solid substrates have an effect on slurry droplet evaporation. Ambient evaporation rates could be determined from the IAS and compares to DIS data and to the evaporation model for consistency. Furthermore, data from rapid evaporation from heating events determined from the IAS could be used to advance droplet evaporation models for heating conditions.

Rigorous thermodynamic treatment of droplet temperature histories should be performed so that droplet thermal expansion can be accurately accounted for when determining droplet evaporation rates. The energy absorption efficiency of the carbon black slurry droplets should be checked to facilitate comparison to CWSF droplets. 
Droplet studies should be repeated using the bituminous CWSF employed previously (19), except without surfactants, thereby revealing the effect of the coal thermoplasticity.

Studies should be performed on CWSF containing a small fraction of carbon black. The objective would be to determine the effect of a bimodal particle size distribution on agglomerate morphology. These experiments might also be performed using a blend of standard grind and micronized CWSFs.

In order to evaluate more thoroughly the effect of devolatilization on explosive boiling, some of the CWSF should be dried, charred, and re-slurried. This method would maintain a much more similar particle size distribution, coal porosity, and slurry rheology than using carbon black.

Studies using dried or partially dried CWSF droplets should be pursued. The potential for a staged CWSF combustion scheme that maximizes the occurrence of secondary atomization could then be evaluated. 


\section{REFERENCES}

1. Skripov, V. P., Metastable Liquids, Translated from Russian by R. Kondor, Wiley, New York, 1974

2. Blander, M. and Katz, J. L., "Bubble Nucleation In Liquids," AIChE J., 21, 833 (1975)

3. Cole, R., "Boiling Nucleation," Adv. Heat Transfer, 10, 85 (1974)

4. Law, C. K., "A Model for the Combustion of Oil/Water Emulsion Droplets," Combust. Sci. Tech., 17, 29 (1977)

5. Law, C. K., "Internal Boiling and Superheating in Vaporizing Multicomponent Droplets," AIChE J., 24, 626 (1978)

6. Wang, C. H., Liu, X. Q. and Law, C. K., "Combustion and Microexplosion of Freely Falling Multicomponent Droplets," Combust. Flame, 56, 175 (1984)

7. Niioka, T. and Sato, J., "Combustion and Microexplosion Behavior of Miscible Fuel Droplets Under High Pressure," Twenty-first Symposium (International) on Combustion, The Combustion Institute, 1986, p.625

8. Lasheras, J. C., Fernandez-Pello, A. C. and Dryer, F. L., "Experimental Observations on the Disruptive Combustion of Free Droplets of Multicomponent Fuels," Combust. Sci. Tech., 22, 195 (1980)

9. Lasheras, J. C., Yap, L. T. and Dryer, F. L., "The Effect of Ambient Pressure on the Disruptive Vaporization and Burning of Emulsified and Multicomponent Fuel Droplets," Paper WSCI 82-94 (1982)

10. Yap, L. T., Kennedy, I. M. and Dryer, F. L., "Disruptive and Micro-Explosive Combustion of Free Droplets in Highly Convective Environments," Combust. Sci. Tech., 41, 291 (1984)

11. Matthews, K. J. and Street, P. J., "Combustion Histories of Various Coal-Water Fuels," Sixth International Symposium on Coal Slurry Combustion and Technology, 1984, p.109

12. Saito, M., Sadakata, M. and Sakai, T., "Single Droplet Combustion of CoalOil/Methanol/Water Mixtures," Fuel, 62, 1481 (1983)

13. Law, C. K., Law, H. K. and Lee, C. H., "Combustion Characteristics of Droplets of Coal/Oil and Coal/Oil/Water Mixtures," Energy (Oxford), 4, 329 (1979)

14. Yao, S. C. and Manwani, P., "Burning of Suspended Coal-Water Slurry Droplet with Oil as a Combustion Additive," Combust. Flame, 66, 87 (1986) 
15. Yao, S. C. and Liu, L., "Behavior of Suspended Coal-Water Slurry Droplets in a Combustion Environment," Combust. Flame, 51, 335 (1983)

16. Zghoul, A. M. and Essenhigh, R. H., "Ignition and Combustion Characteristics of Captive Drops of CWS," Paper \#CSS/CI-\#85, Joint Technical Meeting Central/Western States Secs. Comb. Inst. (1985)

17. Wong, S. -C., and Turns, S. R., "Ignition of Aluminum Slurry Droplets," Combust. Sci. Tech., 52, 221 (1987)

18. Takahashi, F., Dryer, F. L. and Williams, F. A., "Combustion Behavior of Free Boron Slurry Droplets," Twenty-first Symposium (International) on Combustion, The Combustion Institute, 1986, p.1983

19. Maloney, D. J. and Spann, J. F., "Evaporation, Agglomeration, and Explosive Boiling Characteristics of Coal-Water Fuels Under Intense Heating Conditions," Twenty-second Symposium (International) on Combustion," The Combustion Institute, 1988

20. Murdoch, P. L., Pourkashanian, M. and Williams, A., "The Mechanism of Combustion of Coal-Water Slurries," Twentieth Symposium (International) on Combustion, The Combustion Institute, 1984, p.1409

21. Yu, T. U., Kang, S. W., Toqan, M.A., Walsh, P.M., Teare, J.D., Beer, J.M. and Sarofim, A.F., "Effect of Fuel Treatment on Coal-Water Fuel Combustion," Twentyfirst Symposium (International) on Combustion, The Combustion Institute, 1986, p.369

22. Nydick, S. E., Porchet, F. and Steiger, H. A., "Continued Development of a Coal/Water Slurry-Fired Slow-Speed Diesel Engine: A Review of Recent Test Results," J. Eng. Gas Turbines Power, 109, 465 (1987)

23. Spiro, C. L., Chen, C. C., Wong, J., Kimura, S. G. and Greegor, R. B., "Characterization of Products from a Gas Turbine Combustor Fired Directly with Coal-Water Mixture," Fuel, 66, 563, (1987)

24. Laflesh, R. C., Lachowicz, Y. V. and McGowan, J. G., "Combustion Characteristics of Coal-Water Fuels," Eighth International Symposium on Coal Slurry Fuels Preparation and Utilization, 1986, p.438

25. Warchol, J. J. and Farthing, G. A., "Commercial Coal-Water-Fuel Burner Demonstration," Eighth International Symposium on Coal Slurry Fuels Pieparation and Utilization, 1986, p.706

26. Dunn-Rankine, D., Hoornstra, J., Gruelich, F. A. and Holve, D. J., "Combustion of Coal-Water Slurries: Evolution of Particle Size Distribution for Coals of Different Rank," Fuel, 66, 1139 (1987)

27. Kaji, R., Muranaka, Y., Otsuka, K. and Hishinuma, Y., "Water Absorption by Coals: Effects of Pore Structure and Surface Oxygen," Fuel, 65, 288 (1986) 
28. Srinivasachar, S., Kang, S. W., Timothy, L. D., Froelich, D., Sarofim, A. F. and Beer, J. M., "Fundamentals of Coal-Water Fuel Combustion," Eighth International Symposium on Coal Slurry Fuels Preparation and Utilization, 1986, p.330

29. Hauserman, W. B., Patel, R. C., Brown, R. A., Hurley, J. P, Steadman, E. and Jones, M. L., "Low-Rank Coal-Water Slurry Combustion," Final Report DOE/FE/60181-2128 (1986)

30. Miyasaka, K. and Law, C. K., "Combustion and Agglomeration of Coal-Oil Mixtures in Furnace Environments," Combust. Sci. Tech., 24, 71 (1980)

31. Szekely, G. A. Jr., Turns, S. R. and Faeth, G. M., "Effects of Carbon-Black Properties on Combustion of Carbon-Black Slurry Agglomerates," Combust. and Flame, 58, 31 (1984)

32. Cheong, H. W., Jeffreys, G. V. and Mumford, C. J., "A Receding Interface Model for the Drying of Slurry Droplets," AIChE J., 32, 1334 (1986)

33. Antaki, P., "Transient Processes in a Rigid Slurry Droplet During Liquid Vaporization and Combustion," Combust. Sci. Tech., 46, 113 (1986)

34. Antaki, P. and Williams, F. A., "Transient Processes in a Non-Rigid Slurry Droplet During Liquid Vaporization and Combustion," Combust. Sci. Tech., 49, 289 (1986)

35. Walsh, P. M., Zhang, M., Farmayan, W. F. and Beer, J. M., "Ignition and Combustion of Coal-Water Slurry in a Confined Turbulent Diffusion Flame," Twentieth Symposium (International) on Combustion, The Combustion Institute, 1984, p.1401

36. La Mer, V. K., ed., Retardation of Evaporation by Monolayers: Transport Processes, Academic Press, New York, 1962.

37. Garrett, W. D., "Retardation of Water Drop Evaporation with Monomolecular Surface Films," J. Atmospheric Sci., 28, 816 (1971)

38. Barnes, G. T., "Insoluble Monolayers and the Evaporation Coefficient of Water," $J$. Colloid Interfuce Sci., 65, 566 (1978)

39. Bradley, R. S., "Retardation of Evaporation of Micro-Drops in the Presence of Insoluble Monolayers," J. Colloid Interface Sci., 10, 571 (1955)

40. Smit, F. J. and Maas, D. J., "Preparation and Analyses of Low-Rank Coals for Combustion Applications," Final Report, DOE/FC/10623-2225 (1986)

41. Maloney, D. J., Fasching, G. E., McCarthy, L. A., Lawson, W. F. and Casleton, K. H., "Design and Operating Characteristics for a Laboratory Coal-Water Fuel Droplet Generator," U.S. DOE Technical Note, DOE/METC-87/4067 (1986)

42. Davis, E. J. and Ray, A. K., "Single Aerosol Particle Size and Mass Measurements Using an Electrodynamic Balance," J. Colloid Interface Sci., 75, 566 (1980) 
43. Maloney, D. J., Fasching, G. E., Lawson, L. O. and Spann, J. F., "An Automated Imaging and Control System for the Continuous Determination of Size and Relative Mass of Single Compositionally Dynamic Droplets," Rev. Sci. Instr., 60, 450 (1989)

44. Incropera, F. P. and DeWitt, D. P., Fundamentals of Heat and Mass Transfer, Second Edition, Wiley, New York, 1985, ch. 7

45. Speight, J. G., The Chemistry and Technology of Coal, Chemical Industries Vol. 12, Marcel Dekker, New York, 1983, ch. 6

46. Merrick, D., "Mathematical Models of the Thermal Decomposition of Coal," Fuel, 62, 540 (1983)

47. Tran, P. X., private communication, 1988

48. Faulkner, A. R., "CWM Large Burner Development Tests and Demonstrations in the United States and Canada -- 1983-1986," Eighth International Symposium on Coal Slurry Fuels Preparation and Utilization, 1986, p.717

49. Maloney, D. J. and Jenkins, R. G., "Coupled Heat and Mass Transport and Chemical Kinetic Rate Limitations During Coal Rapid Pyrolysis," Twentieth Symposium (International) on Combustion, The Combustion Institute, 1984, p.1435 


\section{Appendix \\ EQUATIONS AND SLURRY CHARACTERIZATIONS}

\section{A.1 Slurry Preparation}

\section{A.1.1 Slurry Dilution and Surfactant Addition}

$$
\begin{aligned}
& \text { Dependent Variables: } \quad \boldsymbol{W}=\text { weight of water to be evaporated to yield the } \\
& \text { final desired loading } \\
& \mathbf{S}=\text { weight of surfactant to be added } \\
& \text { Independent Variables: } \mathrm{M}=\text { weight of the original mixture } \\
& \mathrm{W}=\text { weight of water in the original mixture } \\
& \mathrm{C}=\text { weight of solids in the original mixture } \\
& \begin{array}{l}
x=\text { weight fraction of surfactant desired in the final } \\
\text { mixture }
\end{array} \\
& y=\text { weight fraction of solids in the original mixture } \\
& z=\text { weight fraction of solids desired in the final }
\end{aligned}
$$

The weight of the mixture is simply the sum of the weights of its solid and liquid components.

$$
\mathrm{M}=\mathrm{C}+\mathrm{W}
$$

For a final mixture of $\mathrm{z}$ weight $\%$ solids,

$$
C=\frac{z}{1-z}(W-w+S)
$$

Knowing the solids loading of the original mixture, equation (A.2) can be rewritten as

$$
y M=\frac{z}{1-z}[(1-y) M-w+S]
$$


Also, by definition

$$
\mathrm{x}=\frac{\boldsymbol{S}}{\mathrm{M}-\boldsymbol{W}+\boldsymbol{S}}
$$

There are two unknowns, $\boldsymbol{W}$ and $\boldsymbol{S}$, and two equations, (A.3) and (A.4). First, equation (A.4) is solved for $S$.

$$
\boldsymbol{S}=\frac{\mathrm{x}}{1-\mathrm{x}}(\mathrm{M}-\boldsymbol{W})
$$

Next, equation (A.5) is substituted into equation (A.3), and the resulting expression is solved for $W$, yielding

$$
w=\left[\frac{\frac{z}{1-z}\left(1-y+\frac{x}{1-x}\right)-y}{\frac{z}{1-z}\left(1+\frac{x}{1-x}\right)}\right] M
$$

$\boldsymbol{W}$ is then used to find $\boldsymbol{S}$ in equation (A.5). Because it could never be certain what the exact loading of a droplet would be, the value of $z$ was maintained at 0.5 so that, regardless of the droplet loading, the concentration of surfactant on the solid particles would be constant for a given value of the desired surfactant concentration, $x$.

\section{A.1.2 Carbon Black Slurry}

Three sarbon blacks were obtained from Columbian Chemicals. The carbon black powder designated as Raven 1040 dispersed in water slightly better than the other two, so it was chosen for the experiments. According to the manufacturer, the Raven 1040 had a mean particle size of $28 \mathrm{~nm}, \mathrm{~N}_{2}$ surface area of $87 \mathrm{~m}^{2} / \mathrm{g}, 5.0 \%$ volatile matter (CO and $\mathrm{CO}_{2}$ ), and a $\mathrm{pH}$ of 2.9 .

The carbon black powder was slurried with deionized water in an Oster kitchen blender. Because of its high porosity, the solids loading had to be very low, $4 \%$ by 
weight, before a pourable slurry would form. The slurry was blended for five minutes using the entire range of blending speeds.

\section{A.2 Slurry Analyses}

Ultimate analyses were provided by the vendors and particle size distribution analyses were performed by EG\&G personnel at M.E.T.C. on slurries of lignite and carbon black. The slurries were originally free of additives, however Lomar D dispersant was necessary to perform the particle size distribution analyses.

\section{A.2.1 Hot Water Dried Lignite}

Table A.1 Ultimate Analysis of the Lignite

$\begin{array}{lrcr}\text { Carbon: } & 71.86 \% & \text { Moisturea: } & 7.10 \% \\ \text { Hydrogen: } & 4.75 \% & \text { Volatile Matter: } & 36.28 \% \\ \text { Nitrogen: } & 1.04 \% & \text { Fixed Carbon: } & 58.00 \% \\ \text { Sulfur: } & 0.33 \% & & \\ \text { Ash: } & 4.72 \% & \text { Slurry Moisture: } & 72.40 \% \\ \text { Oxygen: } & 16.20 \% & & \end{array}$

a On a Moist Coal Basis 
Table A.2 Particle Size Distribution of the Lignite CWSF

\begin{tabular}{|c|c|c|c|}
\hline $\begin{array}{l}\text { Electrolyte: } \\
\text { Equipment: } \\
\text { Apertures: }\end{array}$ & $\begin{array}{l}\text { Isoton } \\
\text { TA II } \\
70\end{array}$ & & \\
\hline $\mathrm{Ch} \#$ & Size & Diff $\mathrm{Vol} \%$ & Cum Vol \% \\
\hline 1 & 1 & 0 & 100 \\
\hline 2 & 1.26 & 15 & 100 \\
\hline 3 & 1.59 & 7.37 & 85 \\
\hline 4 & 2 & 6.98 & 77.63 \\
\hline 5 & 2.52 & 8.29 & 70.65 \\
\hline 6 & 3.17 & 9.49 & 62.36 \\
\hline 7 & 4 & 10.69 & 52.88 \\
\hline 8 & 5.04 & 8.68 & 42.19 \\
\hline 9 & 6.35 & 9.88 & 33.51 \\
\hline 10 & & 7.84 & 23.63 \\
\hline 11 & 10.08 & 5.28 & 15.79 \\
\hline 12 & 12.7 & 5.67 & 10.51 \\
\hline 13 & 16 & 3.01 & 4.84 \\
\hline 14 & 20.16 & 1.49 & 1.83 \\
\hline 15 & 25.4 & 0.16 & 0.34 \\
\hline 16 & 32 & 0.18 & 0.18 \\
\hline
\end{tabular}

Table A.3 Volume \% Statistics of the Lignite CWSF

$\begin{array}{lr}\text { Mean: } & 4.30 \mu \mathrm{m} \\ \text { Median: } & 4.26 \mu \mathrm{m} \\ \text { Mode: } & 1.12 \mu \mathrm{m} \\ \text { Standard Deviation: } & 2.19 \mu \mathrm{m} \\ \text { Coef. Var.: } & 50.84 \\ \text { Skewness: } & 1.1 \text { positive } \\ \text { Kurtosis: } & 2.18 \text { platykurtic }\end{array}$

\section{A.2.2 Carbon Black Slurry}

Table A.4 Ultimate Analysis of the Carbon Black

$\begin{array}{lrlr}\text { Carbon: } & 92.30 \% & \text { Moisture: } & 2.90 \% \\ \text { Hydrogen: } & 0.55 \% & \text { Volatile Matter: } & 5.00 \% \\ \text { Nitrogen: } & 0.35 \% & \text { Slurry Moisture: } & 95.07 \% \\ \text { Sulfur: } & 0.81 \% & & \\ \text { Ash: } & 0.61 \% & & \\ \text { Oxygen: } & 2.48 \% & & \end{array}$




\section{Table A.5 Particle Size Distribution of the Carbon Black Slurry}

$\begin{array}{cl}\text { Electrolyte: } & \text { Isoton } \\ \text { Dispersant: } & \text { Lomar D } \\ \text { Equipment: } & \text { TA II } \\ \text { Apertures: } & 70 \\ \text { Ch \# } \\ 1 \\ 2 \\ 3 \\ 4 \\ 5 \\ 6 \\ 7 \\ 8 \\ 9 \\ 10 \\ 11 \\ 12 \\ 13 \\ 14 \\ 15 \\ 16\end{array}$

Size
1
1.26
1.59
2
2.52
3.17
4
5.04
6.35
8
10.08
12.7
16
20.16
25.4
32

Diff Vol \%
0
10.05
14.41
20.77
22.1
14.04
8.59
4.25
1.98
0.5
0.26
0.13
1.1
1.46
0.18
0.18

Cum Vol \%
100
100
89.95
75.55
54.78
32.67
18.63
10.05
5.79
3.81
3.31
3.05
2.92
1.83
0.37
0.18

Table A.6 Volume \% Statistics of the Carbon Black Slurry

$\begin{array}{lr}\text { Mean: } & 2.85 \mu \mathrm{m} \\ \text { Median: } & 2.65 \mu \mathrm{m} \\ \text { Mode: } & 2.6 \mu \mathrm{m} \\ \text { Standard Deviation: } & 1.71 \mu \mathrm{m} \\ \text { Cocf. Var.: } & 60.2 \\ \text { Skewness: } & 1.29 \text { positive } \\ \text { Kurtosis: } & 1.84 \text { platykurtic }\end{array}$

The carbon black particles must have agglomerated in the slurry because the measured particle size is two orders of magnitude higher than expected. According to the vendor, the arithmetic mean aggregate size is $28 \mathrm{~nm}$ with approximately 10 to 15 particles per aggregate. 


\section{A.3 Droplet Mass and Composition Measurement}

When a slurry droplet evaporates it loses liquid mass but maintains all of its solids mass. Therefore, solids loading will continuously increase during evaporation. If the initial solids loading of a droplet is known and converted to initial droplet density, then, using the cross-sectional areas and balancing voltages measured continually by the DIS, an expression can be derived that calculates the droplet mass during evaporation.

Variables

droplet mass, $\mathrm{m}$

balancing voltage, $v$

measured cross-sectional area, $\mathrm{S}$
Constants

initial droplet mass, $m_{0}$ initial balancing voltage, $v_{0}$ initial cross-sectional area, $S_{0}$ initial droplet density, $\rho_{0}$ initial droplet volume, $\mathrm{V}_{0}$ $\gamma$, defined as $\mathrm{m} / \mathrm{v}$

First, the initial droplet mass is calculated.

$$
\begin{gathered}
\mathrm{m}_{0}=\rho_{0} \mathrm{~V}_{0} \\
\mathrm{~m}_{0}=\frac{4}{3} \pi^{-1 / 2} \rho_{0} s_{0}^{3 / 2}
\end{gathered}
$$

The initial balancing voltage and $\mathrm{m}_{0}$ are substituted into the definition of $\gamma$ in order to determine its value.

$$
\gamma=\frac{\mathrm{m}_{0}}{\mathrm{v}_{0}}
$$

Expressing the change in droplet mass as

$$
\Delta \mathrm{m}=\mathrm{m}_{0}-\mathrm{m}
$$

and the change in balancing voltage as

$$
\Delta \mathrm{v}=\mathrm{v}_{0}-\mathrm{v}
$$

then by substitution into the definition of $\gamma$, 


$$
\Delta \mathrm{m}=\gamma \Delta \mathrm{v}
$$

Solving equation (A.9) for $m$ and substituting equations (A.7), (A.10), and (A.11) yields the final expression,

$$
\mathrm{m}=\frac{4}{3} \pi^{-1 / 2} \rho_{0} \mathrm{~s}_{0}^{3 / 2}-\gamma\left(\mathrm{v}_{0}-\mathrm{v}\right)
$$

The temporal droplet mass calculated in equation (A.12) is divided by the temporal droplet volume to give the temporal droplet density. The solids loading of the droplet at any time can be determined by inserting the temporal droplet density into a second order correlation of slurry density as a function of the mass fraction of solids. The correlation is from a fit to plotted theoretical slurry density points over the range of no solids to all solids. The theoretical slurry density, $\rho$, is determined as follows:

By definition,

$$
\rho=\frac{m}{V}=\frac{m_{w}+m_{c}}{V_{w}+V_{c}}
$$

where subscripts $w$ and $c$ indicate water and solid, respectively. Also by definition,

$$
\begin{gathered}
v_{w}=\frac{m_{w}}{\rho_{w}} \\
v_{c}=\frac{m_{c}}{\rho_{c}}
\end{gathered}
$$

Defining $\Phi$ as the solid mass fraction, a one gram basis gives $\mathrm{m}_{\mathrm{c}}=\Phi$ and $\mathrm{m}_{\mathrm{w}}=1-\Phi$. Substitution into the definition of $\rho$ and assuming the density of water to be one gram per milliliter yields the theoretical slurry density,

$$
\rho=\left(1=\Phi+\frac{\Phi}{\rho_{c}}\right)^{-1}
$$

The second order correlation depends on the density of the solid (1.361 for the lignite and 1.55 for the carbon black). 


\section{A.4 Calculations}

\section{A.4.1 Incident Energy}

Calculating the energy incident upon a droplet requires the energy flux, the droplet cross-sectional area, and the time the droplet was subjected to the energy flux. The energy flux was read indirectly as the energy reading of detector A. The following expression converts $A$ to $B$ in $\left(W / \mathrm{cm}^{2}\right)$ :

$$
\mathrm{B}=\frac{\left(\frac{\mathrm{B}}{\mathrm{A}}\right) \mathrm{A}(4)(0.57)}{\mathrm{S}_{\mathrm{p} \mathrm{t}_{\mathrm{p}}}}
$$

where $(\mathrm{B} / \mathrm{A})$ is the calibration ratio of $8.462, \mathrm{~S}_{\mathrm{p}}$ is the beam cross-sectional area of $0.01131 \mathrm{~cm}^{2}$, and $\mathrm{t}_{\mathrm{p}}$ is the pulse duration which was constant at 0.01 second. The coefficient 4 , corrects for the 2.5 millisecond detection time of the detector, and 0.57 is the central fraction of the beam cross-section that is considered to be of uniform energy flux. The final expression for the energy flux is

$$
\mathrm{B}=17.06 \times 10^{-4} \mathrm{~A}
$$

The droplet cross-sectional area is doubled to account for irradiation from the opposing beams and then multiplied by the irradiation time and flux to yield the total incident energy expression,

$$
\mathrm{E}_{\mathrm{T}}=2 \mathrm{StB}
$$

\section{A.4.2 Mass of Water Evaporated}

The mass of water evaporated from a droplet was determined by measuring the change in droplet cross-sectional area using either the IAS or DIS and assuming that the size difference was the result of water loss. Since the original radius, $\mathrm{r}_{0}$, of the droplet is known, the change in cross-sectional area, $\Delta \mathrm{A}$, is used to determine the radius after a given amount of time, $r_{t}$, 


$$
r_{t}=\sqrt{r_{0}^{2}-\frac{\Delta A}{\pi}}
$$

Then, the new radius is used with the density of water at its boiling point, $\rho$, to find the weight of the water-filled shell volume, $\Delta \mathrm{m}$.

$$
\Delta \mathrm{m}=\frac{4}{3} \pi\left(\mathrm{r}_{0}^{3}-\mathrm{r}_{\mathrm{l}}^{3}\right) \rho
$$

\section{A.4.3 Droplet Energy Absorption}

By normalizing out ambient evaporation, all of the energy absorbed by a heated droplet that does not fragment goes into vaporizing mass $\Delta \mathrm{m}$ of water, as determined by the difference in droplet size before and after heating. The energy required to vaporize $\Delta \mathrm{m}$ of water is the sum of the energy to raise $\Delta \mathrm{m}$ of water to $100{ }^{\circ} \mathrm{C}$ and the latent heat of vaporization,

$$
\mathrm{E}_{\Delta \mathrm{m}}=\Delta \mathrm{m}\left(\mathrm{C}_{\mathrm{pw}} \Delta \mathrm{T}+\lambda\right)
$$

This energy is then divided by the total incident energy to determine the energy absorption efficiency, $\eta$,

$$
\eta=\frac{E_{\Delta m}}{E_{T}}
$$

\section{A.5 Calibrations}

$\mathrm{X}$ represents the corresponding digital signal from the DIS. 


\section{A.5.1 Droplet Size Measurements}

These relations are most accurate for droplets between 96 and $226 \mu \mathrm{m}$ in diameter.

$$
\begin{aligned}
& \text { diameter }(\mu \mathrm{m})=-5.99217 \times 10^{-5} \mathrm{X}^{2}+0.21668 \mathrm{X}+56.0249 \\
& \text { cross-sectional area }\left(\mathrm{cm}^{2}\right)=3.51344 \times 10^{-7} \mathrm{X}+1.29248 \times 10^{-6}
\end{aligned}
$$

\section{A.5.2 Balance Voltage}

$$
I(\text { volts })=-4.83808 \times 10^{-2} X+100.05
$$

\section{A.5.3 Balance Control Signal}

$$
\mathrm{I}(\mathrm{mV})=-0.414206 \mathrm{X}+895.87
$$




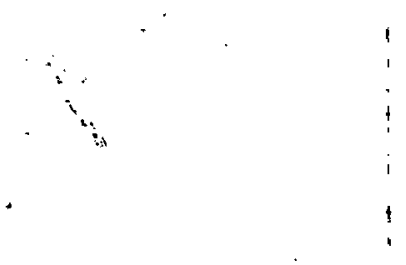

